\title{
GEOMECHANICS OF BEDDED SALT
}

purchase Order No. 4413609

Prepared for:

University of california

Lawrence Livermore Laboratory

Livermore, California 94550

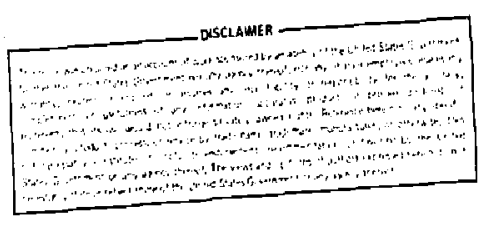

Prepared by:

Dr. Shosei Serata

Stefan $\%$. Milnor

,

Serata Geomechanics, Inc.

1229 Eighth street

Berkeley, California 94710

June 8, 1979

* This work was supported by the U.S. Nuclear Regulatoly Commission under Interagency Agreement DOE 40-550-75 with the U.S. Department of Energy. 


\section{ABSTRACT}

This technical report on the geomechanical behavior of bedded salt is the result of a literature and data base review conducted by Serata Geomechanics, Inc. (SGI) for the University of California Lawrence Livermore Laboratory (LLL) Waste Management Program under University Purchase Order No. 4413609. Results of the literature review are summarized and important papers are abstracted. Creep data from the literature search is reinterpreted by SGI, resulting in a better understanding of the temperature and stress state dependence of the octahedral creep rate and the octahedral shear strength. The concept of a transition strength between the elastic and the plastic states is in agreement with the data. The elastic and rheological properties of salt are descrjbed, and a set of constitutive equations is presented. The dependence of material properties on parameters such as temperature is considered. Findings on the permeability of salt are summarized, and the in-situ behavior of openings in bedded salt is described.based on extensive engineering experience. A stress measuring system utilizing a finite element computer code is discussed. Geological factors affecting the stability of salt openings are considered, and the stress Control Technigue for designing stable openings in bedded salt formations is explained. 


\section{ACKNOWLEDGEMENT}

Appreciation is extended to Andrew Law, Research Assistant, for his able work on the permeability of salt. 
TABLE OF CONTENTS

Chapter

page

1 INTRODUCTION AND LITERATURE REVIEW 1

1.1 Introduction 1

1.2 Results of Literature Review 6

1.2 .1 Constitutive Equations of 6 Rock Salt

1.2.2 Fundamental Creep Mechanisms $\theta$

1.2.3 Finite Element Computer 9 Program

1.2.4 Laboratory Creep Data 10

1.2.5 In-Situ Creep Data 11

1.2.6 Stress Measurements 12

1.2.7 Tilt Measurements 16

1.2.8 Permeability 17

1.2.9 Geological Factors 18

1.3 Abstracted References 19

2 DEFORMATION AND STRENGTH OF ROCK SALT 27

2.1 Deformation Characteristics 29

2.1.1 Stress-strain Relationship 29

2.1.2 Strain Hardening and Young's 31 Modulus

2.1.3 Compressibility and Bulk 35

Modulus

2.2 Failure and Yielding Strength 38

2.2.1 Two Basic Failure Processes 38

2.2.2 Yield Strengths 41

2.2.3 Brittle Behavior 44

3 CREEP BEHAVIOR OP ROCK SALT 50

3.1 Two Different Creep Components 50

3.2 Viscoelastic Creep 52

3.3 Viscoplastic Creep $\quad 55$

3.4 Transition from Elastic to Plastic 60 State

3.5 Ultimate Octahedral Shearing 64 Strength 


\section{TABLE OF CONTENTS}

(Continued)

Chapter

$\underline{\text { Page }}$

4

FORMULATION OF CONSTITUTIVE EQUATIONS

68

4.1 principles of Formulation

68

4.1.1 Separation of Behavior $\quad 68$

4.1.2 Behavioral Componeats 69

4.1.3 Nonlinearity of Components 69

4.1.4 Consistency of Behavioral 69

Components

4.1.5 Octahedral Shearing Strength 70

4.1.6 Threshold Stress of 70

Transition

4.1.7 Elastic Strength 71

4.1.8 Yield Strength 71

4.1.9 Transition Strength 71

4.1.10 Viscoelastic state 71

4.1.11 Viscoplastic state 72

4.2 Rheological Model of Constitutive $\quad 72$

Equations

4.3 Constitutive Equations in Visco- $\quad 77$

elastic state

4.4 Constitutive Equations in Visco- $\quad 79$

plastic State

5 EVALUATION OF PARAMETERS AFFECTING 84

MATERIAL PROPERTIES OF ROCK SALT

5.1 Confining pressure 84

5.2 Cumulative Creep Strain 85

5.3 Octahedral Shearing stress $\quad 89$

5.4 Elevated Temperature Effect 91

5.4.1 Effects on Elasticity 91

5.4.2 Effects on Viscoelasticity 93

5.4.3 Effect on Octahedral Shearing 95

Strength

5.4.4 Effect on Viscoplasticity $\quad 97$ 


\section{TABLE OF CONTENTS}

(Continued)

Chapter

$\underline{\text { Page }}$

6 PERMEABILITY

6.1 Permeability and Its Relationship 100 with Porosity

6.2 Darcy's Law for Liquid and Gas 101

6.3 Physio-chemical Factors for 102 Permeability

6.4 Results of studies on Permeability 104

6.5 Conclusions

7 IN-SITU MEASUREMENT OF SALT OPENING $\quad 120$ BEHAVIOR

7.1 Room Closure and Roof Failure $\quad 120$

7.2 Pillar Deformation and Failure 128

7.3 Floor Heave and Failure 129

7.4 Surface Subsidence $\quad 129$

8 IN-SITU MEASUREMENT OI' STRESS IN 134

BEDDED SALT

8.1 Tectonic Stress Field and its 134 Measurement

8.2 Stress Distribution in Roof and 137 Floor

8.3 Stress Distribution in Pillars $\quad 140$

8.4 Stress Measurement in Rock Salt 145 Formation

9 EVALLATION OF GEOLOGICAL FACTORS 151

AFFECTING STABILITY OF SALT OPENINGS

9.1 Stratification $\quad 151$

9.2 Gas and Water 153

9.3 Stress Conditions $\quad 156$

9.4 Design Considerations $\quad 159$ 
TABLE OF CONTENTS

(Continued)

Chapter

Page

10 STRESS CONTROL TECHNIQUE FOR

161

STABILIZING SALT OPENINGS

10.1 principle of Stress control $\quad 161$ Technique

10.2 Stress Relief Method in 162

10.3 Parallel-Room Method in Weak 165

10.4 Time-Control Metnod in Failing 170 Ground

BIBLIOGRAPHY

177 


\section{LIST OF TABLES}

Table

Page

2-1 Young's Modulus of Rock Salt at Room Temperature

2-2 Elastic and Viscoelastic Coefficients of Dilatancy (Compressibility) of Rock Salt

3-1 $v_{4}$ Values Determined from Laboratory Data obtained by Various Investigators

3-2 Ultimate Octahedral Shearing Strength, $\mathrm{K}_{\mathrm{B}}$

4-1 Material Properties of Rock Salt at Room

6-1 Initial and Minimum Permeabilities of

108 Grand Saline Salt 
2-1 Various Strain States of Media in a Deep Underground Cavity Defined by Octahedral Parameters.

2-2 Stress-strain Relation of Weakly Bonded (Louisiana) Salt under Various Confining Pressures.

2-3 Development of Strain-Hardened StressStrain Relation (Louisiana Salt).

2-4 Octahedral Shearing Strengths of Elastic Limit, Transition Point, Yield Point, and Failure Point of Rock Salt in Relation to Mean Stress.

2-5 Deformation and Poisson's Ratio Under 750 psi Confining Pressure.

2-6 Differential Stress-Strain Curves for Polycrystalline Halite Extended at $2 \mathrm{~kb} \cong$ $29,400 \mathrm{psi}, \epsilon=1.5 \cdot 10^{-3}$ to $1.5 \cdot 10^{-8}$ $\sec ^{-1}$, and $100^{\circ} \mathrm{C}$.

2-7 Elastic, Yielding, and Failure Characteristics of Rocks in Stress Space.

3-1 Components of Salt Deformation. 51

3-2 First Two Elements of Viscoelastic Creep. 53

3-3 Comparison of Octahedral Shearing Strain 57 Rates Obtained from Four Specimens Tested under Various Loading Conditions.

3-4 Octahedral Creep Rate Rises Sharply with Excess Octahedral. Shear Stress $\left(\tau_{0}-k_{0}\right)$.

3-5 Transition Test--Lines with Small Slope Represent Elastic State; Lines with Slopes Approaching $45^{\circ}$ are in Plastic state.

4-1. Generalized Rheological Model for Rock salt.

4-2 Two Sets of Simplified Rheoloqical Models of Rock Salt for viscoelastic and Viscoplastic Stress states Adapted for Long-Term Design Analysis of Salt openings. 


\section{IIST OF FIGURES}

(Cont'd)

\section{Figure}

Page

5-1 Modification of Octahedral Shear Stress as a Function of Octahedral Shear Strain and Mean Stress.

5-2 Modification of Bulk Modulus as a Function of octahedral Shear Strain and Mean Stress. Moduli.

5-4 Ratio of Viscoelastic Coefficients Determined from slope of Tangential Strain Rate Against Time, for a Cylindrical Cavity.

5-5 Ultimate Octahedral Shear strength as a Function of Terperature. on the octahedral Creep Rate as a Function of Octahedral Shear Stress. Temperature in ${ }^{\circ} \mathrm{C}$.

6-1 Steady State Flow of Argon Gas Through Bedded Rock Salt. Adapted from Sutherland and Cave '(17).

6-2. Permeability of Rock Salt vs, Confining Pressure under Hydrostatic Conditions. Adapted from Reynolds (8).

6-3 Non-reactive Iiquid Permeability of Argon Gas Through Bedded Salt. Cyclic Test Starts at 1 (Top). Source: Sutherland and Cave (1979).

6-4 The Effect of octahedral Shearing Stress Upon Permeability for Various Mean Stresses. Source: Lai (5).

6-5 The Effect of Mean Stress Upon Permeability for Various octahedral Shear Stresses. Source: Lai (5).

6-6 Three-Dimensional Plot of Mean Stress, octahedral Shear Stress; and Permezbility. Source: Lai (5). 


\section{LIST OF FIGURES}

(Cont'd)

Figure

$\underline{\text { Page }}$

7-1 Wide Range of Room Closure of Salt Openings in Depth Range of 2000 to 3500 feet, Mainsy Dictated by Roof and Floor stratification.

7-2 Cross-Sectional Design of Measurement Station for Internal and External Creep Deformation.

7-3 Microcreepmeter Diagram.

7-4 Room Closure Creep Rate Distribution Pattern Indicating Potential Roof Failure Problems.

7-5 Microcreep Rate and Sag Ratio of Salt Opening Relating Long-Term Stability of Openings with Various Widths Constructed from Data obtained from Saskatchewan Potash Mines at Depth Range of 3200 Feet to 3500 Feet.

7-6 Pillar Deterioration with Time: Cumulative Creep Strain versus Depth into Pillar.

7-7 Illustration of Surface Subsidence, Deep Separation, Roof Expansion, Room Closure, and Floor Heave.

8-1 Maximum Possible Range of Earth Lateral Stress in Relation to Vertical Stress of Overburden Pressure Determined by Strengths of Individual Rock Strata.:

8-2 Stress Distribution Change over Roof Formations in Relation to stress Relief.

8-3 Comparison of Three Different Vertical Stress Distribution Patterns in Salt Pillars Demonstrating Functional Mechanism of Yield, Critical, and Abutment Pillars. Developea in Saskatchewan Potash Mines, Depths Ranging 3100--3500 Feet.

8-4 Summary of Experimental Observation Relating Safety Period of Multiple Salt Openings and Size of Separating pillars, Identifying Dimension of Yieid, Critical, and Abutment Pillars Deve? oped in Saskatchewan Potash Mines at Depths Ranging $3200--3500$ Feet. 


\section{LIST OF FIGURES \\ (Cont'd)}

Figure

Page

8-5 Schematic Illustration of stress Measuring System, Consisting of Pressure Regulated and Non-Pressurized Chambers, for Measuring Stress State Through Single Hole in Elastic and Nonelastic Ground.

8-6 Response of Stressmeter Operated in Three Different Hydrostatic In-Situ Stress Conditions of $\mathrm{P}_{0}=5,0$ and 10,000 psi under Three Different Instrumert Pressures of $P_{i}=6000 ; 10,000$; and 20,000 psi.

8-7 Time-Dependent Change in Distribution Patterns in 5-Room Entry in One of Saskatchewan Potash Mines at Depth of 3200 Feet Illustrating Function of Yielding Pillar, ?ormation of Stress Envelope, and Mechaniem of Establishing Long-Term Structural Stalility of Multiple-Room Entry System.

9-1 Radial closure of Cylindrical Salt Opening at Depth of 2000' at Age of 100 and 10,000 Days in Relation to Overburden Depth under Hydrostatic Stress State Computed bv Using Rheological Finite Element simulation.

:-2 Radial Closure of Cylindrical Salt opening at Depth of juvo' at Various Ages in Relation to Excess Lateral Stress Expressed in Terms of Percent of Maximum Excess Value of $1200 \mathrm{psi}$.

10-1 Stress-Relief Method of Stabilizing Underground openings.

Evolution of Mine Entry Design from Failing Room to Highly Stabilized Multiple-Room Entries.

10-3 Parailel-Room Method of Stabilizing Underground openings. Note the Formation of a Secondary Stresa Envelope.

10-4 Repeated Apolication of the Parallel-Room Method. 


\section{LIST OF FIGURES \\ (Cont'd.)}

\section{Figure}

10-5 Development of the Two Primary Stress

Envelopes during the Initial Stages of

Development using the Time-Control Method.

10-6 The Secondary Stress Envelope Develops when Excavating the Center Room During the Final Stages of the Time-Control Method.

10-7 Safety Period of Roof vs. Room Width. 


\begin{tabular}{|c|c|c|}
\hline Symbol & Meäning & Dimensions \\
\hline \multirow[t]{2}{*}{ a } & $\begin{array}{l}\text { Coefficient of Elastic surface } \\
\text { Curvature. }\end{array}$ & Pressure $^{-1}$ \\
\hline & $\begin{array}{l}\text { Empircal Constant Relating octa- } \\
\text { heiral Shear Stress and Permea- } \\
\text { bility. }\end{array}$ & Pressure/Length ${ }^{2}$ \\
\hline \multirow[t]{2}{*}{$A$} & $\begin{array}{l}\text { Cross-Sectional Area Perpendic- } \\
\text { ular to Flow. }\end{array}$ & Length ${ }^{2}$ \\
\hline & $\begin{array}{l}\text { Empirical Constant in Permeabi- } \\
\text { lity-Mean Stress Relationship. }\end{array}$ & Dimensionless \\
\hline$a$ & $\begin{array}{l}\text { Coefficient of Yield Surface } \\
\text { Curvature. }\end{array}$ & Pressure $^{-1}$ \\
\hline \multirow[t]{2}{*}{$b$} & Klinkenberg Constant. & Pressure \\
\hline & $\begin{array}{l}\text { Empirical Exponent in Oct. Shear } \\
\text { Stress-Permeability Relation. }\end{array}$ & Dimensionless \\
\hline B & $\begin{array}{l}\text { Empirical Constant in Permea- } \\
\text { bility-Mean Stress Relation. }\end{array}$ & Pressure $^{-1}$ \\
\hline$\beta$ & $\begin{array}{l}\text { Slope Angle of Lateral Stress } \\
\text { vs. Vertical Stress, Elastic } \\
\text { State. }\end{array}$ & \\
\hline$c$ & $\begin{array}{l}\text { Coefficient Depending on Shape } \\
\text { of Pore Cross Section. }\end{array}$ & Length ${ }^{2}$ \\
\hline$d \lambda$ & $\begin{array}{l}\text { Scalar Factor Relating Plastic } \\
\text { Strain and Deviatoric Stress } \\
\text { Tensors. }\end{array}$ & Pressure $^{-1}$ \\
\hline$D_{2}$ & $\begin{array}{l}\text { Bulk viscosity or volumetric } \\
\text { Elastoviscosity. }\end{array}$ & Pressure · Time \\
\hline$\delta_{i j}$ & Kronecker delta. & \\
\hline$\delta_{\mathrm{L}}$ & Lateral Deformation. & Length \\
\hline$\Delta H$ & Roon closure. & Length \\
\hline$\Delta F$ & Floor Heave. & Length \\
\hline
\end{tabular}




\begin{tabular}{|c|c|c|}
\hline Symbol & Meaning & Dimensions \\
\hline$\Delta \mathrm{P} / \mathrm{L}$ & Pressure Gradient. & Pressure/Length \\
\hline$\Delta \mathbf{R}$ & Roof Expansion. & Length \\
\hline$\Delta S$ & Surface Subsidence. & Length \\
\hline${ }^{\Delta o} \mathrm{~L}$ & $\begin{array}{l}\text { Lateral Stress Difference } \\
\text { Between Plastic Lines in } \\
\text { Transition Test. }\end{array}$ & Pressure \\
\hline$\Delta \mathrm{X}$ & Deep Separation. & Length \\
\hline$e_{i j}$ & $\begin{array}{l}\text { Components of Deviatoric Strain } \\
\text { Tensor. }\end{array}$ & Length/Length \\
\hline$\dot{e}_{i j}$ & $\begin{array}{l}\text { Components of Time Derivative } \\
\text { of Deviatoric Strain Tensor. }\end{array}$ & Tíne ${ }^{-1}$ \\
\hline$\dot{\mathrm{E}}_{\mathrm{a}}$ & $\begin{array}{l}\text { Roon Closure Rate, Center of } \\
\text { Room. }\end{array}$ & Time ${ }^{-1}$ \\
\hline$\dot{\mathrm{E}}_{\mathrm{b}}$ & Room Closure Rate, Edge of Room. & Time $^{-1}$ \\
\hline E & Young's Modulus. & Pressure \\
\hline $\mathrm{E}_{1}$ & Young's Modulus at $\sigma_{m}=0$. & Pressure \\
\hline$E_{2}$ & Ultimate Young's Modulus. & Pressure \\
\hline $\begin{array}{l}\varepsilon_{1}, \varepsilon_{2}, \varepsilon_{3} \\
\varepsilon_{x^{\prime}} \varepsilon_{y^{\prime}} \varepsilon_{z}\end{array}$ & Three Principal Strains. & Length/Length \\
\hline$\varepsilon_{\theta^{f}} \varepsilon_{r^{\prime}} \varepsilon_{z}$ & $\begin{array}{l}\text { Tangential, Radial, and Vertical } \\
\text { Strains. }\end{array}$ & Length/Length \\
\hline$\varepsilon_{\mathrm{m}}$ & Mean strain $=\frac{1}{3}\left(\varepsilon_{1}+\varepsilon_{2}+E_{3}\right)$ & Length/Length \\
\hline$\varepsilon_{i i}$ & Sum of Principal Strains. & Length/Length \\
\hline$\varepsilon_{i j}$ & Components of Strain Tensor. & Length/Length \\
\hline$\varepsilon_{i j}^{e}$ & Elastic Strain Tensor. & Length/Length \\
\hline$e_{i j}^{p}$ & Plastic strain Tensor. & Length/Length \\
\hline $\mathbf{f}$ & $\begin{array}{l}\text { Decay Rate of Perched Water } \\
\text { Flow. }\end{array}$ & Time $^{-1}$ \\
\hline
\end{tabular}




\section{LIST OF SYMBOLS}

(Cont'd)

\begin{tabular}{|c|c|c|}
\hline Symbol & Meaning & Dimensions \\
\hline $\mathrm{G}$ or $\mathrm{G}_{1}$ & Elastic Shear Modulus. & Pressure \\
\hline $\mathrm{G}_{2}$ & $\begin{array}{l}\text { Retarded Shear Modulus of Least } \\
\text { Transient Component of vE Creep. }\end{array}$ & Pressure \\
\hline $\mathrm{G}_{2} / \mathrm{V}_{2}$ & $\begin{array}{l}\text { Decay Rate of Least Transient } \\
\text { Component VE Creep. }\end{array}$ & Time $^{-1}$ \\
\hline $\mathrm{G}_{2}^{\prime}$ & $\begin{array}{l}\text { Retarded Shear Modulus of Second } \\
\text { Component of VE Creep. }\end{array}$ & Pressure \\
\hline $\mathrm{G}_{2} \mathrm{\prime}_{2} \mathrm{\prime}$ & $\begin{array}{l}\text { Decay Rate of Second Component } \\
\text { of VE Creep. }\end{array}$ & $\operatorname{Time}^{-1}$ \\
\hline $\mathrm{G}_{3}$ & $\begin{array}{l}\text { Retarded Shear Modulus of VE } \\
\text { Creep under VP Condition } \\
\left(\tau_{0}>\mathrm{K}_{0}\right) \text {. }\end{array}$ & Pressure \\
\hline $\mathrm{G}_{3} / \mathrm{V}_{3}$ & $\begin{array}{l}\text { Decay Rate of vE creep under vP } \\
\text { Condition }\left(\tau_{0}>\mathrm{k}_{0}\right) \text {. }\end{array}$ & Time $e^{-1}$ \\
\hline$\gamma_{c}$ & $\begin{array}{l}\text { Critical oct. Strain at which } \\
\mathrm{K}_{\mathrm{A}}^{\prime} \simeq 0 \text { and at which } \mathrm{K}_{\mathrm{D}}^{\prime} \simeq 0 \text {. }\end{array}$ & Length/Length \\
\hline$\gamma_{0}$ & octahedral Shear Strain & Leng th/Length \\
\hline & $=\frac{2}{3} \sqrt{\left.\varepsilon_{1}-\varepsilon_{2}\right)^{2}+\left(\varepsilon_{2}-\varepsilon_{3}\right)^{2}+\left(\varepsilon_{3}-\varepsilon_{1}\right)}$ & 2 \\
\hline$\dot{\gamma}_{0}$ & octahedral Creep Rate. & Time ${ }^{-1}$ \\
\hline$\dot{\gamma}_{0}^{B}$ & Brittle Fracture Strain Rate. & Time ${ }^{-1}$ \\
\hline$\dot{\gamma}_{0}^{p}$ & viscoplastic Strain Rate. & Time $^{-1}$ \\
\hline$\dot{\gamma}_{0}^{V E}$ & Viscoelastic Creep Rate. & Time $^{-1}$ \\
\hline$\left(\ddot{Y}_{0}^{V E}\right)_{i}$ & $\begin{array}{l}\text { Components of vE Creep Rate } \\
(i=1,2, \ldots, n) .\end{array}$ & Time -1 $^{-1}$ \\
\hline $\mathrm{H}$ & Pillar Height & Length \\
\hline$\theta$ & Slope Angle. & \\
\hline k & Coefficient of Permeability. & Length ${ }^{2}$ \\
\hline K & Permeability, & Length $^{2}$ \\
\hline
\end{tabular}




\begin{tabular}{|c|c|c|}
\hline Symbol & Meaning & Dimensions \\
\hline $\mathrm{K}_{\mathrm{A}}$ & $\begin{array}{l}\text { Octahedral Shear strength at } \\
\sigma_{\mathrm{m}}=0 .\end{array}$ & Pressure \\
\hline $\mathrm{K}_{\mathrm{A}}^{\prime}$ & $\begin{array}{l}\text { Deteriorating Octahedral shear } \\
\text { Stress at } \sigma_{m}=0 \text {. }\end{array}$ & Pressure \\
\hline$k_{B}$ & $\begin{array}{l}\text { Ultimate Octahedral shear } \\
\text { Strength = Transition Strength. }\end{array}$ & Pressure \\
\hline $\mathrm{K}_{\mathrm{p}}$ & Initial Bulk Modulus at $\sigma_{\mathrm{m}}=0$ & Pressure \\
\hline $\mathrm{K}_{\mathrm{D}}^{\prime}$ & $\begin{array}{l}\text { Deteriorating Inicial Bulk } \\
\text { Modulus, at } \sigma_{\mathrm{m}}=0 \text {. }\end{array}$ & Pressure \\
\hline $\mathrm{K}_{\mathrm{E}}$ & Ultimate Bulk Modulus. & Pressure \\
\hline $\mathrm{K}_{\mathrm{G}}$ & Gas Permeability. & Length ${ }^{2}$ \\
\hline $\mathrm{K}_{\mathrm{L}}$ & Liquid Permeability. & Length ${ }^{2}$ \\
\hline $\mathrm{K}_{0}$ & octahedral shear Strength. & Pressure \\
\hline $\mathrm{K}_{\mathrm{Y}}$ & Yield Strength. & Pressure \\
\hline$K_{Y A}$ & Yield Strength at $\sigma_{\mathrm{m}}=0$. & Pressure \\
\hline $\mathrm{K}_{\mathrm{YB}}$ & Ultimate Yield Strength. & Pressure \\
\hline$k$ or $k_{1}$ & Bulk Modulus. & Pressure \\
\hline $\mathrm{K}_{2}$ & Retarded Bulk Modulus. & Pressure \\
\hline $\mathbf{L}$ & Pillar Width. & Length \\
\hline$\mu$ & Absolute Viscosity. & Pressure $\cdot$ Time \\
\hline 7 & $\begin{array}{l}\text { Exponent of Octahedral stress } \\
\text { Difference }\left(\tau_{Q}-k_{0}\right) \text { in VP } \\
\text { Creep Rate Law. } \\
\text { Integer, Index of Last Component } \\
\text { of VE Creep. }\end{array}$ & \\
\hline$v$ & Poisson's Ratio. & Length/Length \\
\hline$P_{b}$ & Base Pressure. & Pressure \\
\hline$P_{I}$ & $\begin{array}{c}\text { Initial Lateral Stress. } \\
\text { xvi }\end{array}$ & Pressure \\
\hline
\end{tabular}


(Cont'd)

\begin{tabular}{|c|c|c|}
\hline Symbol & Meaning & Dimensions \\
\hline $\mathrm{P}_{\mathrm{m}}$ & Mean Gas Pressure. & Pressure \\
\hline$P_{0}$ & Overburden Pressure. & Pre:sure \\
\hline $\mathrm{P}_{1}$ & $\begin{array}{l}\text { Absolute Pressure at Entrance } \\
\text { of Flow. }\end{array}$ & Pressure \\
\hline $\mathrm{P}_{2}$ & $\begin{array}{l}\text { Absolute Pressure at Exit of } \\
\text { Flow. }\end{array}$ & Pressure \\
\hline$Q$ & Volume Flow Rate. & Volume/Time \\
\hline$Q_{b}$ & Flow Rate at Base Pressure. & Volume/Time \\
\hline$Q_{0}$ & $\begin{array}{l}\text { Initial Flow Rate of Perched } \\
\text { Water. }\end{array}$ & Volume/Time \\
\hline & Radial Distance. & Length \\
\hline$s_{i j}$ & $\begin{array}{l}\text { Components of Deviatoric Stress } \\
\text { Tensor. }\end{array}$ & Pressure \\
\hline$\dot{S}_{i j}$ & $\begin{array}{l}\text { Components of rime Rate of } \\
\text { Change of Deviatoric Stress } \\
\text { Tensor. }\end{array}$ & Pressure/Time \\
\hline $\mathrm{s}_{\mathrm{v}}$ & Specific Surface Area. & Area/srea \\
\hline${ }^{o} \mathrm{c}$ & Confining pressure. & Pressure \\
\hline$\sigma_{m}$ & Mean stress $=\frac{1}{3}\left(\sigma_{1}+\sigma_{2}+\sigma_{3}\right)$. & Pressure \\
\hline$\sigma^{\sigma} \mathrm{L}$ & Lateral Stress. & Pressure \\
\hline$\sigma_{i j}$ & Components of Stress Tensor. & Pxessure \\
\hline$\sigma_{i i}$ & Sum of Principle Stresses. & Pressure \\
\hline 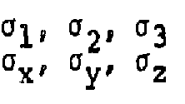 & Three principal stresses. & Pressure \\
\hline$\sigma_{\theta}, \sigma_{r}, \sigma_{z}$ & $\begin{array}{l}\text { Tangential, Radial, and Vertical } \\
\text { Stresses. }\end{array}$ & Pressure \\
\hline$\sigma_{0}, \sigma_{1}, \sigma_{2}$ & $\begin{array}{l}\text { Succesive Lateral stresses in } \\
\text { Time Control Method (Ch. 10). }\end{array}$ & Pressure \\
\hline
\end{tabular}




\begin{tabular}{|c|c|c|}
\hline Symbol & Meaning & Dimensions \\
\hline$\sigma_{\mathrm{T}}$ & $\begin{array}{l}\text { Transition Stress between } \\
\text { Elastic and Plastic States. }\end{array}$ & Pressure \\
\hline$\sigma_{\mathrm{V}}$ & $\begin{array}{l}\text { Overburden Pressure, Vertical } \\
\text { Stress. }\end{array}$ & Pressure \\
\hline \multirow[t]{2}{*}{$t$} & Time. & Time \\
\hline & Tortuosity Factor. & Dimensionless \\
\hline$T$ & Temperature. & Temperature \\
\hline $\mathrm{T}_{\mathrm{s}}$ & Safety Period. & Time \\
\hline$T_{0}$ & Room Temperature. & Temperature \\
\hline \multirow[t]{2}{*}{$\tau_{0}$} & Octahedral Shear Stress & Pressure \\
\hline & $=\frac{I}{3} \sqrt{\left(\sigma_{1}-\sigma_{2}\right)^{2}+\left(\sigma_{2}-\sigma_{3}\right)^{2}+\left(\sigma_{3}-\sigma_{1}\right)^{2}}$ & \\
\hline$\stackrel{\circ}{\mathrm{T}}_{0}$ & $\begin{array}{l}\text { Rate of Change of octahedral } \\
\text { Shear Stress. }\end{array}$ & Pressure/Time \\
\hline$\phi$ & Porosity. & Volume/Volume \\
\hline $\mathrm{v}_{2}$ & $\begin{array}{l}\text { Viscoelastic Coefficient of } \\
\text { Least Transient Component of } \\
\text { VE Creep. }\end{array}$ & Pressure-Time \\
\hline $\mathrm{v}_{2}^{\prime}$ & $\begin{array}{l}\text { Viscoelastic Coefficient of } \\
\text { Second Component of VE Creep. }\end{array}$ & Pressure Time \\
\hline$v_{3}$ & $\begin{array}{l}\text { Retarded Shear Modulus of VE } \\
\text { Creep under VP Condition } \\
\left(\tau_{0} \simeq \mathrm{K}_{0}\right)\end{array}$ & Pressure-Time \\
\hline$v_{4}$ & $\begin{array}{l}\text { Viscosity; Viscoplastic } \\
\text { Coefficient in VP state. }\end{array}$ & Pressure-Time \\
\hline$V_{4}^{\prime}$ & $\begin{array}{l}\text { Effective Viscoplastic Coeffi- } \\
\text { cient; } V_{4} \text { Compensated for Effect } \\
\text { of Stress Difference. }\end{array}$ & Pressure-Time \\
\hline $\mathrm{x}$ & $\begin{array}{l}\text { Exponent of (absolute) Tempera- } \\
\text { ture Dependance of } \dot{\gamma}_{0} \text {. }\end{array}$ & Dimensionless \\
\hline
\end{tabular}




\subsection{Introduction}

The most important geomechanical consideration for storage of radioactive material in underground salt openings is longterm stability. The opening should be stable for at least 30 years and preferably for many hundreds of years. An assurance of the long-term stability requires a theoretical basis for analyzing the long-term creep behavior of the openings. Such an analysis is essential for achieving optimal design for stability. To establish the necessary basis for numerical analysis, constitutive equations of rock salt shorld be formulated. The formulation of the equations requires modeling of the rheological behavior of rock salt in a form which is compatible with computer simulation using the finite element method. In addition, appropriate field instrumentation is required not only to determine the geomechanical condition of the ground for necessary input to the computer program, but also to examine the validity of output from the computer inalysis. Because of the highly rheological nature of the material, the requirement for the instrumentation is unique, especially in determination of stress and strain distribution patterns in salt media in relation to age and geometry of the cpenings.

The objective of this work was to conduct an up-to-date literature study on the geomechanics of salt openings, 
considering both the constitutive equations of rock salt and instrumentation for the in-situ measurements. The study was intended to consolidate available knowledge and technology in a form useful for designing stable openings in bedded salt formations.

A study of the available materials reported to date disclosed that there is ro consensus either on the constitutive equations of rock salt or the methods of testing the material properties. Geomechanics of rock salt was found to be an area of wide controversy. Furthermore, development of field instrumentation was found to be limited. The study also disclosed that there are no generally accepted criteria for designing rock salt openings. However, the study identified that the rheological technique of rock salt developed by Serata over the past 20 years of academic and field work is useful for designing the salt openings. The rheological technigue was found to be the only technique routinely applied to field design. It has produced a substantial amount of in-situ verificiation over the past ten years. Therefore, the rheological technique is given in formulating the constitutive equations, applying field instrumentation, and designing underground openings. In this report, the technique is presented and then compared with the available data to examine the validity of the technique. 
Evaluation of rock salt material properties led to formulation of the constitutive equations. In this report, the theoretical basis of the constitutive equations is evaluated especially with regard to the equations' adaptibility to the finite element method. The field instrumentation tecisnique is presented with some field examsles, and geological parameters which are critical in the design of salt openings are identified from experience gained by applying the computer analysis and field instrumentation method. Finally, the design principles of salt openings under various geomechanical conditions are described with special consideration for the storage application.

Presentation of the material properties of rock salt are given in Chapter 2, Deformation and Strength of Rock Salt, and Chapter 3, Creep Behavior of Rock Salt. The brittle properties which affect the stability of salt openings are discussed in Chapter 2, while the plastic property of rock salt is described in Chapter 3. Based on the experimental findings presented in these two chapters, the constitutive equations of rock salt are formulated as in Chapter 4. Factors affecting the material properties of rock salt, including stress state, strain state, and elevated temperatures, are discussed in Chapter 5. In Chapter 6, the permeability of rock salt is discussed exclusively. The in-sicu measurement of deformation is discussed in Chapter 7, while in-situ stress 
measurement is discussed in Chapter 8. Some newly-developed instrumentation techniques are described in these two chapters. Chapter 9 deals with important factors in the design of salt openings in bedded salt. Among the different factors considered, the geometrical configuration of discontinuity planes due to geological stratification in the salt in relation to the dimensions and elevations of prospective openings is found to be the single most important factor directly affecting the sticility of the openings. In order to optimize the design to deal with the effects of stratification, the stress Control Technigue was developed as presented in chapter 10 .

The scope of this work was limited to an investigation of bedded salt formations. However, the major portion of this work should be applicable to dome salt. No significant difference was found in the material properties of rock salt obtained from the different formations of bedded salt and dome salt, so there should be no difference in the application of instrumentation techniques to the two different Lypes of salt formations. The major differences between the two types of fomations are their geometries and initial stress states. In bedded salt formations, the stratification of discontinuity planes is a major design consideration. In dome salt, on the other hand, the global geometry -- such as location and properties of cap rock and surrounding sedimentary rock 
formations -- becomes a major design consideration. Lateral stresses are also expected to be different depending upon the geomechanical history of the individual formations. 


\subsection{Results of Literature Review}

The literature survey conducted by SGI had four goals:

1. To identify and discuss reports and publications important to the geomechanics of rock salt;

2. To abstract the most important of these;

3. To fird data obtained by other investigators on the laboratory and in-situ deformation of salt; and

4. To compare these results with SGI data.

Important papers are abstracted in Section 1.3. Additional sources consulted are included in the Bibliography at the end of this report. Papers are referred to by the author's name and year of publication.

\subsubsection{Censtitutive Equations of Rock Salt -- The rheo-} logical constitutive equations used by SGI for numerous analyses of salt opening behavior in bedded and domal formations were initially developed as a result of six years of basic research funded by the National Science Foundation (NSF). The research was conducted at Michigan State University from 1960 to 1966 . The final outcome of the NSF research is documented in Sakurai's dissertation (1966). The NSF research on the constitutive equations was preceded by preliminary research work on the develcpment of design criteria for storage of radioactive materials i.n underground salt cavities, funded by the Atomic Energy Commission; this AEC research was conducted at the University 
of Texas, Austin, Texas, from 1956 to 1959. The results of the AEC study are locumented in Serata's dissertation (1959). The constitutive equations were further refined after 13 years of experimental and theoretical work at the SGI laboratory. An earlier portion of results of this work is presented in Adachi's dissertation (1970).

Of the many constitutive equations proposed in the literature, none were found to have been subjected to such an extensive set of laboratory and field verification tests as the rheological equations. Serata's papers $(1959,1961,1968$, 1969, 1974, 1976, 1979) detail some of the laboratory and field tests. The large portion of the work has been kept confidential by the industries.

Creep models for rock salt can, very roughly, be spit into three categories:

1. Purely empirical laws;

2. Rheological models based on observations; and

3. Physical models supported by observations. The rheological approach is used by Adachi (1970): Albrecht and Langer (1974); Sakurai (1966); Shoua and Mase (1966); and Winkel, Gerstle, and Ko (1972).

A very useful sumary of constitutive models and creep laws by investigators using all three approaches is given in Dawson (1979) . 


\subsubsection{Eundamental Creep Mechanisms--The rheological}

constitutive equations are an elaborate set of well-tested stress-strain relations, which are found to be most useful for engineering applications. The equations represent the stress-strain relations with respect to time based on creep mechanism of aggregate salt.

More fundamental work on the mechanisms of salt deformation does exist, but it is at a relatively early stage. Such fundamental work of rock salt does not necessarily promise any practical value in design of safe salt openings because underground behaviors of salt openings are largely dictated by factors which are completely outside the srope of such work. The most critical factors are clay seams in the vicinity of openings, initial lateral stress in the salt formation, creep deterioration of granular bonding in the opening boundary, and the time sequence of excavation. The effects of these factors are found to be most realistically analyzed by the rheological method.

Sandia Laboratories in New Mexico are currently conducting some fundamental work on salt deformation mechanisms. Munson (1979) presents a deformation-mechanism map for salt, along with a discussion of the mechanisms and a first-cut constitutive equation. Some of the creep laws in Dawson's summary article (1979) are based on physical rodels; others are purely empirical. Fossum (1977) of RE/SPEC in South Dakota describes 
creep laws for salt derived from thermodynamic principles. Some mechanisms thought to be responsible for different types of creep are also discussed in Höfer (1971) and odé (1968). Creep mechanisms of poly-crystalline materials (not specifically on salt) can be found in Raj and Ashby (1971); Coble (1963); Nabarro (1948): and Herring (1950). Burke's thesis (1968) has a chapter on the creep of crystalline materials and extensive references to papers on this subject.

Single crystals of salt were tested by Poirier (1972), Le Comte (1965), and Carter and Heard (1979). Deformation mechanisns relevant to single crystal samples are discussed in these papers. Poirier's tests were done near the melting point of salt, and le comte did only one test, so the amount of relevant single crystal data from these sources is límited. Agullo-Lopez and Levy (1964) exposed single salt crystals to gamma rays and found that the irradiated samples had higher yield points and extended "easy glide" or plastic regions.

\subsubsection{Einite Element Computer Program--A theological finite} element computer program (REM) developed by Serata is found to be most effective in analyzing the long-term behavior of salt mine openings and solution caverns. Usefulness of the REM program as been demonstrated in the computer prediction and field measurement of massive creep closure of the Eminence gas storage caverns in Mississippi. It is this field verification that made the REM program an accepted means of designing 
major salt caverns such as the Ruhrgas cavern in West Germany, compressed air energy storage for Nordwestdeutsche Kraftwerke in West Germany, and the 15-cavern Louisiana Offshore Oil port (LOOP) oil storage system in the clovelly salt dome, Louisiana. At present, the program is being used on a routine basis for design analysis of a number of salt and potash mines in Canada, the United States, and England.

Other authors who have done finite element work on salt include Anderson (1976); Dwyer and Thoms (1973); Nair et al. (1973); and Fossum (1976). Dwyer and Thoms did a finite element simulation of a storage dome with hot wastes. Nair et al. describe time-dependent finite element analyses of salt openings. General introductions to the finite element method can be found in Desai and Abel (1972) and Zienkiewicz (1971). There will be numerous finite element solutions available. However, the only useful one is the one having the most field verifications.

\subsubsection{Laboratory Creep Data--Laboratory data on creep of} rock salt under triaxial loading due to Adachi (1970); Hansen (Iune, 1977); Heard (1972); Le Comte (1965); Sakurai (1966); Thompson (1964); and Wawersik (1979) are considered to be the most reliable data available. Heard's data were especially useful due to the range of temperatures tested. A review by SGI of data from these investigators concluded that the octahedral creep rate increases with absolute temperature raised to the power $x=9.7$, and with stress difference raised to the power $n=2.6$. Full results are presented in chapter 5. Burke (1968) has a valuable set 
of data on polycrystalline rock salt. Unfortunately, a copy of his work was obtained too late to be included in this data review.

Serata (1961) presents the concept of a transition strength which predicts the existence of a critical stress state in rock salt at which the transition between elastic and plastic stress states occurs very sharply. Data from the sources listed above was found to be consistent with this concept.

There are numerous publications dealing with laboratory tests of model pillars. Most of these should be avoided as end friction effects in the samples plague the interpretation of the results. The laboratory results of model pillar tests are very hard to correlate with in-situ observations. The work by Lomenick (1968) is perhaps an exception. Lomenick studied the effects of temperature and friction on the deformation of model pillars. The effects of shale partings that sometimes exist in bedded salt were simulated by sandwiching Teflon disks into the model pillars.

\subsubsection{In-Situ Creep Data--In the Project Salt-Vault} report, Bradshaw and McClain (1971) describe in-situ creep measurements in rooms which were electrically heated to simulate radioactive waste storage conditions. 
As expected, the convergence rate increased sharply with temperature, although the authors concluded that the increased rate was acceptably low. The heating test was too short and incomplete to draw firm conclusions, and more such tests seem advisable to correlate laboratory predictions with in-situ facts.

Hedly (1967) compares convergence data from five mines in bedded salt formations. The data is interesting because the age of the openings ranges from two to 70 years, and all show constant or decreasing creep rates. Bradshaw and Boegly (1964) discuss data from two of these mines.

The paper by wieselmann (1968) can serve as an introduction to closure measurements, and the paper by Mraz (1978) discusses the correlation between theoretical predictions and in-situ observations. The book by Baar (1977) is also useful in this respect.

\subsubsection{Stress Measurements--Stress measurement in salt} is problematical due to the nonlinear behavior of the material. A short but interesting discussion of the dilemmas of stress measurement can be found in an article 
by Panek (1961). He makes the point that stress "measurements" are very roundabout and more often than not, "determine" is a better word to use since the stress is usually calculated from some other measurable quantity, such as strain, De La Cruz and Raleigh (1972) tested five in-situ stressmeters. Although their tests were in sandstone and depended on elastic properties of the rock, their paper is useful for comparative purposes--there was wide scatter in the magnitude of the stress, ever1 for the "easier" case of elastic media.

Obert's 1962 paper is a qualitative discussion of the disturbing effect of sampling, and his 1966 paper has some remarks on the applicability of several stress measuring devices to nonelastic media.

High modulus plug stressmeters can indicate stress changes in plastic media and, given a very long time (up to one year for salt), can determine absolute stress, according to Skilton (1971) and Fairhurst (1968). Dreyer (1972) describes attempts to match the Young's moduli of the plug and the rock media by making the plug out of rock salt. 
He got mixed results and apparently dropped the matter.

Discussions on the hydraulic fracturing method of stress determination can be found in Fairhurst (1968), Haimson (1974), and Hall and Hoskins (1972). This method is based on elastic theory but can give an indication of the direction of maximum stress, Hall and Hoskins' manual (1972) is an application-oriented guide to several stress measuring systems. Unfortunately, the problem of stress measurement in nonelastic media is not given much attention in that publication.

De La Cruz and Goodman (1970) describe the "borehole deepening method of absolute stress measurement." Stressrelief creep is measured just behind the advancing borehole drill bit. The stress state is determined from the horehole creep data via a finite element computer program. The concept of immediate measurement is a good one, but there are technical problems due to the noise of the drill bit. To our knowledge, the method was never fully developed. 
Translation of borehole creer, data to the gtress state by means of a finite element program is the basis of Serata's stress measuring device, described in Chapter 8 of this report. A borehole pressure cell fitted with several LVDT linear displacement devices loads the borehole and obtains borehole creep data in the threedimensional configuration of the test hole. This data is interpreted with the rheological finite element (REM) computer method, and the complete stress state can be determined very reliably. Rocha (1966) describes a very similar method, but according to Hall and Hoskins (1972). use of Rocha's stressmeter is impractical $\mathrm{s}$ ince the creep data has to be sent to Portugal for interpretation and service is sporadic. In addition, Rocha's cell is a relatively low pressure device. Serata's stress measi-ing system is believed to be the most reliable method available for nonelastic media, since the cell is capable of loading the media to more than $10,000 \mathrm{psi}$, the resulting borehole deformation is accurately measured, and the finite element program used for the stress determination has been well tested. 


\subsubsection{Tilt Measurements--Literature on surface tilt}

mu asuring devices was researched since surface subsidence gives important information on the stability of an underground opening (Chapter 7 ). Long baseline tiltmeters are preferred for measurement of surface tilt above underground openings. Eaton's 1959 paper is useful for advice on operation and sources of error encountered when using liquid-level meters. The liquid level in Eaton's device is read with a micrometer device, Allen et al. (1973) compare long baseline mercury-level tiltmeters with pendulum-type tiltmeters. Both are capable of high resolution $\left(10^{-8} \mathrm{rad}\right)$ and low drift $(1.5 \mathrm{microrad} /$ year $)$. Hugget and Slater (1976) describe a relatively simple physical means of compensating for temperature differences along the ba:eline. Serata has developed a practical liquid level meter which measures vertical displacement between two points connected by a liquid line with a resolution equal to that cf the LVDT device $\left(10^{-4} \sim 10^{-6}\right.$ in) used to measure the liquid level.

Thoms et al. (1977) discuss several methods to monitor movement of salt domes. Some of the methods are equally 
applicable to surface movements caused by openings in bedded formations.

1.2.8 Permeability--Works by Lai (1971), Reynolds and Gloyna (1960), and Sutherland and Cave (1978) on permeability of rock salt were found relevant to this study. close relationships among the different results obtained from the different test methods were identified. The permeability of rock salt exhibits generally consistent values as a function of the stress state defined by both mean stress and octahedral shear stress. Strain hardening and viscoelastic consolidation reduce the permeability value in a consistent manner. The laboratory data indicate that there are two different regions that exist around the prospective caverns. The first is the viscoplastic region, where the permeability is reduced by strain hardening caused by stress relief after the creation of the storage caverns. The second is the boundary region of the caverns inside the viscoplastic 2one, where the medium will be subjected to concentration of creep strain and subsequent stress reduction with brittle granular deterioration. In this brittle region, permeability is expected to increase. Development of such a brittle region is 
discussed by Serata $(1959,1974)$. It is expected to be strongly affected by the depth and geometry and age of the cavern opening as well as lateral tectonic stress.

\subsubsection{Geological Factors--Methods for detecting water} and other anomalies in salt formations can be found in Cook (1973) and Unterberger (1973). Geological aspects of radioactive waste storage in salt domes are described in Ledbetter et al. (1975). For literature on fluid inclusions, refer to the bibliography by Isherwood (1979). Serata has shown that geomechanical discontinuity planes in bedded salt formations are the single most critical design factor determining the long-term stability of salt openings. A technique of controlling the effect of the discontinuity planes was developed (1976). Usefulness of the technique (the Stress Control Method) is becoming widely accepted in Canada, the United States, and England. 


\subsection{Abstracted References}

(1) Adachi, T. "Construction of Continuum Theories and Their Application to Underground Detection of Stress Conditions." Ph.D. Dissertation, University of California, Berkeley, 1970

The constitutive equations of rack salt were re-examined and refined to yield greater accuracy. Based on the refinement, the behavior of cylindrical cavities under various stress states was evaluated for the purpose of developing a stressmeasuring device based on the rheological properties of the material. A stress-measuring device was developed and successfully applied to measure the state of stress in salt formations in a Canadian potash mine.

(2) Barr, C. A. "The In-Situ Behavior of Salt Rocks." Applied Salt-Rock Mechanios, 1; Elsevier Scientific Publishing Company, 1977

Geology of salt formations and observation of salt opening deformation are described with an extensive collection of . data. This is considered an excellent source book on salt geology. Field data on the mine observation are found usefu: but the rock mechanics interpretation of the data is erroneous and misleading, and requires careful re-evaluation.

(3) Dawson, P. R. "Constitutive Models Applied in the Analysis of Creep of Rock Salt." Sandia Laboratories, Rough Draft, January 15, 1979.

In Dawson's summary article, a general discussion of the various forms that creep laws and constitutive models can assume is presented. Creep literature is discussed, and then specific 
models by numerous investigators are presented. Among those whose work is presented are Lomenick; Maxwell, Wahi, and Dial; Ratigan and Callahan; Hansen; Russel; Menzel et al.; Parrish and Gangi; Le Comte; Hedley; Obert; Thompson and Ripperger; neard; Hansen and Mellegard; Dawson and Tillerson; Munson; Mraz; Winkel, Gerstle, and Ko; and Langer. Dawson concludes that as of yet thrre is no suitable set of constitutive equacions which covers all aspects of salt behavior.

(4) Dreyer, $w$. "The Strength Properties of Rock." Science of Rock Mechanics, Part 2, TransTech Publications, January 1972, P.0. Box 9797, Bay Village, Ohio, 44140

This is a large collaction of various laboratory test results on salt behavior. For the individual tests, corresponding empirical „quations are elaborately established, However, the results are not found to be particularly useful and are misleading. Most of the results obtained, and the empirical equations derived, are merely representing specific boundary conditions used for the specific testing rather than the material properties themselves. Many test results are distorted unintentionally by friction conditions of the testing set-up itself. The work is considered to be an interesting exercise in salt experiments, but not particularly useful for providing basic data essential for geomechanical analysis of salt structures in-situ. 
(5) Hansen, F.D. "Triaxial Quasi-Static Connression and Creep Behavior of Bedded Salt from Southeastern New Mexico." For Sandia, Technical Report RSI 0055, RE/SPEC, Inc., February, 1977.

Creep data for New Mexico salt are given for confining pressures of 500 to $2000 \mathrm{psi}$, temperatures of $28^{\circ} \mathrm{C}$ and $100^{\circ} \mathrm{C}$, and stress difierences up to $4500 \mathrm{psi}$. Tests at atmospheric confinement presisure are given in another paper by Hansen ("Design Aspects of the Alpha-Repository," June, 1975).

(6) Heard, H.C. "Steady-State Flow in Polycrystalline Halite at Pressure of 2 Kilobars." Geophys. Monograph Series, Vol. 16, Flow and Fracture of Rocks, AGU, 1972.

The stress-strain relationship of annealed, articicial polycrystalline salt was exarnined at constant creep rates, at temperatures from $23^{\circ} \mathrm{C}$ to $400^{\circ} \mathrm{C}$, ana at a confining pressure of $2 \mathrm{~kb}(\approx 29,400 \mathrm{psi})$. Strain hardening was observed, Flow mechanisms are discussed. The high confining pressure makes this study more of a geological interest but the high temperature data was found to be very useful in geomeclianical studies.

(7) Lai, C-S. "Fluid Flow Through Rock Salt under various Stress states." Ph.D. dissertation, Michigan State University, East Lansing, 1971.

Laboratory testing of permeability of rock salt by using kerosene as a permeant verified the assumption that the permeability of the material is a function of two independent variables, octahedral shearing stress and mean stress. 
Permeability under different stress states varied from $3.6 \times 10^{-14} \mathrm{~cm}^{2}$ to $4.1 \times 10^{-10} \mathrm{~cm}^{2}$.

(8) Le Comte, P. "Creep in Rock Salt." J. Geology 73, pp. 469-484, May, 1965.

Creep tests were conducted on artificial polycrystalline rock salt. Most of the tests were under very large confining pressures $\left(\sigma_{c}=1 \mathrm{kbar}=14,700 \mathrm{psi}\right)$, with stress differences up to 158 bar ( 22000 psi) and temperatures ranging from $20^{\circ} \mathrm{C}$ to $200^{\circ} \mathrm{C}$ with most near $100^{\circ} \mathrm{C}$. The activation energy for creep was determined at atmospheric pressure for temperatures ranging from $29^{\circ} \mathrm{C}$ to $300^{\circ} \mathrm{C}$.

(9) Munson, D.E. "Preliminary Deformation--Mechanism Map for Salt (with Application to WIPP)." Sandia 79-0076, Rough Draft, January, 1979.

Munson's rough draft paper gives a "preliminary deformationmechanism map for salt"; that is, a chart of (dimensionless) temperature against (dimensionless) stress, divided into areas in which certain creep mechanisms are expected to occur. Munson includes five creep mechanisms, including an "undefined mechanism." A first-cut constitutive equation is presented.

(10) Reynolds, T.D., and E.F. Gloyna. "Permeability of Rock Salt and Creep of Underground Salt Cavities." Reactor Fuel Waste Disposal Project, Atomic Energy Commission, 1960.

Permeability for dome salt was found to vary from zero to $1.5 \times 10^{-9} \mathrm{~cm}^{2}$ under various confining pressures. The 
permeability of bedded salt ranged from zero to $2.3 \times 10^{-13} \mathrm{~cm}^{2}$ under high confining pressure. Although Reynolds concluded that the permeability of bedded salt was less than that of dome salt, examination of his data indicated that under identical stress states, the permeabilities of the two types of salt were quite comparable. Different permeating fluids used for the test included helium gas, kerosene, mineral oil, saturated brine solution, calcium sulphate solution, and a synthetic waste solution. Results are all converted to the nonreactive liquid permeability for comparison by using the Klinkenberg formula.

(11) Sakurai, S. "Time-Dependent Behavior of Circular Cylindrical Cavity in Continuous Media of Brittle Aggregate." Ph.D. dissertation, Michigan State University, East Lansing, 1966.

The rheological constitutive equation of rock salt was established based on tensor behavior of stress and strain. Legitimate coefficients of material properties of rock salt were determined experimentally. The octahedral shearing strength of the material was established by two different methods, the transition method and the viscoplastic creep method, resulting in a close agreement of approximately 700 psi. By using the constitutive equations of the material, time-dependent behaviors of cylindrical cavities were analyzed. 
(12) Serata, S. "Transition from Elastic to Plastic States of Rocks under Triaxial Compression." Transactions of the Fourth Symposium on Rock Mechanics, Pennsylvania State University, April, 1961

Transition phenomena from elastic to plastic states of rock salt under triaxial conditions were postulated based on the yield surface principle. The postulation was verified by laboratory experiments illustrating the principle of the transition mechanism of rock salt.

(13) Serata, S., Sakurai, S., and Adachi, T. "Theory of Aggregate Rock Behavior Based on Absolute ThreeDimensional Testing (ATT) of Rock Salt." proceedings of the Tenth Symposium on Rock Mechanics, University of Texas, Austin, April, 1968

The laboratory testing method for establishing constitutive equations of rock salt was explained. Values of the material property coefficients were derived.

(14) Serata, S. "Stress Control Technique--An Alternative to Roof Bolting?" Mining Engineering, AIME, May, 1976

A rheological concept of stabilizing underground openings excavated in various salt formations having different roof stability conditions was developed. The concept was proven useful by the combined use of the REM computer method and in-situ stress measurement in rock salt. The concept is now widely applied in salt and potash mining and fundamentally changes the conventional approach to mine design, 
(15) Serata, S. "Geomechanical Basis for Design of Underground Salt Cavities." Energy Technology Conference, ASME, Houston, Texas, November, 1978

The development and application of the Rock Salt Technique used for designing underground salt cavities was sumarized in its entirety with various field examples.

(16) Sutherland, H. J., and cave, S. "Gas Permeability of SENM Rock Salt." SAND 78-2287. Prepared by Sandia Laboratories, AIbuquerque, Nex Mex:co, and Livermore, California, 1978

Laboratory measurements of argon gas permeabilities for rock salt are obtained by using a transient, pressure-step technique. Results indicate that hydrostatic pressure states can "heal" the specimens to their original undisturbed states and that in-situ permeability of these undisturbed formations is less than $.5 \times 10^{-15} \mathrm{~cm}^{2}$.

(17) Thompson, E., and Ripperger, A. "An Experimental Technique for the Investigation of the Flow of Halite and sylvinite." proceedings of the Sixth Symposium on Rock Mechanics, University of Missouri, at Rolla, 1964

Thompson presents a small but useful set of room temperature creep data for halite. He uses a confining pressure of $1650 \mathrm{psi}$, and stress differences from $1400 \mathrm{psi}$ to $2400 \mathrm{psi}$. 
(18) Vorchert, H., and Nirir, R. O. "Mechanical Properties of Evaporates (Chapter 21)," Salt Deposit, D'Van Nostrant Company, Princeton, New Jersey, 1964

This is an excellent documentation on properties of salt deposit, providing general background information on geomechanical behavior of rock salt déuisit.

(19) Wawersik, W. R., and Hannum, D. W. "Interim Sunnary of Sandia Creep Experiments on Rock Salt from the WIPP Study Area, Southeastern New Mexico." Sandia Laboratories, 1979

This rough draft report presents rt:ults of creep tests on New Mexico rock salt under conditions expected to be encountered in the WIPP (Waste Isolation Pilot Plant) study area. Confining pressures range from 0 to 3000 psi, stress differences from 950 to $4800 \mathrm{psi}$, and temperatures to $200^{\circ} \mathrm{C}$. The tests lasted up to 70 days on sone samples. 


\subsection{DEFORMATION AND STRENGTH OF ROCK SALT}

Rock salt exhibits generally consistent behavior under welldefined geomechanical conditions. The reason that the behavior of rock salt appears complex is the fact that the behavicr consists of a number of distinct but diverse behavioral components. Each component conforms rather closely with a well-established behavior pattern such as elasticity, viscoelasticity, viscoplasticity, or compressibility (Serata, Wawersik, and Manson, 1968). A unique feature of rock salt behavior is that its nonelastic behavioral components predominate over its elastic components. Therefore, under well-defined geomechanical conditions, rock salt behaves in a quantitatively predictable manner. The most important requirement for long-term safety analysis of salt openings for the use of radioactive waste storage is to identify various behavioral components of the materiai in relation to underground conditions of the storage openings. Figure 2-1 is a conceptual sketch of geomechanical conditions in salt media surrounding a storage opening illustrating relations among different stress-strain states (Serata, 1969). The stress-strain states are expressed in terms of octahedral shear and mean stresses $\left(\tau_{0}\right.$ and $\left.\sigma_{m}\right)$ and their corresponding 


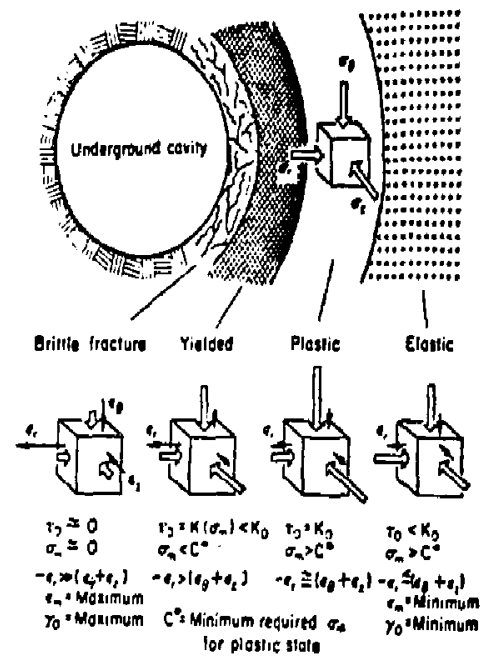

Figure 2-1. Various Strain States of Media in a Deep Underground Cavity Defined by octahedral Parameters.

Source: SGI, 1979. 
strains $\left(\gamma_{0}\right.$ and $\left.\varepsilon_{\mathrm{m}}\right)$, respectively. The major behavioral components required for quantitative analysis of the longterm stability are identified and discussed in relation to the geomechanical conditions.

\subsection{Deformation Characteristics}

\subsubsection{Stress-Strain Relationship--The stress-strain} relationship of rock salt is nonlinear, as illustrated in Figure 2-2. This relationship was obtained from a number of 5-inch cube rock samples exposed to a wide range of uniaxial and triaxial loading conditions as indicated in the figure (Serata et al., 1968). Rock salt test specimens always exhibit a large amount of permanent deformation, even when the applied stresses are much less than the failure strength. Test specimens also exhibit considerable hysteresis deformation under cyclic loading. These behaviors are strongly affected by confining pressure, as observed in the same figure. There is no simple stress-strain relationship which generalizes laboratory observations. Each sample merely reflects its own stress-strain history, including tectonic loading, the disturbing effect of sampling, and the method of laboratory testing. However, 


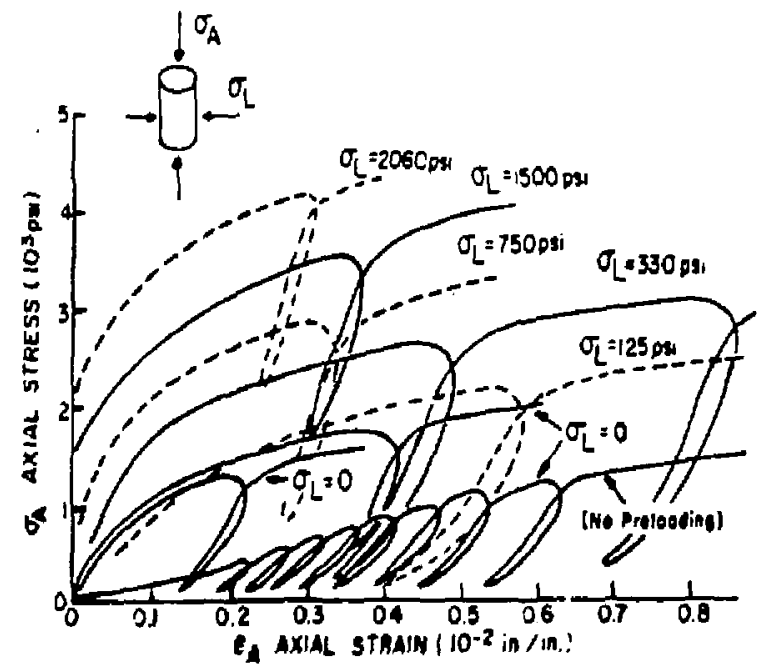

Figure 2-2. Stress-strain Relation of Weakly Bonded (Louisiana) Salt under Various Confining Pressures. Source: Sakurai (1966). 
it should be noted that the unloading behavior of the specimens is found to be highly consistent in all the specimens, regardless of their stress-strain history. The natural condition of rock salt in-situ is to be subjected to certain stresses and strains. Thus, the unloading portion of the behavior of the laboratory specimens is expected to represent behavior of underground salt media following an excavation (Serata et al., 1968). Therefore, the unloading portion of the stress-strain relationship can be utilized for the major portion of the numerical analysis of cavity behavior. The other portion needs to deal with the creep deterioration.

\subsubsection{Strain Hardenin' and Young's Modulus--Rock salt in} underground formations is expected to be in a strain-hardened state. Therefore, the stress-strain relationship of an underground medium should be reproducible in laboratory specimens after a sufficient number of preliminary loadings. Such loadings always produce a rather consistent stress-strain relation with certain values of Young's modulus, as illustrated in Figure 2-3. This figure is reconstructed from Figure 2-2 by shifting the strain-hardened portion of the stress-strain diagrans in such a way that they overlap 


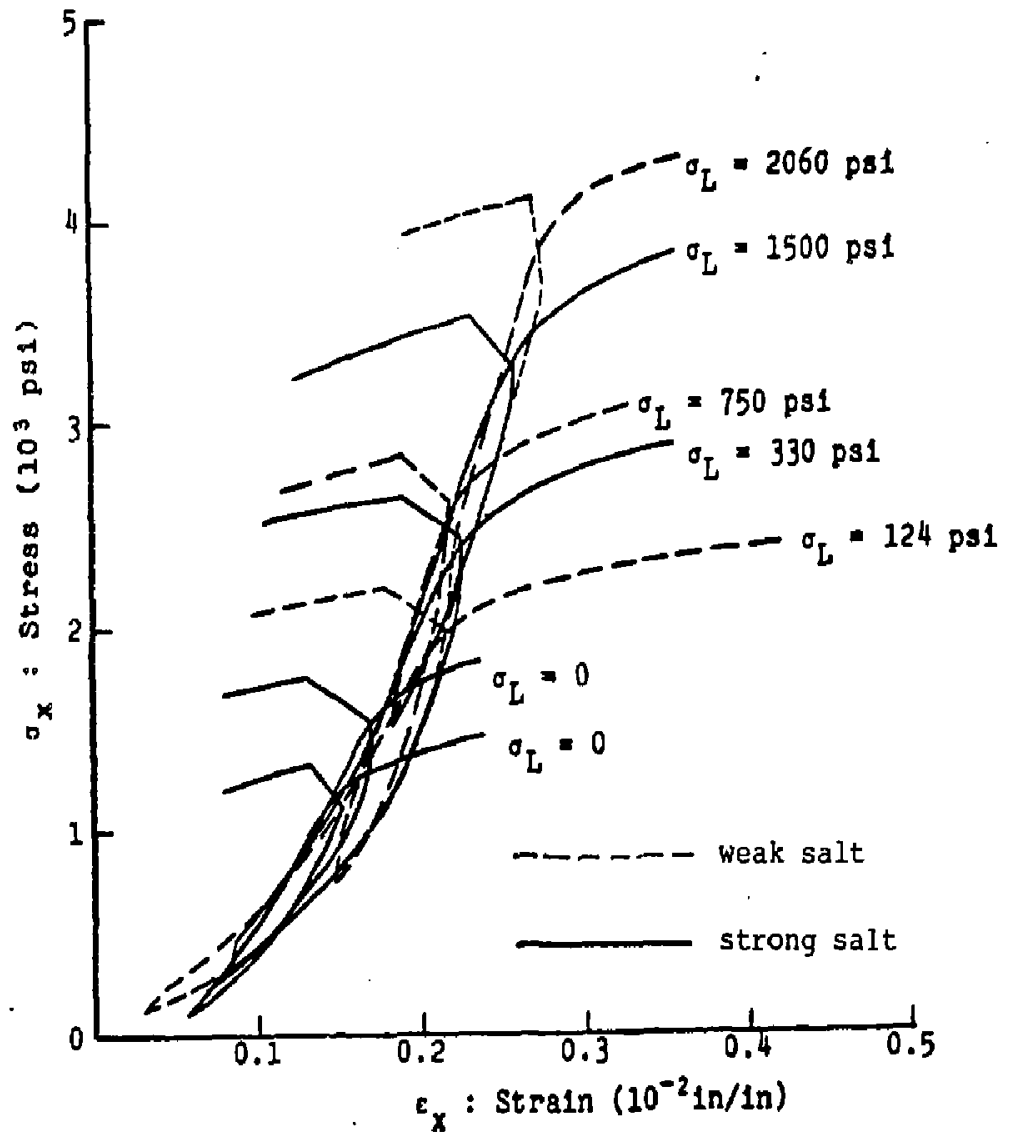

Figure 2-3. Development of Strain-Hardened StressStrain Relation 'Loulsiana Salt):

Source: Sakurai (1966). 
each other for ease of comparison (Serata et al., 1968). In Figure 2-3, the stress-strain relations of two different -ypes of specimens are compared. The two types chosen for comparison represent the most competent (hard) and the weakest friable media, respectively. The comparison reveals that the extreme difference in the appearance of these specimens has very little to do with the stress-strain behaviors of the media, especially at higher mean stress levels (Serata et al., 1968). The main difference found in the comparison is that weak salt has a substantially smaller Young's modulus only when the mean stress is limited to less than a few hundred pounds per square inch.

In the literature, a wide range of values of Young's modulus for rock salt has been reported. The wide variation in values may be attributed to differences in the testing procedures used, as well as the variably compressible nature of the material and its strain-hardening property. The reported E-values are summarized in Table 2-1. Also given in the table are the values of the elastic shear modulus, $G_{1}$, which were either directly measured in the laboratory tests or derived from the E-values assuming Poisson's ratio to be $v=0.1$. 
Table 2-1. Young's Modulus of Rock Salt at Room Temperature

$\begin{array}{llll}\mathrm{E} & \mathrm{G}_{1} & \text { Testing } & \\ \left(1.0^{6} \text { psi }\right) & \left(10^{6} \text { psi }\right) & \text { Method } & \text { Researcher }\end{array}$

\begin{tabular}{|c|c|c|c|}
\hline $0.1-0.3$ & $.045-.14$ & $\begin{array}{l}\text { Conventional Triaxial } \\
\text { Test }\end{array}$ & Handin (1953) \\
\hline $0.1-0.8$ & $.045=.36$ & Transition Method & $\begin{array}{l}\text { Morrison (1962), } \\
\text { Serata (1961) }\end{array}$ \\
\hline $0.6-2.3$ & $.27-1.12$ & Absolute Tensor Testing & Sakurai (1966) \\
\hline $0.95-4.17$ & $.43=1.90$ & Cavity Testing & Serata (1964) \\
\hline $1.4-2.3$ & $.57-1.1$ & Absolute Tensor Testing & Serata (1968) \\
\hline $4.6-5.1$ & $2.09-2.32$ & Ultrasonic Method & $\begin{array}{l}\text { Serata, Abu-Gheida } \\
\text { et al. (1964) }\end{array}$ \\
\hline $4.2-5.45]$ & $1.27-2.04$ & $\begin{array}{l}\text { Cylindrical Cavity } \\
\text { Testing }\end{array}$ & Adachi (1970) \\
\hline
\end{tabular}

Most of the reported values of $\mathrm{E}$ fall within the wide range of $0.1 * 5.5 \times 10^{6} \mathrm{psi}$. This wide range indicates that those samples used for the tests are merely repre. anting different degrees of granular relaxation which are unique to the individual specimens. For design analysis, therefore, all values would be used depending upon actual relaxation conditions to be expected in-situ. In general, precision of the value is found to be much less significant compared to the other coefficient values observed in field calibration work. 
For general use in analyzing salt opening stability, the E-value of $2.0 \sim 5.0 \times 10^{6}$ psi may be used for depths up to 3000 feet (Adachi, 1970). For more accurate analysis of long-term cavity creep behavior, especially for depths, over 1000 feet, the following empirical relation obtained from Figure 2-3 may be utilized (Serata et al., 1968):

$$
E=E_{1}+\left(E_{2}-E_{1}\right)\left(1-e^{\top} \sigma_{m}\right)
$$

where:

$$
\begin{aligned}
E_{1} & =\text { Young's modulus at }\left(\sigma_{\mathrm{m}}=0\right) \\
& =0.1 \times 10^{6} \mathrm{psi} ; \\
E_{2} & =\text { ultimate Young's modulus } \\
& =6.0 \times 10^{6} \mathrm{psi} ; \\
a & =\text { exponential constant }=0.0015 ; \text { and } \\
\sigma_{\mathrm{m}} & =\text { mean stress. }
\end{aligned}
$$

\subsubsection{Compressibility and Bulk Modulus--Rock salt has} both elastic and nonelastic compressibility. The elastic component of the compressibility expressed in terms of mean strain, $\varepsilon_{m^{\prime}}$ is linearly related to the mean stress, $\sigma_{m}$, as (Adachi, 1970; Sakurai, 1966):

$$
E_{m}=\frac{v_{m}}{3 K_{j}}
$$

where $k_{1}=$ bulk mudulus. 
The nonelastic component of mean strain exhibits a creep rate, $\dot{\varepsilon}_{m}$, which reduces exponentially with time in the form:

$$
\dot{\varepsilon}_{m}=\frac{\sigma m}{3 D_{2}} \text { e }^{-\frac{K_{2}}{D_{2}} t}
$$

where:

$$
\begin{aligned}
& \mathrm{D}_{2}=\text { bulk viscosity or volumetric elastoviscosity; and } \\
& \mathrm{K}_{2}=\text { retarded bulk modulus. }
\end{aligned}
$$

Therefore, the cotal mean strain, $\varepsilon_{m}$ at time $t$, can be found in the form:

$$
E_{m}=\left\{\frac{1}{3 K_{1}}+\frac{1}{3 K_{2}}\left(1-e^{-\frac{K_{2}}{D_{2}} t}\right)\right\} \sigma_{m}
$$

It can be seen from Equation 2-4 that both elastic and viscoelastic closures of a salt opening are expected at greater depths where the mean stress, $\sigma_{m}$, will be substantially reduced with time by the development of a plastic zone around the opening. Equation 2-4 also shows that the large $D_{2}$ value will cause the closure process to continue for many years after the initial excavation (Serata, 1969; Serata, 1974). Thus, the property coefficients $K_{2}$ and $D_{2}$ are important parameters in considering creep closure of the salt openings. A further study of these coefficients under a wide range of boundary conditions is warranted.

The elastic and nonelastic coefficients of compressibility determined by various investigators are summarized in Table 2-2. 
Table 2-2. Elastic and Viscoelastic Coefficients of Dilatancy (Compressibility) of Rock Salt

\begin{tabular}{|c|c|c|c|}
\hline Investigators & $\begin{array}{c}\text { Bulk } \\
\text { Modulus } \\
K_{1} \\
\left(10^{6} \mathrm{psi}\right)\end{array}$ & $\begin{array}{l}\text { Retarded } \\
\text { Bulk } \\
\text { Modulus } \\
\mathrm{K}_{2} \\
\left(10^{6} \mathrm{psi}\right)\end{array}$ & $\begin{array}{l}\text { Volumetric } \\
\text { Elasto-Viscosity } \\
\left(10^{6} \text { psi-day }\right)\end{array}$ \\
\hline $\begin{array}{l}\text { Sakurai } \\
\text { Serata }\end{array}$ & $0.5 \sim 0.9$ & 7.6 & 18.7 \\
\hline $\begin{array}{l}\text { Adachi } \\
\text { Serata }\end{array}$ & $0.8=5.5$ & 2.7 & 9.7 \\
\hline $\begin{array}{l}\text { Winkle, } \\
\text { Gerstle, Ko }\end{array}$ & $0.65 \sim 1.2$ & $--=$ & -- \\
\hline $\begin{array}{l}\text { Cundey* } \\
\text { Serata }\end{array}$ & $0.7 * 2.5$ & +-- & --- \\
\hline
\end{tabular}

* Unpublished test conducted at SGI (1979) 
A wide range of $k_{1}$-values have been reported as similar to that of the E-values. The $K_{1}$-value of the same salt specimen can be found in the wide range of 0.5 r

$5.5 \times 10^{6} \mathrm{psi}$, depending on the degree of granular relaxation of the specimens prior to the test loading and also loading procedure used during the test. The smaller values of $\mathrm{K}_{2}$ and $\mathrm{D}_{2}$ are found to be in better agreement with field observations analyzed by the REM computer simulation.

\subsection{Failure and Yielding Strength}

\subsubsection{Two Basic Failure Processes--Rock salt deforms} by two distinctly different processes of brittle fracture and ductile yield (Adachi, 1970; Sakurai, 1966; Serata et al., 1968). The brittle fracture takes place by a deterioration of boundaries between individual granular crystals, while the ductile yield takes place by strain within the crystals. Failure of rock salt usually involves the two different deformation processes which take place simultaneously within the same medium. Therefore, brittle fracture and ductile yield cannot be treated entirely separately in analyzing behaviors of the salt openings. 
Ductile yield starts to predoninate the deformation of a medium with the mean stress, $\sigma_{m}$ generally greater than 1000 psi (Adachi, 1970; Sakurai, 1966; Serata et al., 1968). With the mean stress exceeding $2000 \mathrm{psi}$, the material becomes virtually ductile. However, a reduction of the mean stress below 1000 psi makes the material increasingly friable and less ductile. With a further reduction of $\sigma_{m}$, the material tends to fail more readily by brittle fracture under a relatively small stress. Under uniaxial compression, the material deforms and fails almost entirely by brittle fracture. The shifting of this behavioral pattern from ductile yield to brittle fracture takes place rather gradually with the reduction of $\sigma_{m}$. The general pattern of the shift is seen in the strength analysis of Figure 2-4. In this figure, various failure and yield strengths are plotted in terms of $\tau_{0}$ and $\sigma_{m}$. The failure strengths are found scattered over a wide range depending mainly upon the testing procedures employed, while the yield strength is found to be rather consistent. The yield strength is defined here as the stress state at which the volumetric strain change with respect to the change in octahedral shear stress becomes zero; that is, $\Delta \varepsilon_{\mathrm{m}} / \Delta \tau_{0}=0$. The figure also shows various definitions of 


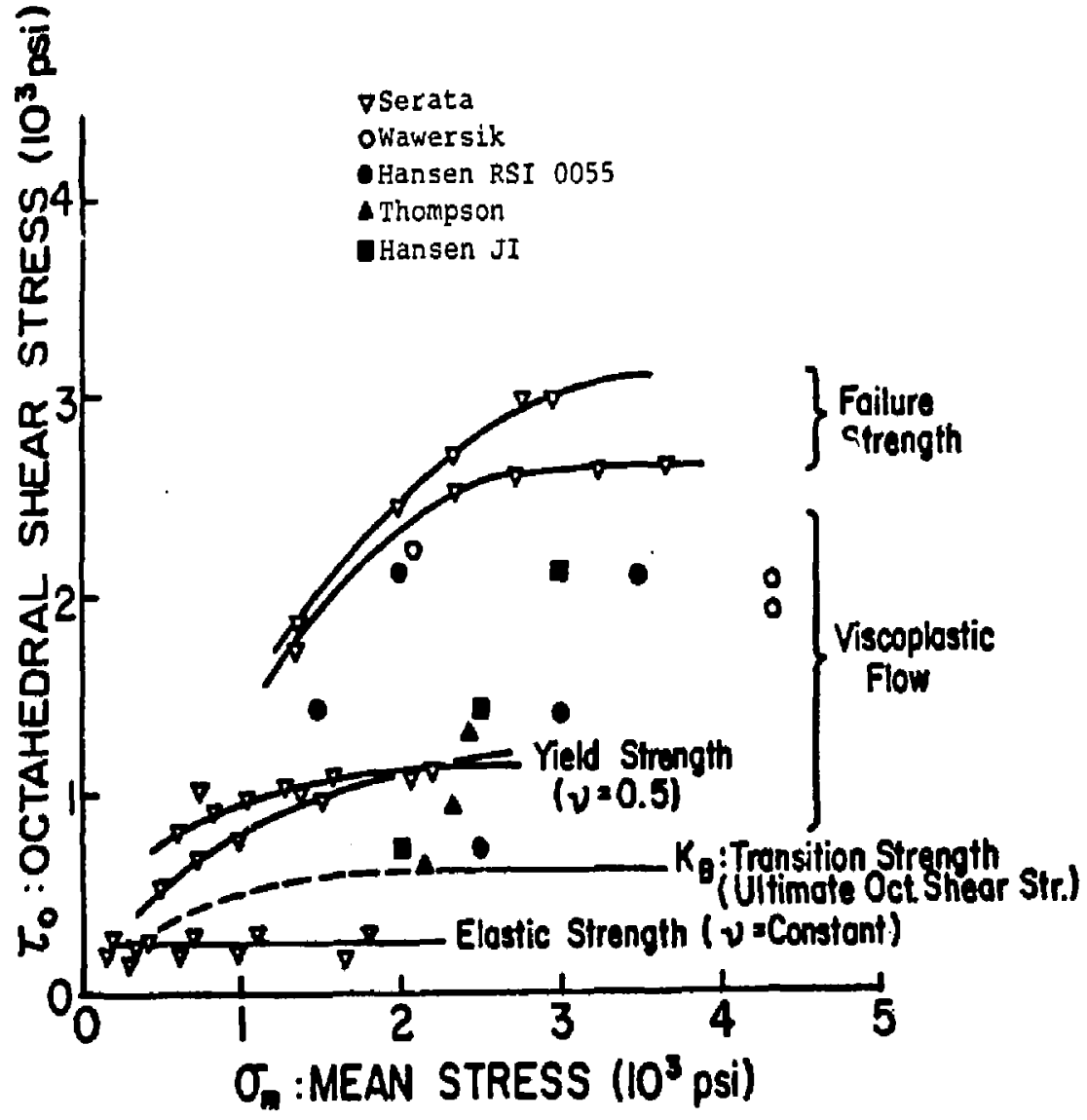

Figure 2-4. Octahedral Shearing Strengths of Elastic Limit, Transition Point, Yield Point and Failure Point of Rock salt in Relation to Mean Stress.

Source: Serata et al. (1968); SGI, 1979. 
material strengths which are devised for the development of the constitutive equations.

\subsubsection{Yield Strengths--Rock salt deforms indefinitely in a} manner similar to viscous flow under a large confining pressure

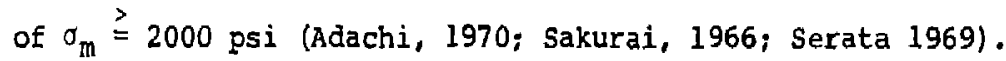
The material, as a continuum, does not fail in such a ductile state under three-dimensional confinement. The strength of the continuun cannot then be determined by the conventional concepts of failure strength of rocks.

The large maximum strength of the mater $j=1$ observed by many investigators as shown in Figure 2-4 represents a large viscous force acting in the individual test medium rather than the true strength of the medium. In order to develop a basis for theoretical analysis, the yielding behavior of rock salt was studied in terms of strict tensor stresses and strains (Adachi, 1970; Sakurai, 1966; Wawersik, 1979). Results of the studies revealed that, in terms of Poisson's ratio, there are two clearly distinguishable stress states which can be directly measured in the laboratory. 
Under an increasing octahedral shear loading with an adequate mean pressure of $\sigma_{\mathrm{m}} \geqslant 1000 \mathrm{psi}$, rock salt experiences two relatively consistent values in poisson's ratios as shown in Figure 2-5 (Serata et al., 1968). Recognizing the rising point of Poisson's ratio, "elastic strength" of rock salt was defined as the stress state at which the initially constant elastic value $(v \simeq 0.10)$ of poisson's ratio begins to rise rather sharply with an increase of $T_{0}{ }$. The elastic strength signifies the stress level at which the behavior of the naterial starts deviating from the elastic state. Poisson's ratio of $v=0.5$ is recognized as another important stress-strain state at which there is no volume change in the medium with respect to change in octahedral shearing stress, that is, $\Delta \varepsilon_{\mathrm{m}} / \Delta \tau_{\mathrm{o}}=0$. Therefore, yielding strength of rock salt was defined as the stress state at which the rising value of Poisson's ratio under increasing octahedral shearing stress reaches a value of $v=0.5$. It was found in a series of studies that between these two strengths, there exists a critical stress state at which a transition between elastic and plastic states occurs rather sharply (Morrison, 1962; Sakurai, 1966; Serata, 1974). The critical stress state is considered as the true strength of the material and is also identified as the transitional strength of the material. 


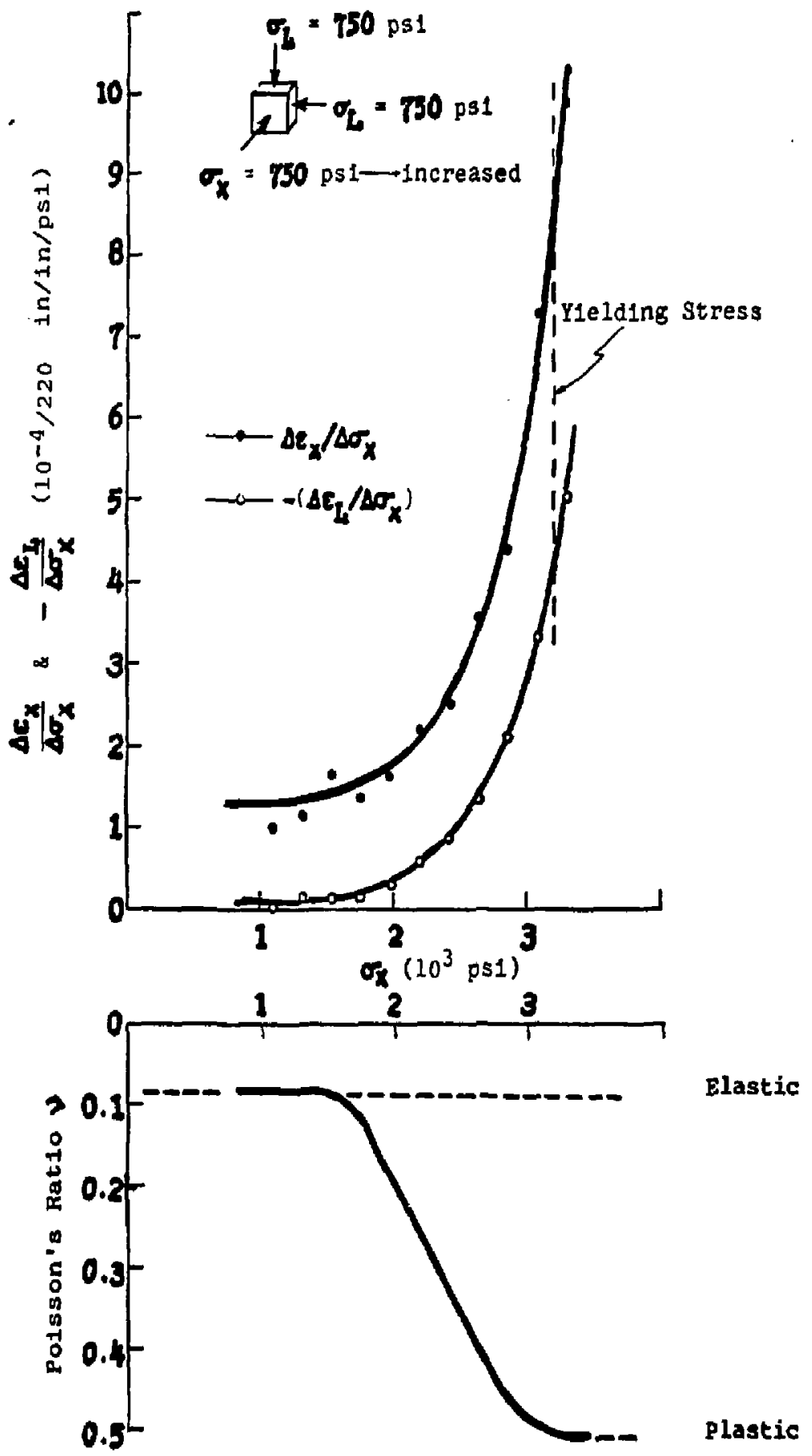

Figure 2-5. Deformation and Poisson's Ratio Under 750 psi Confining Pressure. 
This means that under a fully ductile condition, we have True Strength $=$ Transition Strength

= Ultimate Octahedral shearing Strength, $\mathrm{K}_{\mathrm{B}}$.

Since the viscoplastic creep initiates when the octahedral shearing stress exceeds the transition stress of $K_{0}=K_{B}$, there are an infinite number of stress states of apparent strengths which could exist as a function of the creep rate, $\dot{\gamma}_{0}$. Therefore, it should be noted in analyzing any laboratory test data that the apparent strength approaches the real strength of $K_{B}$ with reduction of the creep rate to zero, as illustrated in Figure 2-6 (heard, 1972). The real strength will be reached only at $\dot{Y}_{0} \equiv 0$ (Serata, 1978). The transition strength, $R_{B}$, has been determined based on this idea and is discussed later in this report. From field observations, the idea is shown to be realistic in analyzing salt opening behaviors in terms of tens to hundreds of years. However, it is uncerta in for the analysis in terms of thousands to millions of years.

2.2.3 Brittle Behavior--The uniform strength characteristics of the ductile behavior of the material begins to disappear when the $\sigma_{\mathrm{m}}$ value is reduced below 2000 psi. Reduction of the strength value starts accelerating as the $\sigma_{m}$ value is further reduced below 1000 psi (Serata et al., 1968). Both the yield and failure strengths deteriorate in a manner generally 


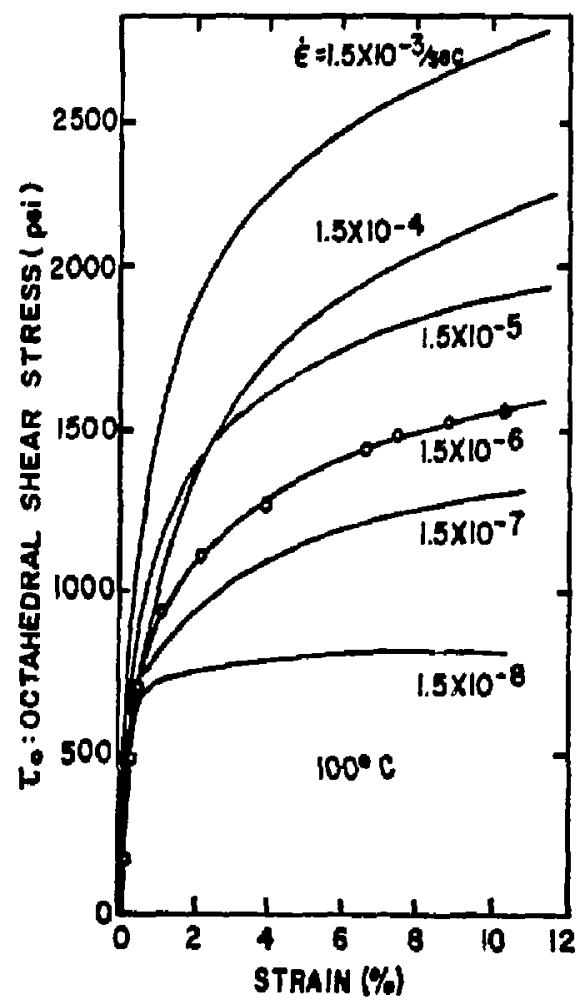

Figure 2-6, Differential strese-strain Curvea for Polycrystalline Halite Extended at $2 \mathrm{~kb} \simeq 29,400 \mathrm{psl}, \dot{\varepsilon}=1.5 \cdot 10^{-3}$ to $1.5 \cdot 10^{-8} \sec ^{-1}$, and $100^{\circ} \mathrm{C}$. Source: Heard, 1972. 
similar to that of the experimental results shown in Figure 2-4. The reduction of the yield strength, $K_{Y}$, can be expressed in terms of $\sigma_{m}$ by the following empirical relation (Serata et al.. 1968) :

$$
K_{Y}=K_{Y A}+\left(K_{Y B}-K_{Y A}\right)\left(1-e^{-\alpha \sigma_{m}}\right)
$$

where:

$$
\begin{aligned}
& \mathrm{K}_{\mathrm{YA}}=\text { yield strength at }\left(\sigma_{\mathrm{m}}=0\right) ; \\
& \mathrm{K}_{\mathrm{YB}}=\text { ultimate yield strength; and } \\
& \alpha \quad=\text { coefficient of yield surface curvature. }
\end{aligned}
$$

The reduction of the octahedral shearing strength, $\mathrm{K}_{0}$, may be assumed to follow the same exponential function of (1 - $\left.e^{-a \sigma} \mathrm{m}\right)$. This assumption is shown by the broken line in the $\tau_{0}-\sigma_{\mathrm{m}}$ diagram of Figure 2-4. This extension of the octahedral shearing strength is intended to provide a numerical basis for approximating the transition strength in the brittle region so that the time-dependent process of brittle failure can be treated by the same numerical means as the ductile yield. Further elaboration of this approach is given in chapter 4.

The elastic strength is found to be only slightly dependent on $\sigma_{m}$ (Sakurai, 1966). Furthermore, the elastic strength is 
found to be not particularly significant for the long-term analysis of salt openings for storage use (Serata, 1978). In contrast, the failure strength is severely decreased by the $\sigma_{\mathrm{m}}$ reduction in the brittle fracture region, as shown in Figure $2-4$. At the saine time, the $\sigma_{m}$ reduction will greatly increase the brittle fractuce strain rate, $\dot{\gamma}_{0}^{B}$, in the region of brittle fracture. The decrease of the failure strength is numerically simulated by the exponential reduction of the octahedral shear strength, $K_{0}$. An increase of the brittle fracture strain rate, $\dot{\gamma}_{0}{ }^{B}$, is numerically simulated by extending the viscoplastic strain rate, $\dot{y}_{0}{ }^{p}$, to the brittle fracture region, as in the following function of $\mathrm{K}_{\mathrm{o}}$ :

$$
\dot{\gamma}_{0}^{B}=\dot{\gamma}_{0}^{P}=f\left(\tau_{0}, K_{0}\right) .
$$

Derivation of the function is given in Chapter 4 . It should be noted here, however, that the strain rate, $\dot{\gamma}_{0}^{\mathrm{B}}$, increases quickly in the brittle region with the exponential reduction of the $K_{0}$ value. Usefulness of the above method has been shown in field application of the numerical simulation for long-term brittle deterioration of mine openings (Serata, 1976; 1978). Because of the importance of the $\sigma_{\mathrm{m}}$ effect for the prospective storage use, this subject is discussed further in chapter 4. 
The brittle effect on the strengths in the brittle fracture region is also shown in the stress space representation of the strength surfaces in Figure 2-7 (Serata et a1., 1968). The effect is characterized by the gradual change of its $\pi-p l a n e$ cross-sectional form from a large circular to a small triangular shape with the reduction of the $\sigma_{m}$ value (Adachi, 1970; Sakurai, 1966). 


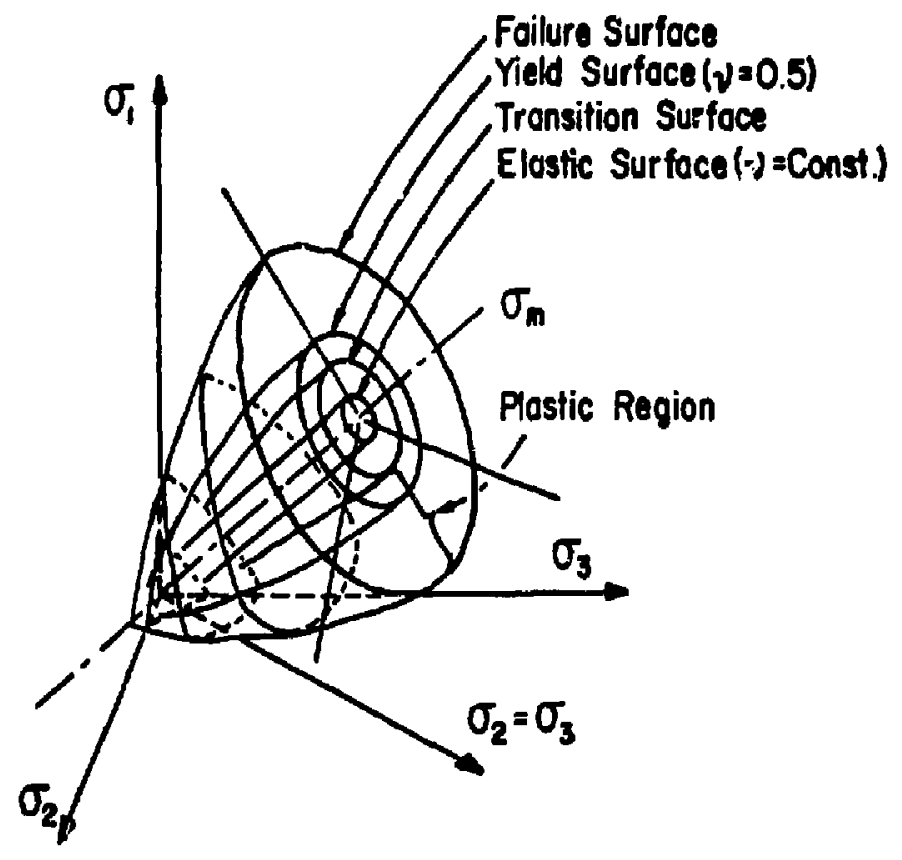

Figure 2-7. Elastic, Yielding, and Failure Characteristics of Rocks in stress space. Source: SGT 1979. 


\subsection{Iwo Different Creep Components}

There are two intrinsically different components of creep behavior in rock salt, viscoelasticity and viscoplasticity. These two components act simultaneously within a given medium of rock salt. Viscoelastic creep originates from intergranular boundary adjustment inducing both octahedral shear strains and volute changes. The viscoelastic creep component is characterized by its gradual disappearance due to the intergranular boundary adjustment finally reaching an equilibrium state. In contrast, viscoplastic creep is caused by the slippage of ionic bonds within sodium chloride crystal structures independent of the granular boundary. Viscoplastic creep continues indefinitely under a constant loading as long as the octahedral shearing stress remains above the threshold limit of the ionic bonds. This threshold limit is recognized as the transition strength of the material, $K_{B}$. The $K_{B}$ value of rock salt is found to fall within 500 and 750 psi at room temperature, regardless of the medium's geological origins. No significant amount of volume change occurs in viscoplastic creep, because of the mechanism of ionic bond slippage. Therefore, for the practical purpose of analysis, the-sverall deformation of rock salt may be conveniently subdivided into three fundamental components of elastic, viscoelastic, and viscoplastic deformations, as shown in Figure $3-1$. 


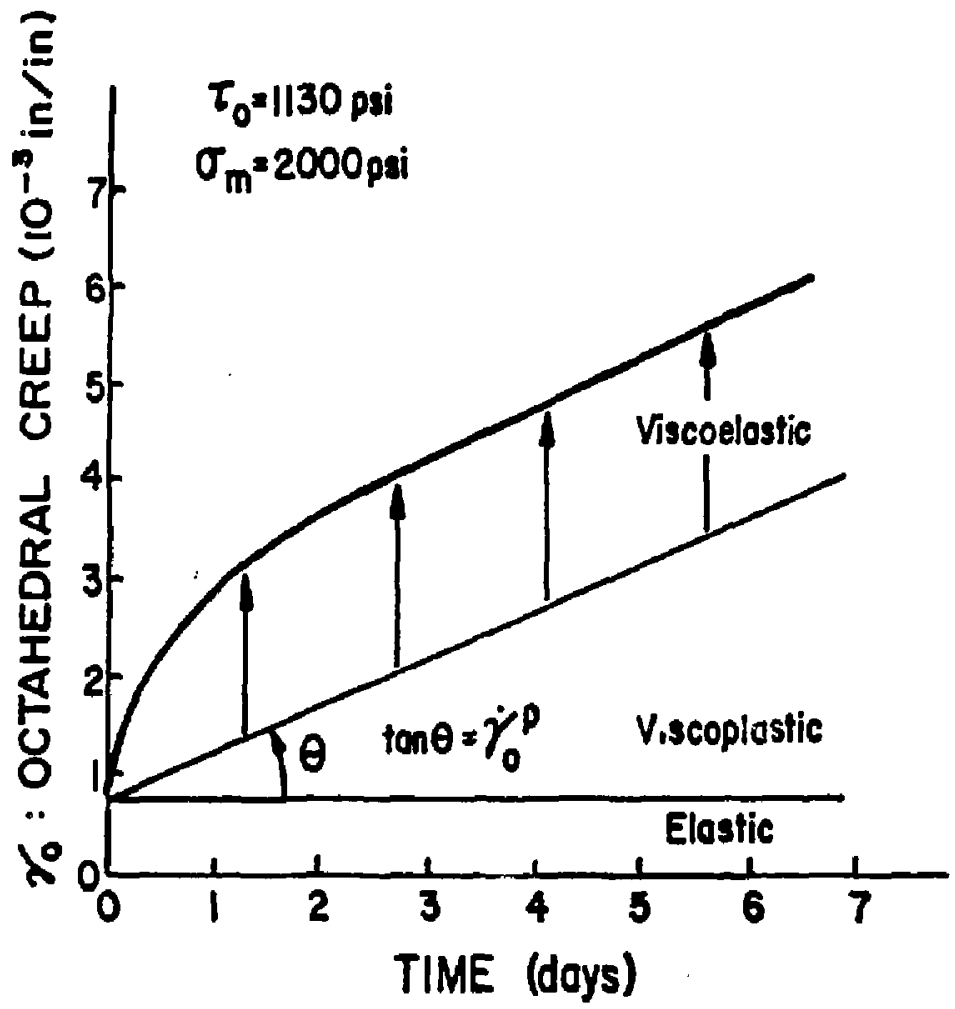

Figure 3-1. Components of Salt Deformation. Source: SEI, 1979. 


\subsection{Viscoelastic Creep}

viscoelastic creep takes place whenever the octahedral shearing stress, $\tau_{0}$, remains less than the octahedral shearing strength, $\mathrm{K}_{0}$. In the viscoelastic state, the creep deformation is characterized by a continuously decreasing creep rate. The creep rate does nut conform to any simple pattern of conventional creep formulae. However, it has been found that the viscoelastic creep rate, $\dot{\gamma}_{0} V E$, can be represented by a sum of different terms as (Adachi, 1970; Sakurai, 1966):

$$
\dot{\gamma}_{0}^{V E}=\left(\dot{\gamma}_{0}^{V E}\right)_{1}+\left(\dot{\gamma}_{0}^{V E}\right)_{2} \ldots\left(\dot{\gamma}_{0}^{V E}\right)_{n}
$$

Here, the first term represents the long-tern component while the following terms represent the transient components with successively shorter half-lives. The half-life is defined here as the time required to reduce the strain rate of each component to half. Since the analysis of radioactive waste storage deals with relatively long-term behavior, the transient terms with shorter half-lives may be safely discarded.

The individual terms of the creep rate, $\left(\dot{\gamma}_{0}{ }^{\mathrm{V}}\right){ }_{i}$, where $i=1,2, \ldots . .$, decrease rapidly and approach straight lines asymptotically in a $\log \dot{\gamma}_{0}$ versus time relationship as illustrated in Figure 3-2. The asymptotic values are all reached within ten days after loading. In accordance with this behavior, each term in Eguation 3-1 is considered tu be an exponential term, as: 


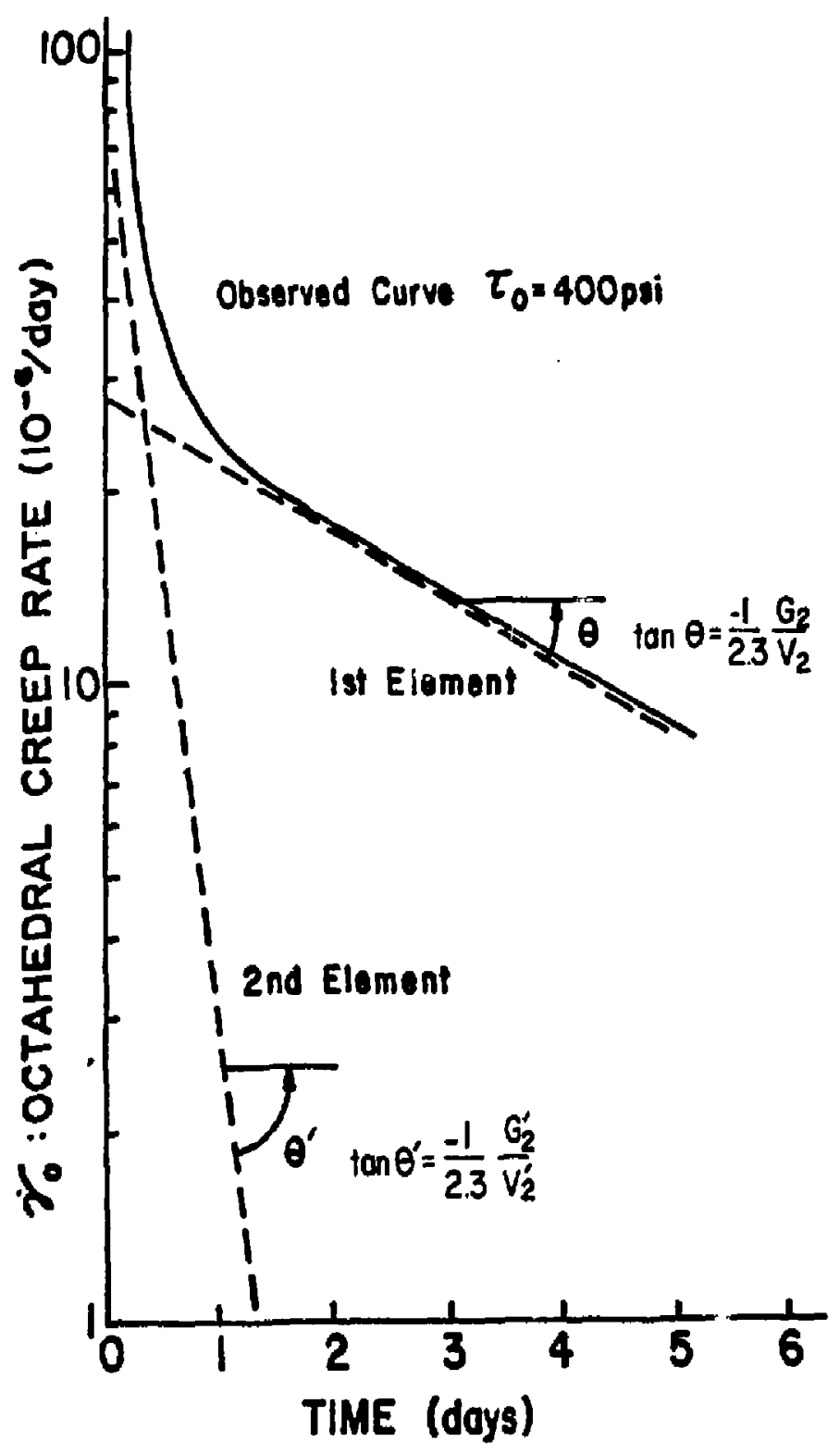

Pigure 3-2, First Two Elements of Viscoelastic Creep. 
$\dot{r}_{0} V E=\frac{d y_{0} V E}{d t}=\frac{\tau_{0}}{V_{2}} \exp \cdot\left(-\frac{G_{2}}{V_{2}} t_{1}+\frac{\tau_{0}}{\nabla_{2}^{\prime}} \exp \cdot\left(-\frac{G_{2}^{\prime}}{\nabla_{2}^{\top}} t_{1}+\cdots(3-2)\right.\right.$

where:

$$
\begin{aligned}
& G_{2}, G_{2}^{\prime}=\text { retarded shear moduli; and } \\
& v_{2}, v_{2}^{\prime}=\text { viscoelasticity coefficients. }
\end{aligned}
$$

Typical experimental results obtained by using 5-inch cube specimens are shown in Figure 3-2. It is apparent in the figure that terms other than the first are highly transient in nature and vanish very quickly with time. Therefore, it is usually adequate to retain only the first and leasttransient term for the analysis of salt openings:

$$
\dot{\gamma}_{0}=\frac{\tau_{0}}{v_{2}} \exp \cdot\left(-\frac{G_{2}}{v_{2}} t_{)}\right. \text {. }
$$

The studies conducted by Sakurai at Michigan State and by Adachi and Serata at SGI in Berkeley yielded the following values for viscoelastic coefficients:

$$
\begin{aligned}
& G_{2}=0.2 \sim 3.2 \times 10^{6} \text { psi; } \\
& G_{2}^{\prime}=15.0 \times 10^{6} \text { psi; } \\
& V_{2}=5.0-13.2 \times 10^{6} \text { psi-day; } \\
& V_{2}=5.0 \times 10^{6} \text { psi-day; } \\
& G_{2} / V_{2}=0.5 \times 2.5 \times 1.44 \times 10^{-1} \text { day }-1 \text {; and } \\
& G_{2}^{\prime} / V_{2}^{\prime}=3.2 \text { day }^{-1} .
\end{aligned}
$$


A definite efiect is produced on the viscoelastic coefficient values when viscoelastic and viscoplastic creep occur simultaneously under the stress condition of $\tau_{0} \simeq k_{0}$. The coefficients' values under the viscoplastic condition were also determined by Adachi, Sakurai, and Serata as follows:

$$
\begin{aligned}
& G_{3}=0.5 \sim 1.5 \times 10^{6} \text { psi: } \\
& V_{3}=1.0 \sim 2.1 \times 10^{6} \text { psi-day; } \\
& G_{3} / V_{3}=0.6 \sim 1.2 \mathrm{day}^{-1} .
\end{aligned}
$$

The research leading to the above values of the viscoelastic coefficients is documented in the theses by Adachi (1970) and Sakurai (1966).

\subsection{Viscoplastic Creep}

When the octahedral shearing stress, $\tau_{0}$, exceeds the strength, $\mathrm{K}_{0}$, viscoplastic creep starts taking place concurrently with viscoelastic creep. Both viscoelastic and viscoplastic creep coexist because the two creep phenomena are caused by two entirely different, independent processes of creep deformation. 
The viscoplastic creep rate is found to be generally constant under a given stress state. Therefore, the creep rate under the viscoplastic state approaches a constant value as the viscoelastic creep component vanishes with time, as illustrated in Figure 3-3. It was found that the viscoplastic component of the creep rate, $\dot{\gamma}_{o}{ }^{p}$, increases sharply with the excess octahedral shear stress $\left(\tau_{0}-K_{0}\right)$, as shown in Figure 3-4. The basic characteristics of the viscoplastic creep rate, $\dot{r}_{0}{ }^{p}$, versus stress state, ' 0 , are established by Adachi (1970) as follows:

$$
\dot{\gamma}_{0}^{p}=\frac{k_{0}}{v_{4}}\left(\frac{{ }^{\top} 0-k_{0}}{k_{0}}\right)^{n}
$$

where:

$$
\begin{aligned}
& \mathrm{a}=2.61 ; \\
& \mathrm{v}_{4}=\text { viscoplastic coefficient determined at } \tau_{0}=2 \mathrm{~K}_{0} ;
\end{aligned}
$$
and

$$
K_{0}=K_{B} \text { in ductile state. }
$$

The $\mathrm{V}_{4}$ values determired in the laboratory are summarized in Table 3-1. The values, ranging $v_{4}=1.4 \sim 3.2$, are found to be compatible with field observations analyzed by the REM computer simulation in various underground test sites. 


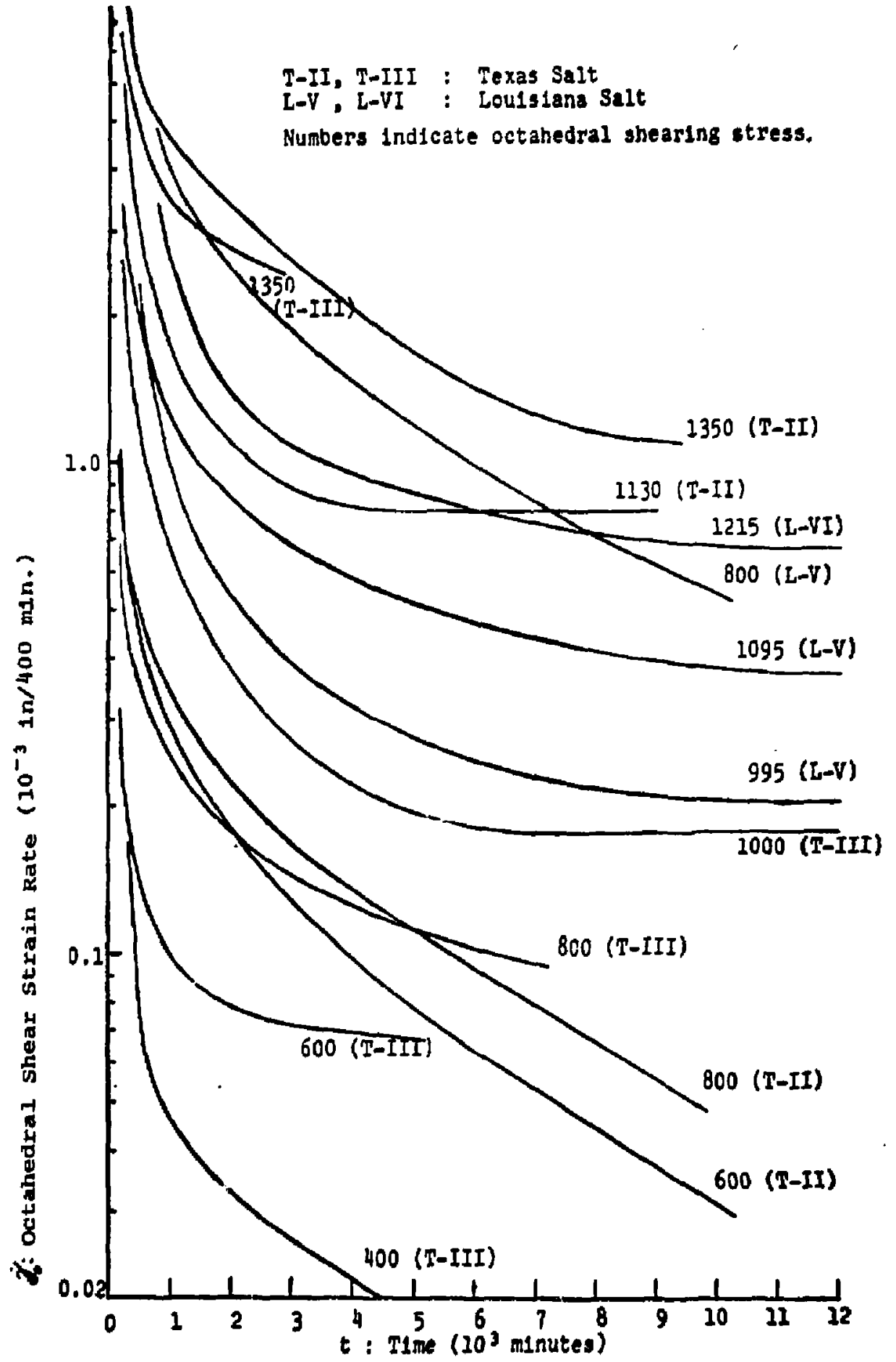

Figure 3-3 . Comparison of Octahedral Shearing Strain Rates obtalned from Four Specimens Tested under Varlous Loading Conditions.

Source: Sakurai (1966) 


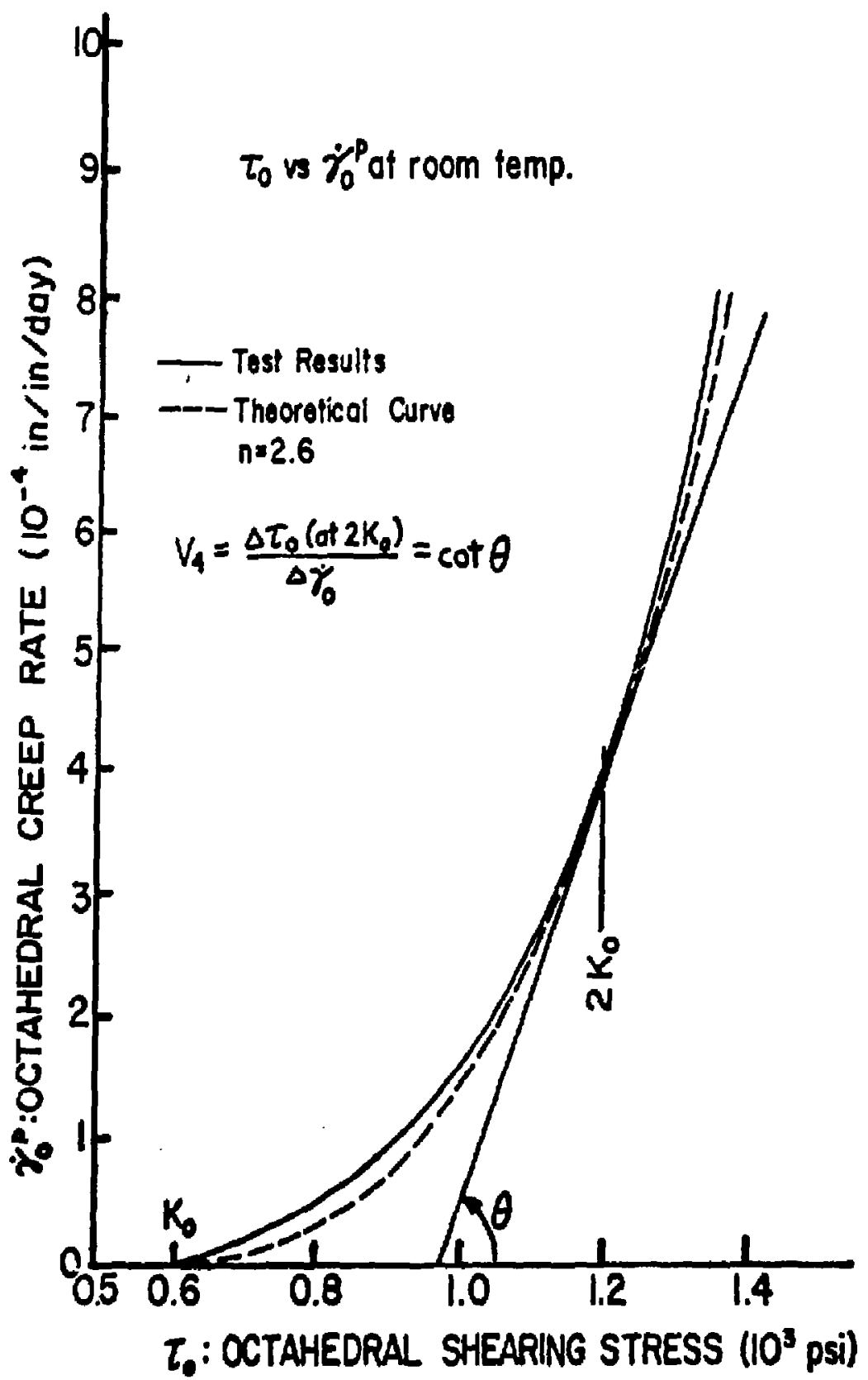

Figure 3-4, Octahedral Creep Rate Rises Sharply with Excess octahedral Shear Stress $\left(T_{0}-K_{0}\right)$. Source: Adachi (1970) 
Table 3-1. $V_{4}$ Values Determined from Laboratory Data obtained by Various Investigators

\begin{tabular}{|c|c|c|}
\hline $\begin{array}{l}\text { V } 4 \text { Values } \\
\text { (10 } 6 \text { psi-day) }\end{array}$ & $\begin{array}{c}\text { Source and/or } \\
\text { Method }\end{array}$ & Comments \\
\hline .70 & $\begin{array}{l}\text { Absolute Tensor } \\
\text { Testing (Sakurai) }\end{array}$ & \\
\hline 1.5 & $\begin{array}{l}\text { Absolute Tensor } \\
\text { Testing (Adachi) }\end{array}$ & $\begin{array}{l}20^{\circ} \mathrm{C}, \mathrm{K}_{\mathrm{O}}=600 \mathrm{psi}, \\
\sigma_{\mathrm{c}}=2000 \mathrm{psi}\end{array}$ \\
\hline 3.1 & $\begin{array}{l}\text { Cylindrical Triaxial } \\
\text { (Sandia WIPP; } \\
\text { Wawersik) }\end{array}$ & $\begin{array}{l}22^{\circ} \mathrm{C}, K_{0}=500 \text { psi, } \\
\sigma_{c}=500 \text { psi } \\
\text { creep data inter- } \\
\text { preted by serata }\end{array}$ \\
\hline 0.65 & $\begin{array}{l}\text { Cylindrical Triaxial } \\
\text { (RE/SPEC RSI 0055; } \\
\text { Hansen) }\end{array}$ & $\begin{array}{l}28^{\circ} \mathrm{C}, K_{O}=520 \text { psi, } \\
\sigma=2000 \text { psi } \\
\text { cfeep data inter- } \\
\text { preted by Serata }\end{array}$ \\
\hline .38 & $\begin{array}{l}\text { Cylindrical Triaxial } \\
\text { (E. Thompson) }\end{array}$ & $\begin{array}{l}32^{\circ} \mathrm{C}, \mathrm{R}_{\mathrm{O}}=550 \mathrm{psi} \\
\sigma_{\mathrm{C}}=1650 \mathrm{psi} \\
\text { creep data inter- } \\
\text { preted by Serata }\end{array}$ \\
\hline
\end{tabular}

Source: SGI, 1979.

The higher $\mathrm{V}_{4}$-values are suitable for stronger salt media such as those with high insoluble contents and finer grains. The lower $v_{4}$-values are suitable for weaker salt media such as those with larger crystal grains and less insoluble content. 
The total octahedral shearing creep rate may be expressed in the form:

$$
\begin{aligned}
& \frac{d \gamma_{0}}{d t}=\frac{d \gamma_{O}}{d t}\left(V_{.} E_{1}\right)+\frac{d \gamma_{O}}{d t}\left(V_{. P .}\right) \\
& =\frac{\tau_{0}}{v_{3}} \exp \cdot\left(-\frac{G_{3}}{V_{3}} t_{)}+\frac{k_{0}}{v_{4}}\left(\frac{\tau_{0}}{k_{0}}-1\right)^{n}\right.
\end{aligned}
$$

where:

$$
K_{0}=K_{B} \text { in ductile state. }
$$

\subsection{Transition from Elastic to Plastic State}

Rock salt exhibits an abrupt transition from an elastic to a plastic state of stress whenever the octahedral shearing stress reaches the ductile condition $\tau_{0}=K_{B}=K_{0}$. This phenomenon can only be observed clearly by eliminating the viscosity effect under the condition of $\dot{\gamma}_{0} \cong 0$ and $\varepsilon_{\mathrm{m}} \cong 0$. The transition phenomenon should come from the existence of a certain threshold limit of the stress, $K_{B}$, beyond which the ionic bonds of the sodium chloride crystal start slipping indefinitely. Under the ductile condition of $k_{O}=K_{B}$, the rate of slippage may be determined in relation to the excess octahedral shearing stress, $\Delta \tau_{0}=\left(\tau_{0}-K_{0}\right)$. This phenomenon was confirmed in laboratory testing on cylindrical specimens which were loaded vertically while the lateral stress was measured under the condition that no literal strains were allowed. (Sakurai, 1966). Orie set of experimental results is shown in Figure 3-5, which compares three different transition parallelograms to illustrate effects from the allowed lateral deformations (Morrison, 1962; Serata, 1961) 


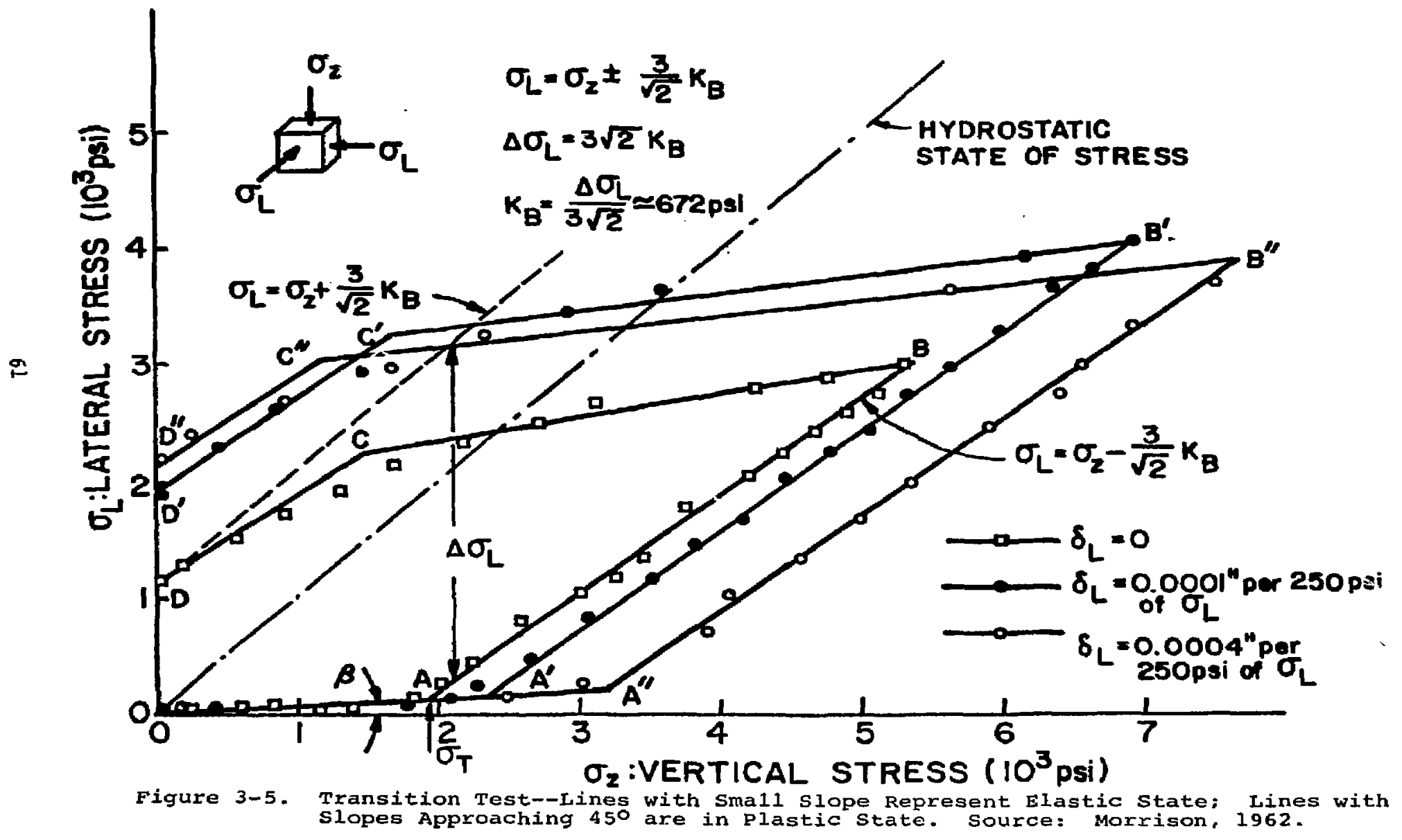


These parallelograms were obtained by observing lateral stress response to increase and decrease of the vertical stress under three different lateral deformations, as shown in the figure. Note that the transition (points $\mathrm{A}, \mathrm{A}^{\prime}, \mathrm{A}^{\prime \prime}$ ) occurs at lower vertical stress values when the allowed deformation is also less. This indicates that the transition under zero deformation gives the most reliable results with the minimum viscosity interference.

With the initial increase of the vertical stress, the lateral stress changes according to the theory of elasticity along Line $\mathrm{OA}$ in Figure 3-5. As soon as the vertical stress reaches the transition stress, $\sigma_{T}$, at $A$, the slope of $\Delta \sigma_{L} / \Delta \sigma{ }_{Z}$ changes abruptly from the small elastic angle of $\beta=3.6^{\circ}$ to the plastic angle of $45^{\circ}$, as shown in the figure. Points $A, A^{\prime}$, and $A^{\prime \prime}$ all indicate the turning point; but it is Point $A$ that represents the true transition point, where $\sigma_{Z}=\sigma_{T}$. Here, Line $O A$ represents the elastic state while Line $A B$ represents the plastic state. If the vertical stress is now lowered at Point $B$, the state of stress will return to an elastic state, represented by Line BC. Point $C$ corresponds to a stress condition where the lateral stress, $\sigma_{L}$, exceeds the vertical stress, $\sigma_{2}$, by $3 \mathrm{~K}_{0} / \sqrt{2}$. Any further unloading from this point will again cause the plastic state to prevail. As expected, the plastic line CD approaches a 45-degree angle with the horizon. 
The following quantitative observations may be made from the transition parallelogram of Figure 3-5. The angle, $B$, of Iine OA relates to Poisson's ratio, $v$, from the elastic relationship of:

$$
\frac{\sigma_{L}}{\sigma_{2}}=\frac{v}{1-v}=\tan \beta, \therefore v=0.06 \text { for } \beta=3.6^{\circ} \quad(3-6)
$$

I'his very small value of $v$ indicates a large amount of granular consolidation taking place in the test specimen.

For the plastic condition, it can be shown that:

$$
\begin{aligned}
\sigma_{L} & =\frac{v}{1-v} \sigma_{T}+\left(\sigma_{Z}-{ }_{T}\right) \\
& =\sigma_{Z}-\frac{1-2 v}{1-v} \sigma_{T} .
\end{aligned}
$$

Since $\sigma_{Z}-\sigma_{L}=\frac{3}{\sqrt{2}} K_{B}$, Equation $3-7$ leads to:

$$
K_{B}=\sqrt{2} \frac{1-2 v}{1-v} \sigma_{T}
$$

By substituting the $v=0.06$ obtained from Equation 3-6. the $k_{B}$ value is calculated to be $k_{B}=838 \mathrm{psi}$, from Equation 3-8.

The $K_{B}$ value can also be obtained from the vertical stress difference, $\Delta \sigma_{Z}$, between the two plastic lines of $A B$ and $C D$ of the parallelogram. This method gives $K_{B}=672$ psi, as illustrated in Figure 3-5. 


\subsection{Ultimate nctahedral Shearing strength}

The uitimate octahedral shearing strength is defined as the stress state at or above which the viscoplastic creep will occur. The ultimate octahedral shearing strength, $\mathrm{K}_{\mathrm{B}}$, can be determined from an observation of the viscoplastic creep rate under various stress states, as shown in Figure 3-4 . Here, che relation of $\dot{\gamma}_{0}^{p}$ versus $\tau_{0}$ is shown, where $\dot{\gamma}_{0}^{p}$ represents the viscoplastic strain only. The $k_{0}$ value can be determined by extrapolating the curve to the point $\dot{\gamma}_{0}{ }^{p}=0$, at which $\tau_{0}=K_{B}$.

The $\mathrm{K}_{\mathrm{B}}$ values determined by the different methods are compared as shown in rable 3-2, where data obtained by researchers other than Serata, Sakurai, and Adachi are interpreted by Serata. It is noted that the observed $K_{B}$ values are widely scattered, ranging from 500 to 5000 psi. However, on close examination, it can be seen that the higher values are produced $b$. unsuccessful elimination of viscous stress and/or friction efiects from the testing methods. The continuous work conducted by Serata, Sakurai, and Adachi led to reduction of the $R_{B}$ value to 600 psi. A recent interpretation of the creep data produced by Thompson (1964), Hansen (Feb. 1977) and Wawersik (1979) disclosed the $K_{B}$ value to be in the range of 500 to $600 \mathrm{Fsi}$ at room temperature. 
Table 3-2. Ultimate octahedral sinearing strength, $K_{B}$

\begin{tabular}{|c|c|c|c|c|}
\hline $\mathrm{K}_{\mathrm{g}} \underset{\mathrm{pai})}{\mathrm{Value}}$ & Method & Invertigator & Year & Comment \\
\hline 5000 & $\begin{array}{l}\text { Conventional } \\
\text { rriaxial Testing }\end{array}$ & Handin & 1953 & $\begin{array}{l}\text { Significant } \\
\text { friction involved; } \\
\text { interpretation by } \\
\text { Serata }\end{array}$ \\
\hline $2000-2000$ & $\begin{array}{l}\text { Cylinarical } \\
\text { Triaxial Tenting }\end{array}$ & $\begin{array}{l}\text { Morribon and } \\
\text { Serata }\end{array}$ & 1962 & Limited strain \\
\hline 550 & $\begin{array}{l}\text { Cylindrical } \\
\text { Triaxial Teating }\end{array}$ & E. Thompson & 1964 & $\begin{array}{l}32^{\circ} \mathrm{C} \text {; creep data } \\
\text { interpreted by } \\
\text { serata }\end{array}$ \\
\hline 1200 & $\begin{array}{l}\text { Absolute Tensor } \\
\text { Testing }\end{array}$ & sakurai & 1966 & $\begin{array}{l}\text { Time-independent } \\
\text { study introduce } \\
\text { no volume change }\end{array}$ \\
\hline $000-1100$ & $\begin{array}{l}\text { Abeolute Teneor } \\
\text { Terting }\end{array}$ & sakurai & 1966 & $\begin{array}{l}\text { Time-depenient } \\
\text { atudy introduce } \\
\text { no volume change }\end{array}$ \\
\hline 900 & $\begin{array}{l}\text { Abeolute Tensor } \\
\text { Testing }\end{array}$ & Sakurai & 1966 & Viscoplastic flow \\
\hline 700 & $\begin{array}{l}\text { Absolute Tensax } \\
\text { Testing }\end{array}$ & $\begin{array}{l}\text { Serata, } \\
\text { Sakurai, and } \\
\text { Adachi }\end{array}$ & 1968 & $\begin{array}{l}\text { Zero atrain } \\
\text { allowed }\end{array}$ \\
\hline
\end{tabular}


Table 3-2. Ultimate octahedral shearing strength. $K_{B}$ (Continued)

\begin{tabular}{|c|c|c|c|c|}
\hline $\mathrm{K}_{\mathrm{B}}$ Value & Method & Investigator & Year & Comment \\
\hline 650 & $\begin{array}{l}\text { Creep Absolute } \\
\text { Tensor Testing }\end{array}$ & $\begin{array}{l}\text { Serata, } \\
\text { Sakurai, } \\
\text { and Adachi }\end{array}$ & 1968 & Long-term creep \\
\hline 600 & $\begin{array}{l}\text { Absolute Tensor } \\
\text { Testing }\end{array}$ & Serata. Adachi & 1969 & $\begin{array}{l}\text { Long-term creep } \\
\text { at room } \\
\text { temperature }\end{array}$ \\
\hline 2100 & $\begin{array}{l}\text { Cylindrical Tentor } \\
\text { Testing ( } 30 \text { psi/sec) }\end{array}$ & Adachi & 1969 & $\begin{array}{l}\text { Constant rate } \\
\text { loading }\end{array}$ \\
\hline 520 & $\begin{array}{l}\text { Cylindrical } \\
\text { Triaxial Testing }\end{array}$ & $\begin{array}{l}\text { Hansen } \\
\text { RE/SPEC } \\
\text { (RSI-0055) }\end{array}$ & 1977 & $\begin{array}{l}28^{\circ} \mathrm{C} \text {; creep data } \\
\text { interpretation } \\
\text { by Serata }\end{array}$ \\
\hline 500 & $\begin{array}{l}\text { Cylindrical } \\
\text { Triaxial Testing }\end{array}$ & $\begin{array}{l}\text { Wawersik } \\
\text { Sandia WIPP }\end{array}$ & 1979 & $\begin{array}{l}22^{\circ} \mathrm{C} \text {; creep data } \\
\text { interpretation } \\
\text { by serata }\end{array}$ \\
\hline
\end{tabular}

SOURCE: SGI, 1979 . 
The $K_{B}$ values derived from data due to Thompson, Hansen and Wawersik are thought to be reliable because of the wide range of stress conditions tested for an extended period of time. The $K_{B}$ value of most rock salt seems to fall well within the range of 500 to $750 \mathrm{psi}$. Application of these $K_{B}$ values to numerical simulation of various mine openings gives data that are in realistic agreement with underground observations (Serata, 1973, 1978).

The existence of the rather consistent $K_{B}$ values verifies that there is indeed a threshold strength, $K_{B}$, at which the transition from the elastic to the plastic state occurs. A similar threshold exists in the other direction; there is a sharp transition from the plastic to the elastic state. No significant deformation is expected in an underground salt formation in which the stress condition is $\tau_{0} \leqq K_{B}$ and $\sigma_{m} \geqq 2000$ psi. Under this stress condition, rock salt media can sustain stress for practically an infinite period of time. It is this quality of having a consistent and clearly defined $k_{B}$ value that distinguishes rock salt from any Newtonian fluid or other plastic materials. Verification of this can be witnessed in a long-range observation of certain underground structures made in rock salt formations, with an ideal geometric form such as a circular opening of vertical mine shafts. The creep closure over 10 years closely agrees with the REM prediction made by $K_{B}=500$ - 750 psi. (Serata, 1978). 


\subsection{FORMULATION OF CONSTITUTIVE EQUATIONS}

\subsection{Principles of Formulation}

The constitutive equations of the rock salt continum were formulated for the purpose of computer simulation of long-term salt cavity behavior. Formulation of the equations was based on experimental observations of the material properties of rock salt, which were described in Chapter 2, The validity of the principles of formulation of the constitutive equations has been examined by use of computer simulation analyses, They are found to be very realistic when compared to long-term underground observations. The formulation is most critically needed in designing underground salt structures by any numerical means such as finite element method. Basic principles of the formulation of the constitutive equations are described.

\subsubsection{Separation of Behavior--The deformation behavior of} rock salt is composed of two distinctly different mechanisns. The first mechanism is intergranular displacement anong salt crystals; the second mechanism is interatomic displacement among, $\mathrm{Na}^{+}$and $\mathrm{Cl}^{-}$ions within the crystals. Since both mechanisms are independently susceptible to shear and hydrostatic stresses, the total behavior of rock salt can be adequately expressed as a sum of two p.rrts: a shearing stressstrain relationship described in terms of $\tau_{0}$ and $\gamma_{0^{\prime}}$ and a 
hydrostatic stress-strain relationship described in terse of $\sigma_{\mathbf{g}}$ and $\varepsilon_{\mathrm{n}}$. Separation of the total be havior of rock salt into these two mechaninms enables un to numerically nimslate time-dependent dilatation of air-exposed bounda- salt media associated with long-term creep of the salt openings.

\subsubsection{Behavioral Components--The octahedral shear stress-} strain $\left(\tau_{0}-\gamma_{0}\right)$ relationship consists of a linear sum of the three basic behavioral components of elasticity, viscoelasticity, and viscoplasticity. At the same time, the hydrostatic stressstrain $\left(\sigma_{m}-\varepsilon_{m}\right)$ relationship consists of a linear sum of the two basic behavioral components of elasticity and viscoelasticity.

\subsubsection{Nonlinearity of Components--The individual behavioral} component is generally considered a nonlinear function of the mean stress, $\sigma_{m}$ octahedral shear stress, $t_{0}$; octahedral shearing strain, $\gamma_{0}$; temperature, $T ;$ and time, $t$. The function may be simplified to become linear only when such approximation is warranted.

\subsubsection{Connistency of Behavioral Componente--The Individual}

- behavioral components of rock salt are consintent in their response to those variables of $\sigma_{\mathbf{m}}, \tau_{0}, T$, and $t$ regardless of geological origin of the rock salt. Any variation of the 
aterial behavior is considered to be a variation in values of the material property coefficients.

\subsection{5 octahedral Shearing Strength--Rock salt has a} definite value of octahedral shearing strength, $k_{0}$, which may be expressed in terms of the mean stress, $\sigma_{a}$ as:

$$
K_{0}=K_{A}+\left(K_{B}-x_{A}\right)\left(1-e^{-a \sigma_{D}}\right)
$$

where:

$\mathrm{k}_{\mathrm{A}}=$ octahedral shearing strength at $\sigma_{\mathbf{m}}=0$;

$\mathrm{K}_{\mathrm{B}}=$ ultimate octahedral shearing strength in psi; and

a = coefficient of yield surface curvature.

\subsubsection{Threshold Stress of Transition--The octahedral} shearing strength, $R_{0}$ is the threshold stress value at which the transition of states between elastic and plastic can take place. Although the transition threshold becowes increasingly vague with reduction of mean stress, particularly with $\sigma_{\mathrm{m}}<500 \mathrm{ps}$, the octahedral shearing strength as given in Equation 4-1 - is still considered as the threshold stress value. When the mean stress, $\sigma_{m}$, is less than about 500 psi, salt is in a brittle state. The octahedral shear strength, $x_{0}$, in this state is the shear stress beyond which the material exporiences an accelerated creep by brittle fracture in a manner sinilar to viscoplastic cresp. 


\subsubsection{Elastic Strength--The elastic strength io dofined as} the stress state in which Poigson's ratio of the matortal renaine unchanged from the initial undisturbed values of approximately $v=0.1$.

\subsubsection{Yield Strength--The yield strength is defined as} the stress state in which the hydrostatic strain gradient with respect to octahedral stress is zero; that is,

$$
\Delta E_{m} / \Delta \tau_{0}=0
$$

Poisson's racio remains as $v=0.5$ at the yield strength.

\subsubsection{Transition Strength--The transition strength is} defined as the stress state of $\tau_{0}=R_{0}$ in which the transition between elastic and plastic states occurs to form the boundary between the stable viscoelastic state and ungtable creep state. The creep state encoupasses both ductile and brittle creep. The transition strength lies between the elastic and yield strengths.

\subsubsection{Viscolastic State-The viscoelastic state is} defined as the strose atate of $\tau_{0}<K_{0}$ existing Inside the transition surface. No $\mathbf{v}$ scoplastic strain takes place in this state. 


\subsubsection{Viscoplantic State--The viscoplastic state is}

defined as the strens state of $\tau_{0}>K_{0}$ existing outside the transition surface. In this state, the stross exceds strength by the magnitude of viscous stress. Therefore, as infinite number of fallure surfaces may exist in this state if the surfaces were defined as a function of the.croep rate.

\subsection{Rheologizal Model of Constitutive Equations}

The constitutive model of rock salt is given in a generalized form in Figure 4-1. The model presented here is a rheological scheme of relating the total stresses and strains. There are two parts to the scheme: the first part relates the octahedral shearing stress, $\tau_{0}$, to the octahedral shearing strain, $Y_{0} ;$ while the second part relates the mean stress, $\sigma_{m}$, to the mean strain, $\varepsilon_{\mathbf{a}}$.

The octahedral shearing part of the model consicts of two options, the viscoelastic E-series and viscoplastic P-series. Under the visconlantic sicress state of $\tau_{0}<x_{0}$ or the transition state of $\tau_{0}=x_{0}$ with a decreasing octabedral shearing struas $i_{0}<0$, the B-series is adopted. The P-series is adopted under the viscoplastic state of $\tau_{0}>K_{0}$ or transition . Itate with an Incroasing octahedral shearing stress of $\dot{\tau}_{0}>0$. The san o $o_{-}-\varepsilon_{\mathrm{a}}$ part is always used with eithor one of the s-series or P-sories of the $\tau_{0}-\gamma_{0}$ part. In applying 


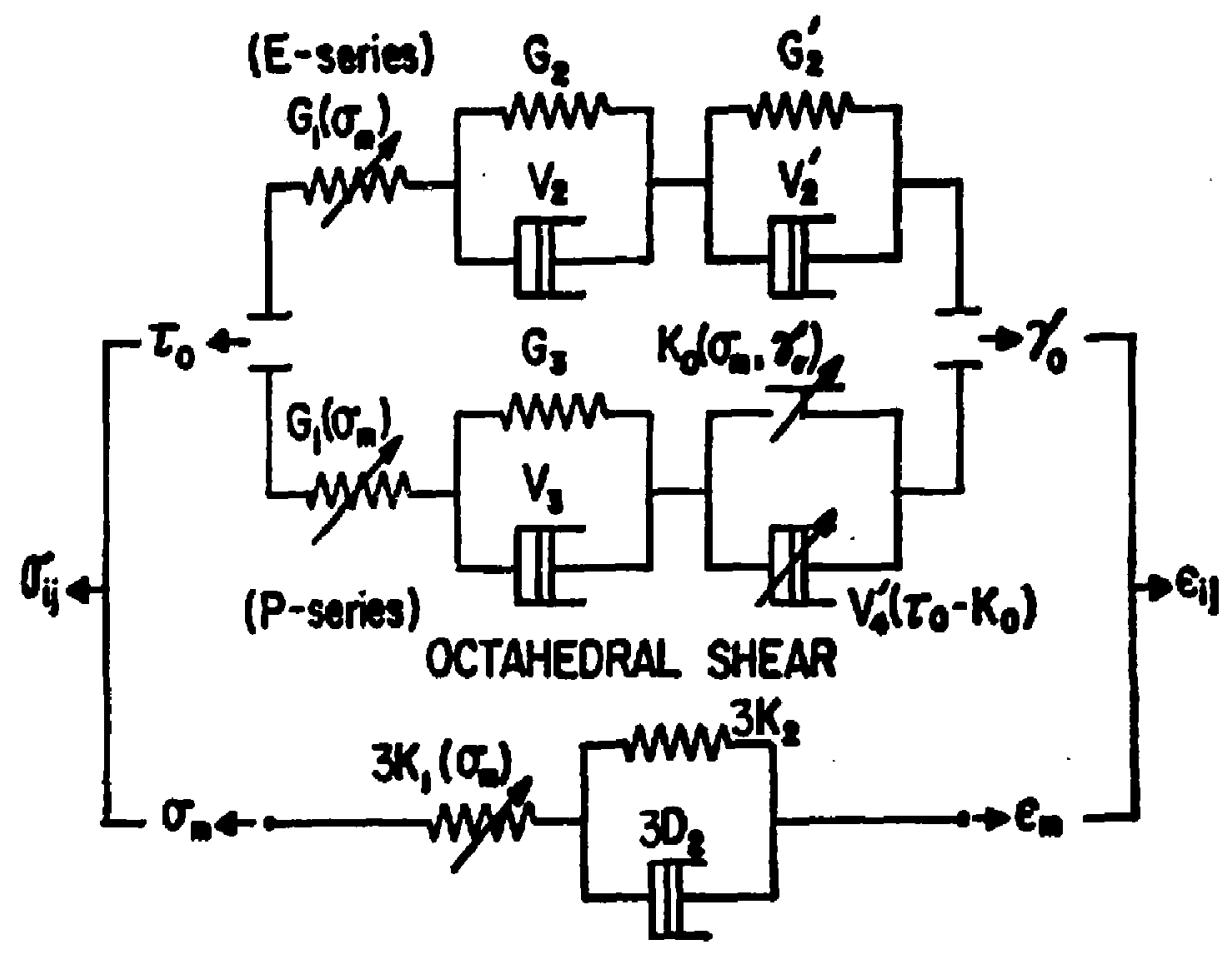

CONTRACTION a EXPANSTON

Pigure 4-1. Conerallzed Rheological Modal for Rock salt. Sources Sakurat (1966). and SGI (1979). 
the model to a finite element analysis, each finite element will be exanined for a proper selecuion of the $\mathrm{E}$ - or P-series at every computational stage. In adapting the generalized model to radioactive waste storage studies, the model may be reduced to two simplified sets, as depicted in Figure 4-2. These sets are used for ease of derivation of the stressstrain relations required in engineering analysis as given in this chapter. Important modifications needed for application to storage use are presented later in Chapter 5.

The coefficient values to be used for salt media in most salt formations are summarized in Table. 4-1. A range of the values for the individual coefficients is given so that the salt properties from different sources can be included in the giver range.

The weaker salt is. usually characterized by larger grain size with a lower impurity content, while the stronger salt is characterized by a finer average grain size with a higher impurity content which is dispersed rather uniformly inside the crystali.

The coefficient values in Table $4-1$ are not considered to be ultimate values; instead, they are subject to further refinement with the continuing efforts currently being made in the field and the laboratory. 
E Series: Viscoelastic States when $\tau_{0}<R_{0}$
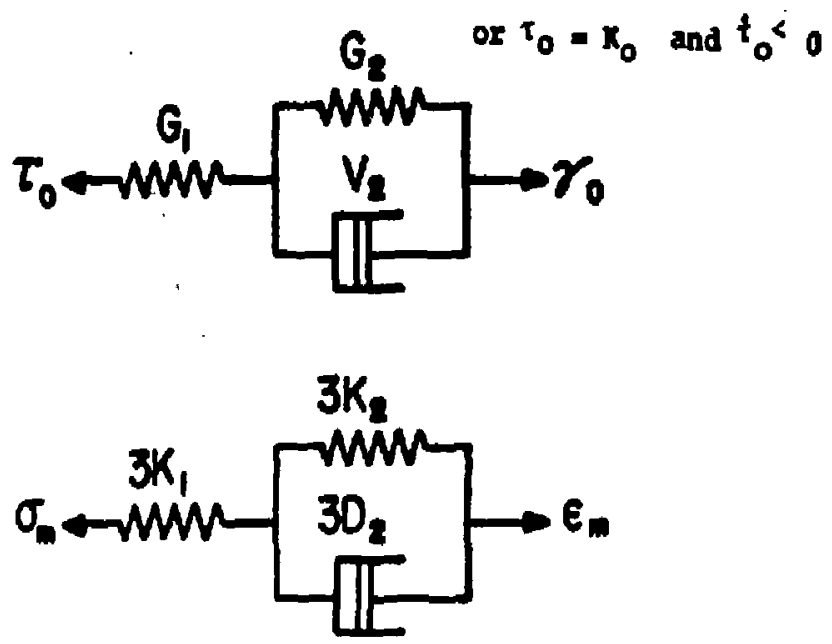

P Series: Viscoplastic state: when $t_{0} \geqslant X_{0}$
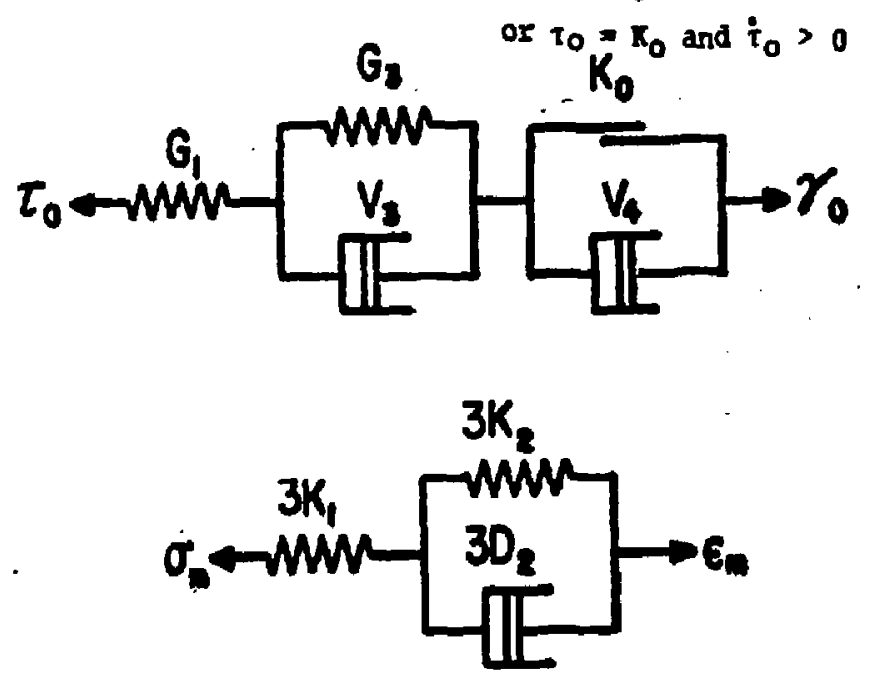

Plgure 4-2. Two Sets of simplifted theologleal vodeln of Rock Salt for Viscoelastic and Viscoplastsc Stress Stater Adapted for Long-Term Denigd Analyats of salt Openings. Source: SGI, 1979. 


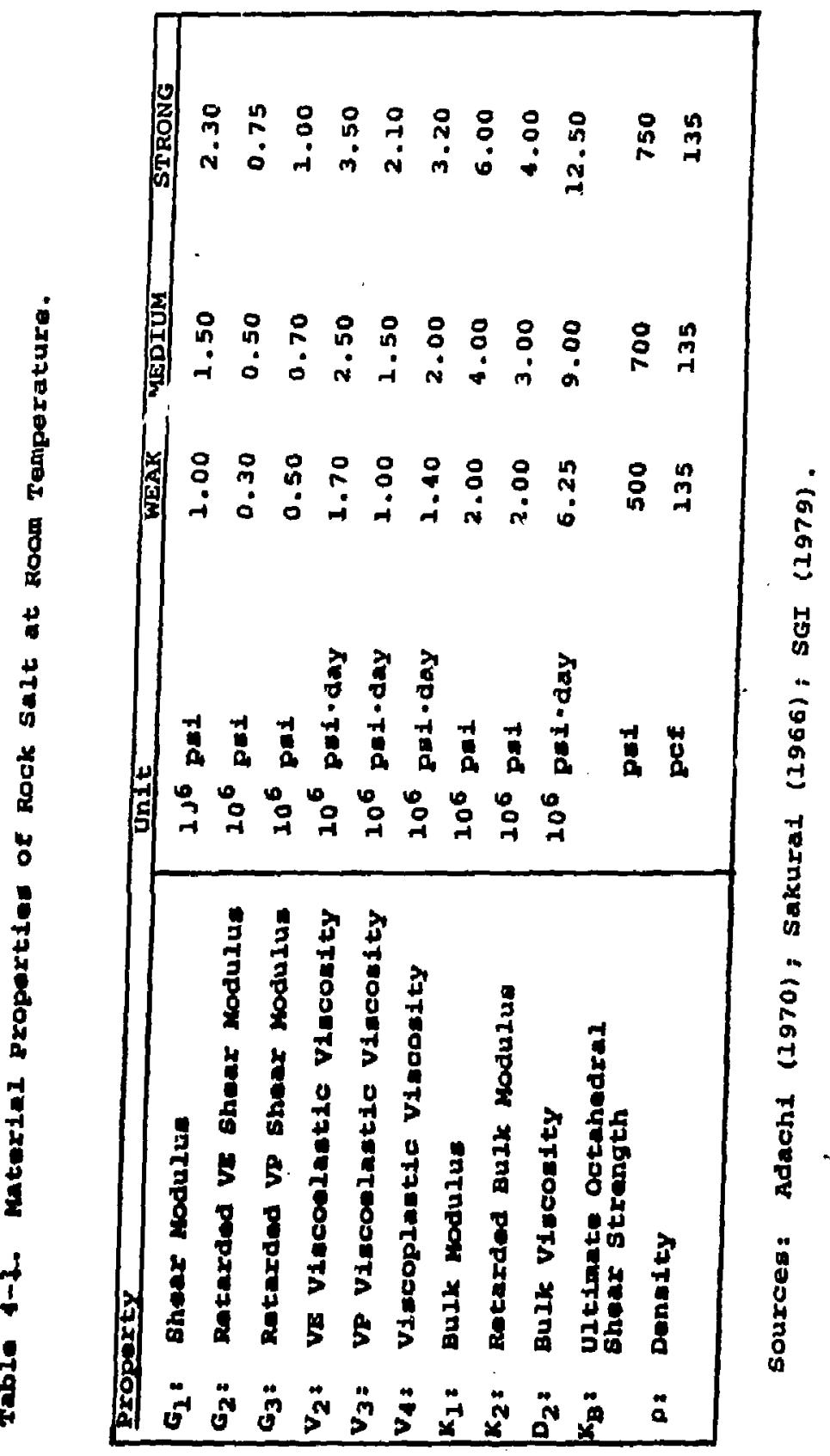




\subsection{Constitutive Equations in Viscoelastic State}

(This section was excerpted from Sakurai's thesis (1966), with permission). Both elastic and viscoelastic deformations take place simultaneously in the viscoelastic state. Under the conditions of $\tau_{0}<k_{0}$ of $\tau_{0}=k_{0}$ with $\dot{\tau}_{0}<0$, the following constitutive equations are derived from the rheorheological model of Figure 4-2.

$$
\begin{aligned}
& \dot{s}_{i j}+\frac{G_{1}+K_{2}}{V_{2}} s_{i j}=2 G_{1} \dot{e}_{i j}+2 \frac{G_{1} G_{2}}{V_{2}} \varepsilon_{i j} \\
& \dot{\sigma}_{i j}+\frac{K_{1}+K_{2}}{D_{2}} \sigma_{i i}=3 K_{1} \dot{\varepsilon}_{i j}+3 \frac{K_{1} K_{2}}{D_{2}} \varepsilon_{i j}
\end{aligned}
$$

where $s_{i j}$ and $e_{i j}$ are the components of the deviatoric stress and strain tensors, respectively, as defined in Equation 4-3.

$$
\begin{aligned}
& s_{i j}=\sigma_{i j}-\frac{1}{3} \sigma_{k k} \delta_{i j} \\
& e_{i j}=\varepsilon_{i j}-\frac{1}{3} \varepsilon_{k k} \delta_{i j}
\end{aligned}
$$

where $\delta_{i j}$ stands for the Kronecker delta. Here, $\sigma_{i j}$ and $\varepsilon_{i j}$ are the components of the stress and strain tensors. The dot above the strain indicates the material time derivative of small strain. The dot above the stress denotes the material time derivative of stress. Equation 4-2 gives the strain and strain rate as a function of stresses and time. 


$$
\begin{aligned}
& \varepsilon_{i j}=\frac{S_{i j}}{2 G_{1}}+\frac{1}{2 V_{2}} e^{-\frac{G_{t}}{V_{2}} t} \int e^{\frac{G_{2}}{V_{2}} t} s_{i j} d t \\
& +\frac{\sigma_{k k}}{9 K_{l}} \delta_{i j}+\frac{\delta i j}{3 D_{2}} e^{-\frac{K_{2}}{\sigma_{2}} t} \int e^{\frac{K_{2}}{D_{2}} t} \sigma_{k k} d t
\end{aligned}
$$

$$
\begin{aligned}
& \frac{d \varepsilon_{i j}}{d t}=\frac{1}{2 G_{1}} \frac{d s_{i j}}{d t}+\frac{s_{i j}}{2 V_{2}}-\frac{G_{2}}{2 V_{2}^{2}} e^{-\frac{G_{2}}{V_{2}} t} \int e^{\frac{G_{2}}{V_{2}} t} s_{i j} d t \\
& +\frac{\delta_{i j}}{9 K_{1}} \frac{d \sigma_{k k}}{d t}+\frac{\sigma_{k k}}{3 D_{2}} \delta_{i j}-\frac{K_{2} \delta_{i j}}{3 D^{2}} e^{-\frac{K_{2}}{D^{2}} t} \int e^{\frac{K_{2}}{D_{2}}} \sigma_{k k} d t
\end{aligned}
$$

$G_{1}$ and $k_{1}$ are expressed by Young's modulus $E$ and Poisson's ratio $v$ as:

$$
\begin{aligned}
& G_{1}=\frac{E}{2(1+v)} \\
& K_{1}=\frac{E}{3(1-2 v)}
\end{aligned}
$$

$(4-6)$

Considering Equation 4-6, Equation 4-4 gives the principal strains as a function of the principal stresses and time.

$$
\begin{aligned}
\varepsilon_{1} & =\frac{1}{E}\left\{\sigma_{1}-v\left(\sigma_{2}+\sigma_{3}\right)\right\}+\frac{1}{6 V_{2}} e^{-\frac{G_{2}}{V_{2}} t} \int e^{\frac{G_{2}}{\nabla_{2}} t}\left(2 \sigma_{1}-\sigma_{2}-\sigma_{3}\right) d t \\
& +\frac{1}{9 D_{2}} e^{-\frac{K_{2}}{D_{2}} t} \int e^{\frac{K_{2}}{D_{2}} t}\left(\sigma_{1}+\sigma_{2}+\sigma_{3}\right) d t
\end{aligned}
$$

78 


$$
\begin{aligned}
& \varepsilon_{2}=\frac{1}{\bar{E}}\left\{\sigma_{2}-v\left(\sigma_{1}+\sigma_{3}\right)\right\}+\frac{1}{6 V_{2}} e^{-\frac{G_{2}}{V_{2}} t} \int e^{\frac{G_{2}}{V_{2}} t}\left(2 \sigma_{2}-\sigma_{1}-\sigma_{3}\right) d t \\
& +\frac{1}{9 D_{2}} e^{-\frac{K_{2}}{D_{2}} t} \int e^{\frac{K_{2}}{D_{2}} t}\left(\sigma_{1}+\sigma_{2}+\sigma_{3}\right) d t \\
& E_{3}=\frac{1}{E}\left\{\sigma_{3}-v\left(\sigma_{1}+\sigma_{2}\right)\right\}+\frac{1}{\delta v_{2}} e^{-\frac{G_{2}}{V_{2}} t} \int e^{\frac{G_{2}}{V_{2}} t} \cdot\left(2 \sigma_{3}-\sigma_{1}-\sigma_{2}\right) d t \\
& +\frac{1}{9 D_{2}} e^{-\frac{K_{2}}{D_{2}} t} \int e^{\frac{K_{2}}{D_{2}} t}\left(\sigma_{1}+\sigma_{2}+\sigma_{3}\right) d t
\end{aligned}
$$

\subsection{Constitutive Equations in Viscoplastic State}

rock salt behavior in the viscoplastic state differs markedly From behavior in the viscoelastic state. The viscoplastic behavior initiates sharply as soon as the stress state reaches the conditions of $\tau_{0}>k_{0}$ or $\tau_{0}=K_{0}$ with $\dot{\tau}_{0}>0$. Then, the total strain Iate is assumed to be a sum of the elastic and plastic parts:

$$
\frac{d \varepsilon_{i j}}{d t}=\frac{d \varepsilon_{i j}^{e}}{d t}+\frac{d \varepsilon_{i j}}{d t}
$$

In Equation $4-8, \varepsilon_{i j}{ }^{e}$ is the elastic strain and $\varepsilon_{i j} p$ is the plastic strain. 
The increment of the plastic strain can be expressed by the Levy-Mises equation in the following form:

$$
d e_{i j} p=d \varepsilon_{i j} p=(d \lambda) s_{i j}
$$

where $d \lambda$ is a scalar factor of proportionality. The octahedral shearing stress $\tau_{0}$ and strain $\gamma_{0}$ are defined in the form:

$$
\begin{aligned}
& \tau_{0}=\frac{1}{\sqrt{3}} \sqrt{S_{i j} S_{i j}} \\
& \gamma_{0}=\frac{2}{\sqrt{3}} \sqrt{e_{i j} e_{i j}}
\end{aligned}
$$

Considering 4-11, the increment of the plastic part of the octahedral shearing strain can be written as:

$$
d y_{0}^{p}=\frac{2}{\sqrt{3}} \sqrt{d \bar{e}_{i j}{ }^{p} d e_{i j} p}
$$

Substituting Equations 4-10 and 4-12 into 4-9 yields:

$$
d \lambda=\frac{d \gamma_{0}{ }^{p}}{2 \tau_{0}}
$$

Hence Equation 4-9 can be rewritten as follows using $\tau_{0}$ and $d \gamma_{0}$ instead of $\mathrm{d} \lambda$.

$$
d \varepsilon_{i j}^{p}=\frac{s_{i j}}{2 \tau_{0}} d \gamma_{0}^{p}
$$


or

$$
\frac{d \varepsilon_{i j} p}{d t}=\frac{s_{i j}}{2 \tau_{0}} \frac{d \gamma_{0}^{p}}{d t}
$$

Considering the rheological model for the viscoplastic state shown in Figure $4-2, d \gamma_{0} P / d t$ can be expressed as a function of the applied octahedral shearing stress and those material constants as $k_{0}, G_{3}, v_{3}$, and $v_{4}$.

$$
\frac{d \gamma_{0} P}{d t}=\frac{\tau_{0}-K_{0}}{V_{4}}+\frac{\tau_{0}}{V_{3}}-\frac{G_{3}}{V_{3}^{2}} e^{-\overline{V_{3}}} \int \tau_{0} e^{\bar{V}_{3}} d t
$$

Substituting Equation 4-16 into 4-15 gives,

$$
\begin{aligned}
\frac{d \varepsilon_{i j}{ }^{p}}{d t} & =\left\{\frac{1}{2 V_{4}}\left(1-\frac{K_{0}}{\tau_{0}}\right)+\frac{1}{2 V_{3}}\right\} s_{i j} \\
& -\frac{G_{3} S_{i j}}{2 v_{3}^{2}} e^{-\frac{G_{3} t}{\nabla_{3}}} \int \tau_{0} e^{\bar{V}_{3}} d t
\end{aligned}
$$

The total strain rate is expressed by Equation $4-8$ in the form as,

$$
\begin{aligned}
\frac{d \varepsilon_{i j}}{d t} & =\frac{1}{2 G_{1}} \frac{d S_{i j}}{d t}+\frac{\delta_{i j}}{9 R_{1}} \frac{d \sigma_{k k}}{d t}+\frac{1}{2}\left(\frac{1}{V_{4}}\left(1-\frac{R_{0}}{\tau_{0}}+\frac{1}{\nabla_{3}}\right\} s_{i j}\right. \\
& =\frac{G_{3} s_{i j}}{2 V_{3}{ }^{2} T_{0}} e^{-\bar{G}_{3}} \int \tau_{0} e^{\bar{V}_{3}} d t
\end{aligned}
$$


The total rates of the principal strains are described as a function of time from (4-18), considering the reration of Equation 4-6,

$$
\begin{aligned}
\frac{d \varepsilon_{I}}{d t} & =\frac{1}{E}\left\{\frac{d \sigma_{1}}{d t}-v\left(\frac{d \sigma_{2}}{d t}+\frac{d \sigma_{3}}{d t}\right)\right\} \\
& +\frac{1}{6}\left\{\frac{1}{V_{4}}\left(1-\frac{K_{0}}{\tau_{0}}\right)+\frac{1}{V_{3}}\right\}\left(2 \sigma_{1}-\sigma_{2}-\sigma_{3}\right) \\
& =\frac{G_{3}}{6 V_{3}^{2} \tau_{0}}\left(2 \sigma_{1}-\sigma_{2}-\sigma_{3}\right) e-\frac{G_{3}}{V_{3}} \int \tau_{0} e^{\frac{G_{3}}{V_{3}}} d t
\end{aligned}
$$

$$
\begin{aligned}
& \frac{d \varepsilon_{2}}{d t}=\frac{1}{E}\left\{\frac{d \sigma_{2}}{d t}-v\left(\frac{d \sigma_{1}}{d t}+\frac{d \sigma_{3}}{d t}\right)\right\} \\
& +\frac{1}{b}\left\{\frac{1}{V_{4}}\left(1-\frac{K_{0}}{\tau_{0}}\right)+\frac{1}{V_{3}}\right\} \quad\left(2 \sigma_{2}-\sigma_{1}-\sigma_{3}\right) \\
& -\frac{G_{3}}{6 v_{3}{ }^{2} \tau_{0}}\left(2 \sigma_{2}-\sigma_{1}-\sigma_{3}\right) e^{-\frac{G_{3}}{\bar{V}_{3}}} \int \tau_{0} e^{{\overline{V_{3}}}^{G_{3}}} d t \\
& \frac{d E_{3}}{d t}=\frac{1}{E}\left\{\frac{d \sigma_{3}}{d t}-v\left(\frac{d \sigma_{1}}{d t}+\frac{d \sigma_{2}}{d t}\right)\right\} \\
& +\frac{1}{6}\left\{\frac{1}{V_{4}}\left(1-\frac{R_{0}}{\tau_{0}}\right)+\frac{1}{V_{3}}\right\} \quad\left(2 \sigma_{3}-\sigma_{1}-\sigma_{2}\right) \\
& -\frac{G_{3}}{6 V_{3}{ }^{2} \tau_{0}}\left(2 \sigma_{3}-\sigma_{1}-\sigma_{2}\right) e^{-\frac{G_{3}}{V_{3}}} \int \tau_{0} e^{\frac{G_{3}}{V_{3}}} d t
\end{aligned}
$$

$(4-19)$

82 
The above constitutive equations are readily adaptable to the rheological finite element method for long-term design analysis of salt openings. The constitutive equations have an advantage of including other geological formations such as clay seams and hard sedimentary layers by simply selecting proper material coefficient values for these different materials. This is particularly useful for the simulation of salt openings in both bedded and dome salt formations which ire confined by sedimentary rocks other than rock salt. The constitutive equations have been shown useful with the finite element method in field applications for design analysis of underground mines and solution cavities (Serata, 1978). Nevertheless, the equations should be regarded as a state of the art which has been continuously improved through a long-term field research progran now being conducted in many underground mines and solution cavities. 


\subsection{EVALUATION OF PARAMETERS AFFECTING MATERIAL PROPERTIES OF ROCK SALT}

Application of the constitutive equations to analysis of salt openings for the storage of radioactive wastes requires certain 'nique modifications to the equations. Important parometers of the constitutive equations that require modification for this application are: mean stress, $\sigma_{\mathrm{m}}$; ultimate octahedral shearing strength, $K_{B}$; octahedreal shearing strain, $Y_{0}$; and ambient temperature, $T$. With the modifications made as described below, the constitutive equations of Chapter 4 can be effectively applied to the finite element anaiysis of the storage openings .

\subsection{Confining Pressure}

Salt openings to be used for radioactive waste storage will be exposed to air pressure. This exposure causes the salt at the opening boundaries to suffer loss of confining pressure, and the loss of confining pressure results in brittle creep deformation of the boundary material. The deformation induces granular deterioration of the material, which in turn substantially reduces the octahedral shearing strength, $K_{0}$, of the material.

Therefore, the octahedral shearing strength of the constitutive equation needs to be modified as a function of the confining pressure, $\sigma_{\mathrm{m}}$, as shown in the following empirical form: 


$$
K_{0}=K_{A}+\left(K_{B}-K_{A}\right)\left(1-e^{-\alpha \sigma_{m}}\right)
$$

where:

$$
\begin{aligned}
& K_{A}=\text { octahedral shearing strength at }\left(\sigma_{m}=0\right)=100-200 \text { psi; } \\
& K_{B}=\text { ultimate octahedral shearing strength }=500-750 \text { psi; }
\end{aligned}
$$

and

$a=$ coefficient of $y$ ield surface curvature

$$
=.0015 * .0030 \mathrm{pgi}^{-1} \text {. }
$$

The loss of confining pressure also affects the bulk modulus, $\mathrm{K}_{1}$, of the material. The decrease of the confining pressure reduces the $k_{1}$ value according to the following empirical relation:

$$
R_{1}=R_{D}+\left(k_{E}-k_{D}\right)\left(1-e^{-\alpha \sigma_{m}}\right.
$$

where:

$$
\begin{aligned}
\mathrm{K}_{\mathrm{D}} & =\text { initial bulk modulus at }\left(\sigma_{\mathrm{m}}=0\right)=0.5 \sim 1.0 \times 10^{6} \mathrm{psi} ; \\
\mathrm{K}_{\mathrm{E}} & =\text { ultimate bulk modulus }=6 \times 10^{6} \mathrm{psi} ; \text { and } \\
\mathrm{a} & =\text { coefficient of yield surface curvature } \\
& =.0015-.0030 \mathrm{psi}^{-1} .
\end{aligned}
$$

\subsection{Cumulative Creep Strain}

Long-term creep deformation of the salt opening results in an accumulation of maximum strains around the boundary of the opening. The material properties of the deformed boundary deteriorate in proportion to the cumplative creep strain. It is thif creep strain that produces, in time, gradual but 
extensive scaling failure on the boundary of an originally flawless opening, This effect can be numerically modeled so that the deterioration is included in the finite element analysis. The deterioration effect may be identified as reduction of both strength, $k_{0}$ and bulk modulus, $k_{1}$, as a function of critical cumulative strain.

The effect of the cumulative octahedral shearing strain, $\gamma_{0}$, on the octahedral shear strength, $K_{0}$ is illustrated in Figure 5-1. The effect can be incorporated in Equation 5-1 by making the following modifications:

$$
K_{0}=R_{A}^{\prime}+\left(K_{B}-K_{A}^{\prime}\right)\left(I-e^{\left.-\alpha \sigma_{m}\right)}\right.
$$

where:

$$
\begin{aligned}
\mathrm{R}_{m}^{\prime} & =\text { deteriorating } \mathrm{K}_{0} \text { value at }\left(\sigma_{\mathrm{m}}=0\right) ; \\
\mathrm{R}_{B} & =\text { ultimate octahedral shearing strength } \\
& =500-750 \mathrm{psi} ; \\
\alpha & =\text { coefficient of yield surface curvature } \\
& =.0015-.0030 \mathrm{psi}^{-1} ; \text { and } \\
\sigma_{m} & =\text { mean stress. }
\end{aligned}
$$

Equation 5-3 is devised to numerically simulate the deterioration effect. Here, $K_{A}^{\prime}$ is the deteriorating value of $k_{0}$ at $\sigma_{m}=0$, defined by the following function of the strain, $\gamma_{0}$ : 


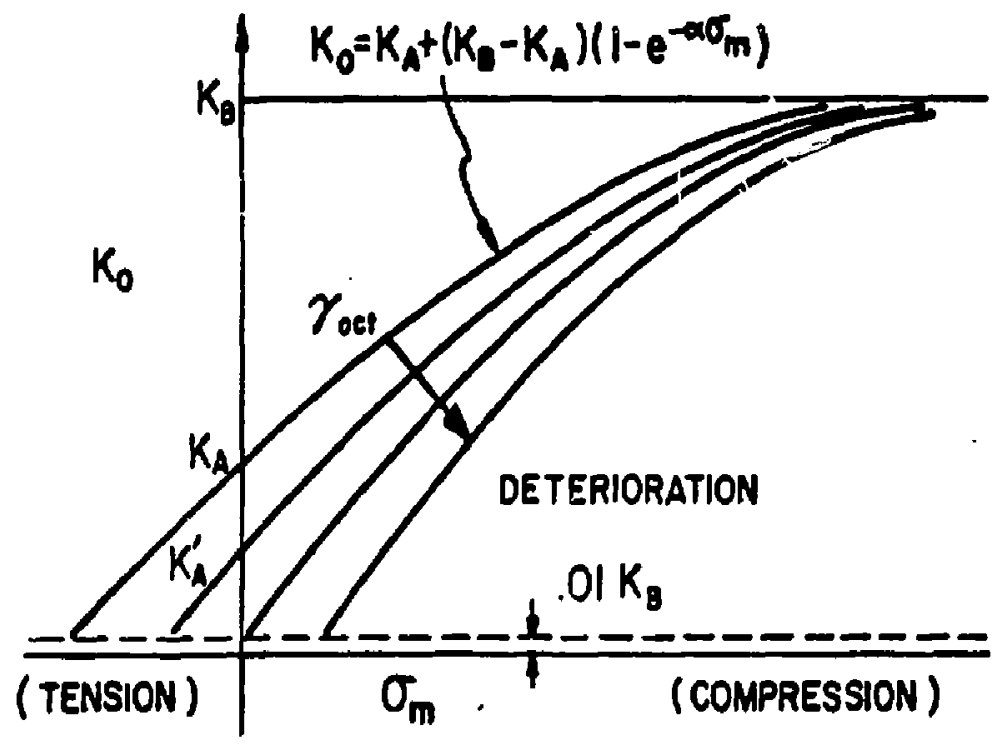

Figure 5-1. Modification of octaheral Shear strength as a Function of octahedra! Shear strain and Mean Stress.

Source: SGI, 1979 .

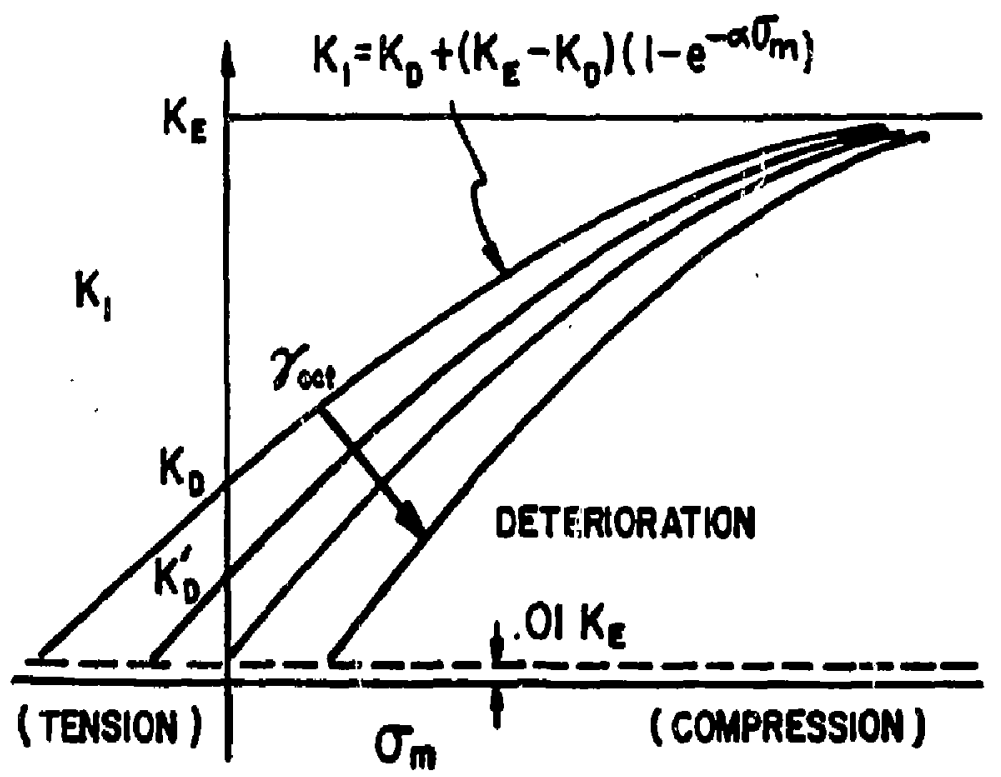

Figure 5-2. Modification of Bulk Modulus as a Function of Octahedral Shear Strain and Mean Stress. Sburce: SGI, 1979. 


$$
\mathrm{K}_{\mathrm{A}}^{\prime}=\mathrm{K}_{\mathrm{A}}\left(\frac{Y_{C}-Y_{O}}{Y_{C}}\right)
$$

Here, $Y_{C}$ is the critical strain at whick $K_{A}^{\prime}$ reaches its minimum value of $k_{A}^{\prime}=0$. The following values of $k_{0}$ and $\gamma_{c}$ have been adopted for use in the finite element program from underground calibration:

$$
K_{0} \stackrel{\geq}{=} 0.01 K_{B} ; \quad r_{C}=0.01 \sim 0.02 \text {. }
$$

The deterioration of the bulk modulus, $K_{l}$, as a function of the cotahodral shearing strain, $Y_{0^{\prime}}$ is shown in Figure 5-2. The modifications necessary to Equation 5-2 are made as:

$$
k_{l}=K_{D}^{\prime}+\left(k_{E}-k_{D}^{\prime}\right)\left(1-e^{-\alpha \sigma_{n}}\right)
$$

where:

$$
\begin{aligned}
k_{D}^{\prime} & =\text { deteriorating } k_{1} \text { value at }\left(\sigma_{m}=0\right) ; \\
k_{E} & =\text { ultimate bulk modulus } \\
& =6 \times 10^{6} \mathrm{psi} ; \\
a & =\text { coefficient of yield surface curvature } \\
& =.0015 . .0030 \mathrm{jsi}^{-1} ; \text { and } \\
\sigma_{m} & =\text { mean stress. }
\end{aligned}
$$

Here, $K_{D}^{\prime}$ is the deteriorated value of $K_{D}$ at $c_{D}=0$, defined by the following function of the octahedral shearing strain,

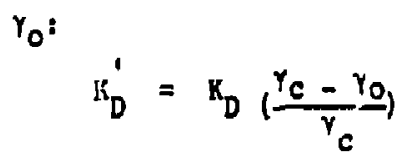


The paraneter $\gamma_{C}$ is the critical strain at which $K_{D}^{\prime}$ vaiue is reduced to its minimum value of $\mathrm{K}_{\mathrm{D}}^{\prime}=0$. For computational convenience, the following relation may be applied;

$$
\begin{aligned}
& x_{1} \stackrel{\geq}{=} 0.01 \mathrm{~K}_{\mathrm{E}} \\
& r_{c}=0.01-0.02 .
\end{aligned}
$$

Equations 5-1 through 5-6 have been developeu and field tested in salt and potash mines (Sifto Salt Division of Domtar Chemicals, Ltd.; Diamond Crystal Salt Company; Potash Corporation of Saskatchewan Cory Division; and Potash Corporation of Saskatchewan Rocanville Division) by using the rheological finite element method.

There is still room for Eurther improvement and higher accuracy. However, the present formulation of the deterioration process provides a useful means of assessing the longterm deterioration problem with an accuracy usually adequate for engineering design.

\subsection{Octahedral Shearing Stress}

Long-term creep behavior of the salt opening will be strongly affected by the octahedral shearing stress present in the surrounding ground. Therefore, the effect of the stress on the creep behavior requires en accurate analysis. Rock salt exhibits a unique characteristic in that the viscoplastic flow takes place only when the octahedral shearing stress exceeds 
its specific threshold point, $k_{0}$. Once viscoplagtic flow is initiated, the creep rate increases rapidly with the excess octahedral shearing siress of $\left(\tau_{0}-K_{0}\right)$ as previously shown in Figure 3-4. The dashed line of that figure illustrates the following power law fit, which gives a good approximation of this effect:

$$
\dot{\gamma}_{0}^{P}=\frac{k_{0}}{v_{4}}\left\{\frac{\tau_{0}-k_{0}}{k_{0}}\right\}^{n}=\frac{\tau_{0}-k_{0}}{v_{4}^{\prime}}
$$

where:

$$
\begin{aligned}
& \mathrm{n}=2.6 ; \\
& v_{4}=\Delta \tau / \Delta \dot{\psi}_{0} \text { at } \tau_{0}=2 \mathrm{~K}_{0} ; \text { and } \\
& v_{4}^{\prime}=v_{4}\left[\frac{f_{0}-\mathrm{K}_{0}}{\mathrm{~K}_{0}}\right]^{1-n} .
\end{aligned}
$$

$\cdot 1$

Here, $v_{4}^{\prime}$ is considered as an effective viscoplastic coefficient replacing $v_{4}$ on the finite element program. The effects of $\tau_{0}$ on other material property coefficients are found to be insignificant relative to the magnitude of the effect that $\tau_{0}$ has on the viscoplastic coefficient, especially when considering the long-term behavior of salt openings. 


\subsection{Elevated Temperature Effect}

Temperature is a very important parameter in the material propertieg of rock salt. However, temperature effects are highly selective, causing profound effects on some behavioral components and virtually no effects on other behavioral components. The temperature effect upon the individual behavioral components has been empirically established for use in the rheological constitutive equations. The modified constitutive equations are used in the computer model to account for temperature effects.

5.4.1. Effects on Elasticity--Effects of elevated temperature on the elasticity of rock salt are unimportant. Almost no changes are observed in the individual elastic coefficient values for temperatures to $300^{\circ} \mathrm{F}$. The temperature dependence of the shear modulus, $G_{1}$; bulk modulus, $K_{1}$; Young's modulus, ..; and Poisson's ratio, $v$, are shown in Figure 5-3,for temperatures to $1400^{\circ} \mathrm{F}$. Since elastic properties of the material have very little to do with the long-term behavior of the salt openings, the temperature effect upon the elastic properties can be ignored. 


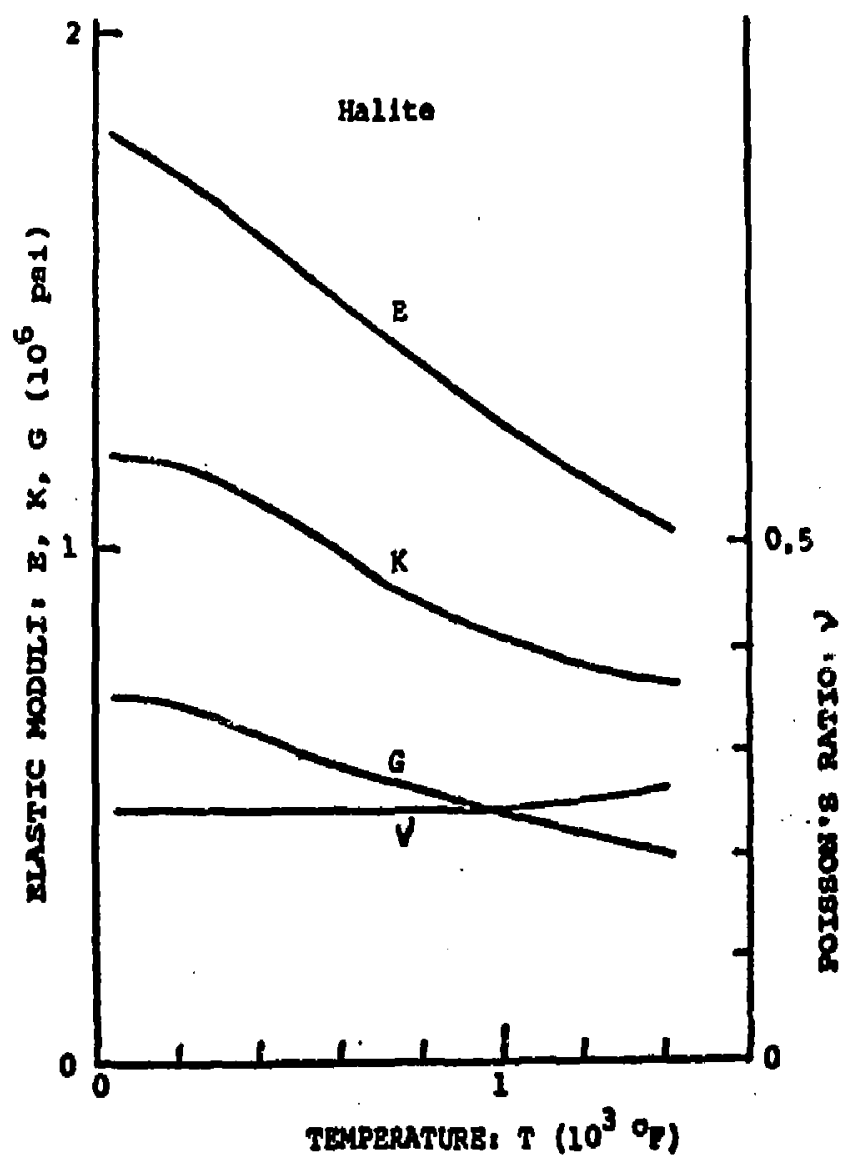

Pigure 5-3. Temperature Dependence of the Blastic Moduli. Source: Adachi (1970) 


\subsubsection{Effects on Viscoelasticity--Temperature effects on}

the viscoelastic behaviocal components of galt are found to be insignificant. The temperature effects were shown by using the model cavity testing method, which utilizes a thick-walled cylinder of rock salt for determination of various creep behaviors of the material. Viscoelastic closure characteristics of a thick-walled cylinder were measured under various temperatures up to $300^{\circ} \mathrm{F}$. The test results were analyzed in the relation of tangential strain rate, $\varepsilon_{\theta}$, versus time, $t$, as shown in Figure 5-4. The slope of the lines in the semi-log diagram is proportional to the ratio of the two viscoelastic property coefficients, $G_{2} / V_{2}$, as illustrated in the figure. Since the slope is not affected by the temperature increase, the temperature's effect upon viscoelasticity is concluded ingignificant. This conclusion is based on the assumption that the delayed elastic modulus, $G_{2}$, is not significantly affected by the temperature. A further investigation is required to verify the agsumption.

The conclusion that the effects of temperature on viscoelasticity are insignificant can be understood by considering the phygical meaning of the viscoelasticity of the material. 


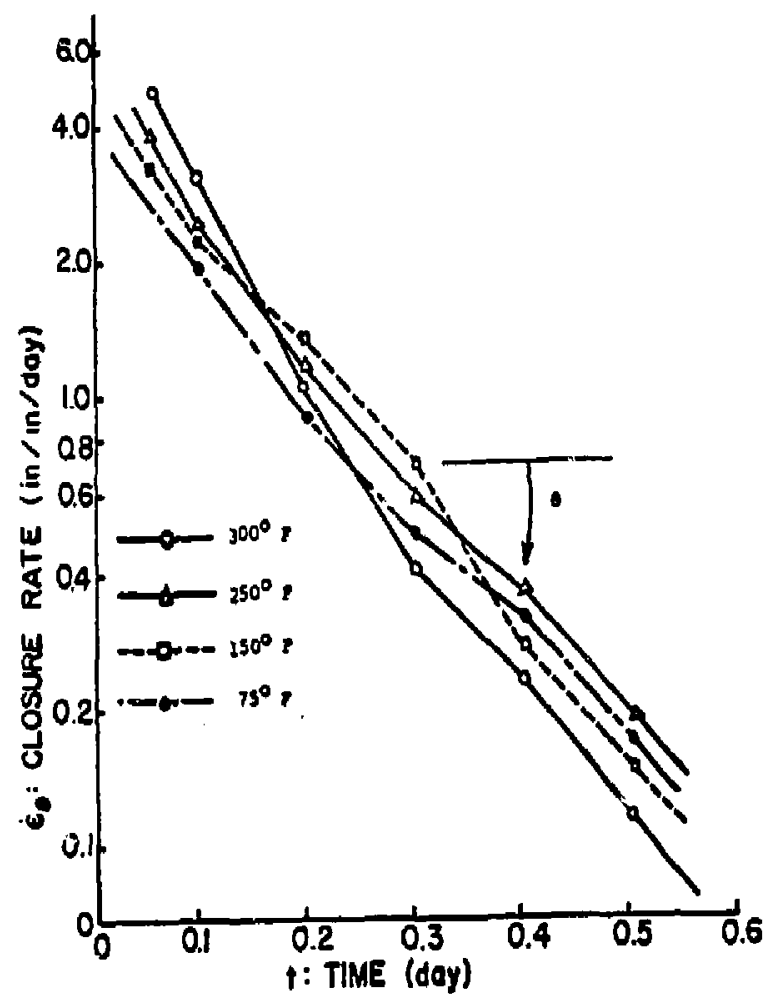

$$
\begin{aligned}
& \dot{\epsilon}_{0}=\frac{2 \sigma_{1}-\sigma_{1}-\sigma_{2}}{G V_{2}} \mathrm{e}^{-\frac{\sigma_{2}}{V_{2}} t} \\
& I_{n} \dot{\epsilon}_{1}=I_{n}\left[\frac{2 \sigma_{1}-\sigma_{1}-\sigma_{2}}{\sigma V_{2}}\right]-\frac{\dot{G}_{2}}{V_{2}} \\
& \frac{G_{2}}{V_{2}}=-2.3 \frac{\Delta \log \epsilon_{0}}{\Delta t}=-2.3 \tan \theta
\end{aligned}
$$

Figure 5-4. Ratio of Viscoelastic Coefficients Determined from Slope of Tangential Strain Rate Against Time, for a Cylindrical Cavity. Source: Adachi (1970) 
The viscoelasticity of rock salt originates from a boundary adjustment among the salt crystals, which behave elastically under a relatively low confining pressure. Since the temperature effects on the elastic properties of the material are minimal, it follows that temperature has a similar minimal effect on the viscoelasticit".

\subsubsection{Effect on Dctahedral Shearing Strength--The octa-} hedral shearing strength, $k_{0}$, of rock salt is responsible for the long-term stability of the salt openings. Since elevated temperature has a strong effect on the octahedral shearing strength, the teperature has an important influence on the long-term stability of the opening. Creep test data due to Adachi (1970), Hansen (1975, Feb. 1977, June 1977), Heard (1972), Le Comte (1965), Sakurai (1966), Serata (1959, 1969), Thompson and Ripperger (1964), and Wawersik (1979) were analyzed for determination of the temperature effect upon the $k_{0}$ value based on the rheological concept of the material properties developed by Serata.

Results of the analysis are presented in relation to the temperature as shown in Figure 5-5, where the solid line represents the most likely relationship. The scatter of some of the values on the line is caused by some irregularities in the testing method applied. This curve may be represented 


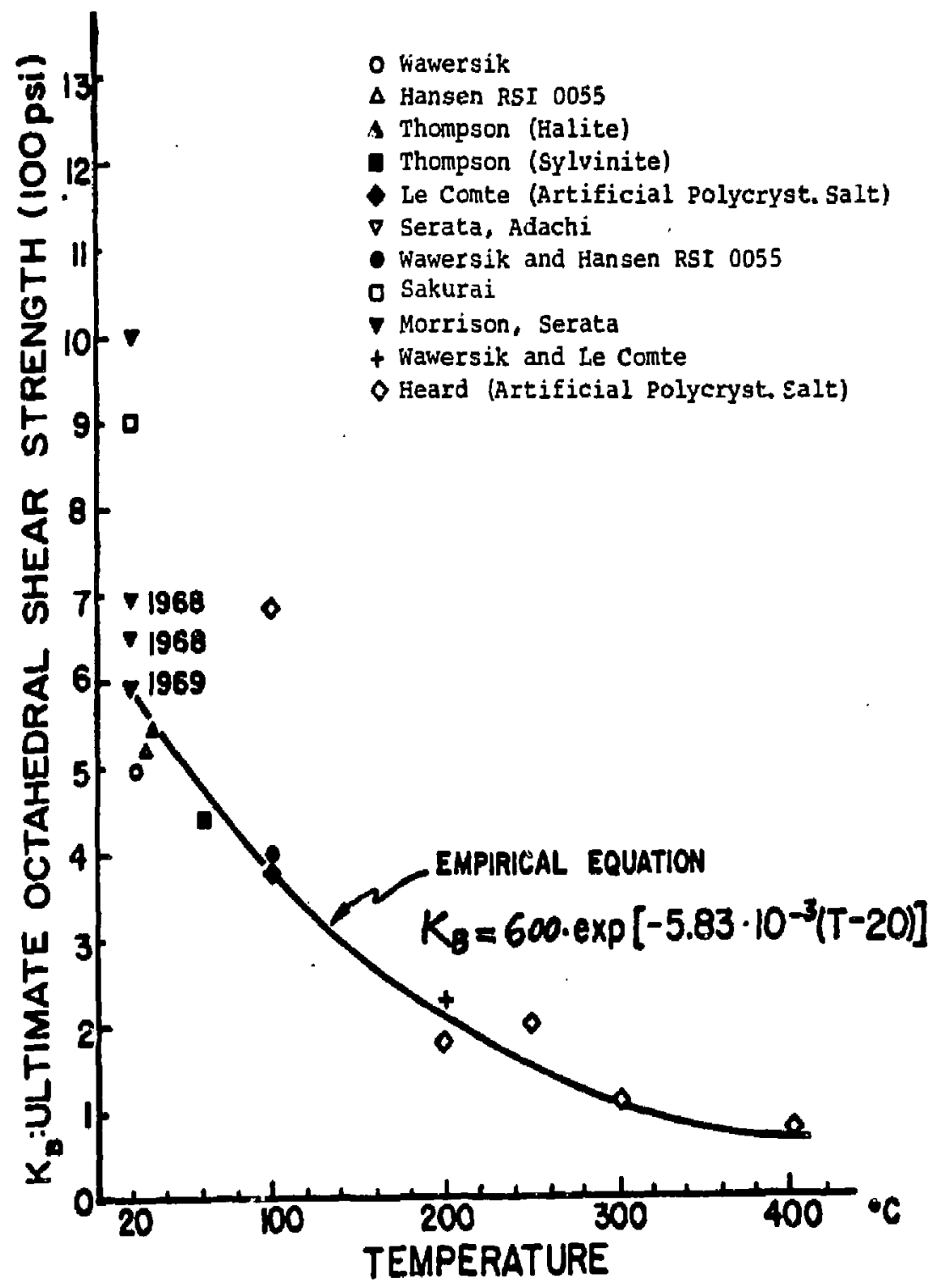

Figure 5-5. Uitimate Octahedral Shear strength as a Function of Temperature. Source: SEI, 1979. 
by the following empirical equation for ultimate octahedral shearing strength, $K_{B}$;

$$
K_{B}=600 e^{-5.83 \times 10^{-3}}(T-20) \quad(p s i)
$$

where:

$$
T=\text { temperature in }{ }^{\circ} \mathrm{C} \text {. }
$$

Data from sources other than Serata, Adachi, and Sakurai were converted to octahedral form by making the assu pt on of zero dilatancy, or $\varepsilon_{1}+\bar{c}_{2}+\varepsilon_{3}=0$.

\subsubsection{Effect on Viscoplasticity--Elevated temperature} has profound effects upon the viscoplastic coefficient of rock salt. The temperature effects upon the viscoplastic creep rate, $\dot{\gamma}_{0} P$, vergus octahedral shearing stress, $\tau_{0}$ for various temperatures are presented in Figure 5-6. Analysis of this data leads to the following expression of the temperature effect upon viscoplastic flow rate, $\dot{\gamma}_{0} p$

$$
\dot{\gamma}_{0}^{P}=\frac{\tilde{h}_{0}}{v_{4}}\left\{\frac{T}{293}\right\}\left\{\frac{\tau_{0}-R_{0}}{k_{0}}\right\}^{n}
$$




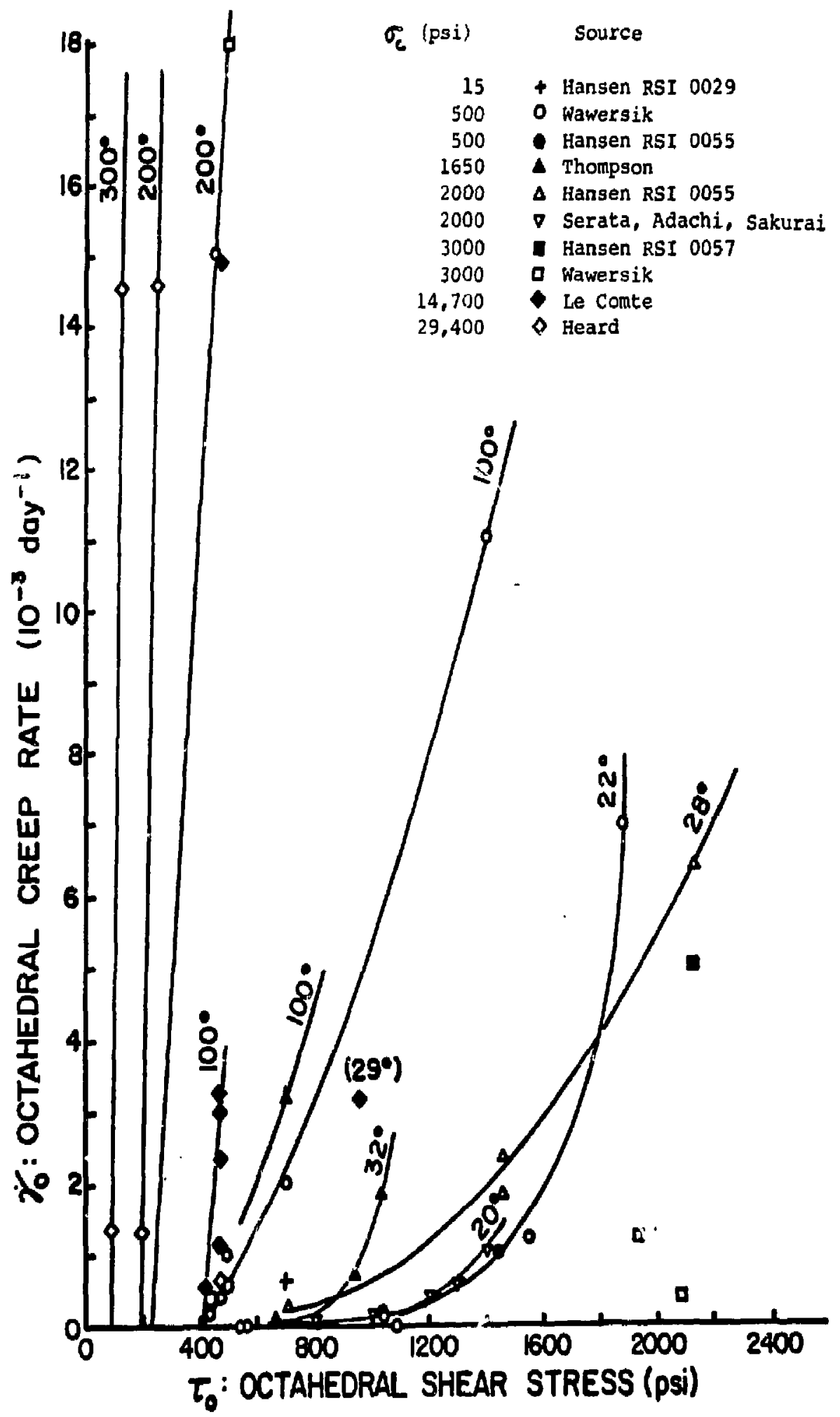

Figure 5-6. Effect of Temperature and Confining Pressure on the octahedral creep Rate as a Function of octahedral Shear Stress. Temperature in ${ }^{\circ} \mathrm{C}$. Source: SGI, 1979. 
where:

$$
\begin{aligned}
& K_{0}=K_{B}=500-700 \text { psi at } 20 \mathrm{Ci} \\
& v_{4}=\text { viscoplastic coefficient at room temperature, } T_{0} ; \\
& T_{0}=\text { absolute temperature in kelvin } \\
& x=9.7 ; \text { and } \\
& n=2.6 .
\end{aligned}
$$

These values are based on the most recent test jata to date from yarious diverse sourses (Adachi, 1970; Hansen, 1975, Feb. 1977, June 1977; Heard, 1972; Le Comte, 1965; Sakurai, 1966; Serata, 1959, 1969; Thompson and Ripperger, 1964; Wawersik, 1979). More data are needed, especially in the high temperature $\left(T=373^{\circ}\right.$ to $\left.573^{\circ} \mathrm{K}\right)$ and high stress $\left(\tau_{0}=2 \mathrm{~K}_{0}\right)$ ranges. 


\subsection{Permeability and Its Relationship with Porosity}

Permeability is defined as the measure of the capacity of a porous medium to transmit fluids. The phenomenon of permeability in rock salt is due to the granular composition of the porous medium, which intrinsically provides intergtitial voids for the passage of molecules. Thus, we would expect that the degree of permeability of a medium is a direct function of its porosity. The relation between porosity and permeability is suggested by kozeny (1927) and is gáven by:

$$
K=\frac{c \phi^{3}}{t s_{v} \cdot(1-\phi)^{2}}
$$

where:

$$
\begin{aligned}
K= & \text { permeability; } \\
c= & \begin{array}{l}
\text { coefficient depending upon the shape of the pore's } \\
\text { cross-sectional area; }
\end{array} \\
S_{V}= & \text { specific surface area or the ratio of the pore's } \\
& \text { surface area to the mineral volume of the medium; } \\
t= & \text { tortuosity factor; and } \\
& =\text { porosity } \\
= & \text { volume of interconnecting pore space/total volume. }
\end{aligned}
$$

A simplified form of Equation 6-1 was suggested by Reynolds (1960) as:

$$
k=k \frac{\not^{3}}{(1-\not)^{2}}
$$

where $k$ is a constant combining the factors $c, t$, and $s_{v}$ in Equation 6-1. This simplification is valid because these three factors remain quite consistent under various pressures. 


\subsection{Darcy's Law for Liquid and Gas}

Darcy's taw for permeability of a liquid can be expressed as:

$$
\mathrm{Q}=\mathrm{K} \frac{\mathrm{A}}{\boldsymbol{\mu}} \frac{\Delta \mathrm{P}}{\overline{\mathrm{L}}}
$$

where:

$Q$ = volume flow rate in $\mathrm{cc} / \mathrm{sec}$;

$K=$ coefficient of permeability;

$A=$ cross-sectional area perpendicular to the flow in $\mathrm{cm}^{2}$;

$\mu=$ absolute viscosity in ce.Itipoise (dyn $\left.\mathrm{sec} / \mathrm{cm}^{2}\right)$; and $(\Delta \mathrm{P} / \mathrm{L})=$ pressure gradient in $\mathrm{dyn} / \mathrm{cm}^{3}$.

As can be seen, the absolute unit of coefficient of permeability, $k$, is $\mathrm{cm}^{2}$. However, the unit "darcy" is commonly used for the case when $\Delta P / L$ is expressed in atm/ cm rather than in $\mathrm{dyn} / \mathrm{cm}^{3}$. It can be shown that:

1 darcy $=.987 \times 10^{-8} \mathrm{~cm}^{2}$.

In addition, the unit of permeability las also been reported in terms of the velocity of water per unit decrease in hydraulic gradient.

Darcy's Law for gas is different from that for liquid due to the fact that the gas flow rate is no longer constant along the length of the flow column. Assuming the gas expands isothermally, the perneability, $\mathrm{k}$, will take the following form: 


$$
K=\frac{2 \mu Q_{b} P_{b L}}{A\left(P_{1}{ }^{2}-P_{2}{ }^{2}\right)}
$$

where:

$Q_{b}=$ flow rate at the base pressure;

$P_{b}=$ base pressure or external pressure;

$P_{1}=$ absolute pressure at entrance; and

$P_{2}=$ absolute pressure at exit.

The other variables, $A, \mu$, and $L$, are similarly defined as in Equation 6-3 for the liquid law.

For Darcy's Law to be valid, the flow of fluid must be laminar or viscous.

\subsection{Physio-Chemical Eactors for Permeability}

The phenomenon of "slip" in gas flow causes the permeability of gas for a medium to be greater than the permeability of liguid. In normal liquid flow, the velocities of the liquid molecules close to the pore passageg approach zero. In gas flow, the mean free path of the gas molecules may be of the same order of magnitude as or even larger than the average diameter of the pores. Thus, the velocities of gas molecules next to the pores are much greater, which accounts for the highar permeability of gas. Furthermore, since the pressure and temperature can directly change the molecular velocity of a fluid, it is expected that the permeability will be dependent on pressli:e and temperature. 
If the pore size of a medium is large compared to the size of a molecule of a fluid, we would expect the measured permeability to be constant for different fluids provided the testing conditions are the same. On the other hand, if their sizes are comparable, we would expect the fluid with smaller molecules to have a higher permeability. This also means a dense gas will have a higher permeability than a less dense one.

A phenomenon that can affect the permeability of a liquid is the electrokinetic effect which may exist between the medium and an ionic solution. A small electromotive force is caused by the movement of innic particles through the pores. This self-generated potential causes a sma+l electro-osmotic resistance to the flow.

Direct chemical reaction between the fluid and the mediun may occur. Usually, the higher the degree of reaction, the lower the permeability.

Liquids which do not show direct chemical reaction or electrokinetic effect are called nonreactive liquids. Equation 6-6 can be used to relate the permeability for nonreactive liguid and the permeability for gas as well as to relate the permeability for gas at different mean gas pressures: 


$$
\mathrm{K}_{\mathrm{L}}=\frac{\mathrm{K}_{\mathrm{G}}}{1+\frac{\mathrm{b}}{\mathrm{P}_{\mathrm{m}}}}
$$

where:

$\mathrm{K}_{\mathrm{L}}=$ permeability for liquid;

$K_{G}=$ permeability for gas;

$\mathrm{b}=$ Klinkengerg constant; and

$\mathrm{P}_{\mathrm{m}}=$ mean gas pressure, $\frac{\mathrm{P}_{1}+\mathrm{P}_{2}}{2}$.

Equation 6-6 is known as the klinkenberg formula. It should be noted that the empirical constant, $b$, is dependent on both the salt medium and the gas involied. Reynolds (1960) uses $b=7$ psi for He gas. This figure is given here only for an indication of the order of magnitude of $b$; it is not considered reliable.

\subsection{Results of Studies on Permeability}

Extensive studies of rock salt permeability have been carried out by Reynolds (1960), Lai (1971) and Sutherland and Cave (1978). Reynolds' tests were on Grand Saline dome salt and Hutchinson mine bedded salt. Lai's test.s used Louisiana dome salt, and Sutherland and cave used bedded salt from the WIPP study area in southeastern New Mexico. Comparison of results from the three experimencers indicates that there is little difference between the permeabilities of bedded and dome salt under a given stress state. The testing methods and 
jinportant findings of the different investigators are discussed in the following paragraphs.

Both Reynolds and Lai used a steady-state method designed and constructed by serata to measure the permeability, $K$. The experimental setup included a triaxial pressure cell which allowed testings under various stress states. The cell permitted application of separate axial and lateral loads, using independent hydraulic systems, which were able to maintain axial and lateral pressures to within \pm 5 psi of selected pressures. The flow of fluid was driven in the axial direction by a differential head pressure, which was held constant by an automatic control system. Since this seepage, pressure was held constant, Equation 6-3 can be used directly to find the permeabilities, $K$. On the other hand, Sutheriand and Cave used a different principle, the transition method. Instead of maintaining a constant seepage pressure, an incremental seepage pressure differential between a large gas volume and a small gas volume was allowed to reach equilibrium through the length of a given sample. The derivation of $k$ is given in Bruce et al. (1973).

Iai and Reynolds found that the measured $K$ would decrease from the beginning of the test until a minimum steady state was reached. The time required for steady state flow is 
approximately five to ten days. Sutherland and Cave, on the other hand, reported that the permeability continues to decrease indefinitely. However, in the test conducted by sutherland and Cave, the mean (hydrostatic) pressure was not kept constant as it was in the experiments conducted by the other two investigators, Replotting a result from Sutherland and Cave (1978) in Figure 6-1, we can see that at constant confining pressure, a minimum steady state flow has actually been reached.

In this particular case, the time required to reach a steady flow is approximately 130 hours $(=51 / 2$ days $)$; this result agrees with that of Lai and Reynolds, Some typical results of minimum permeability determinations as well as the minimum time required for the steady state are given in Table 6-1.

The reason(s) for the phenomenon of steady minimum flow may be one or a combination of the following:

1. Viscoplastic compaction--Time-uepondent viscoelastic deformation of a collection of grains; the deformed grain volumes are moved to fill up the interstitial granular voids, thereby decreasing the passage area for the transmission of fluid molecules.

2. Surface Tension--The initial high flow rate may be due to the strong attraction between the dry 


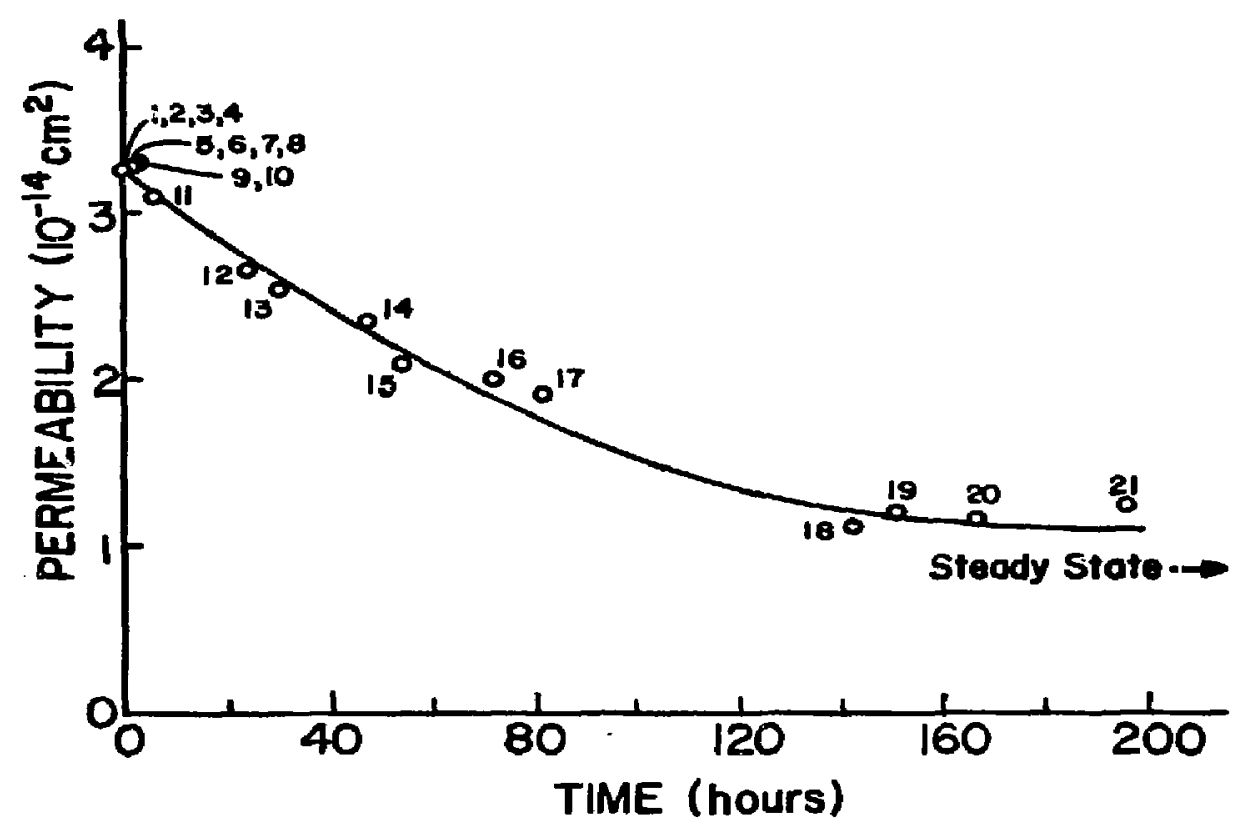

Figure 6-1. Steady State Flow of Argon Gas Through Bedded Rock Salt. Adapted fxom sutherland and Cave (1978). 
Table 6-1. Initial and Mininum Permeabilities of Grand saline Dome Salt

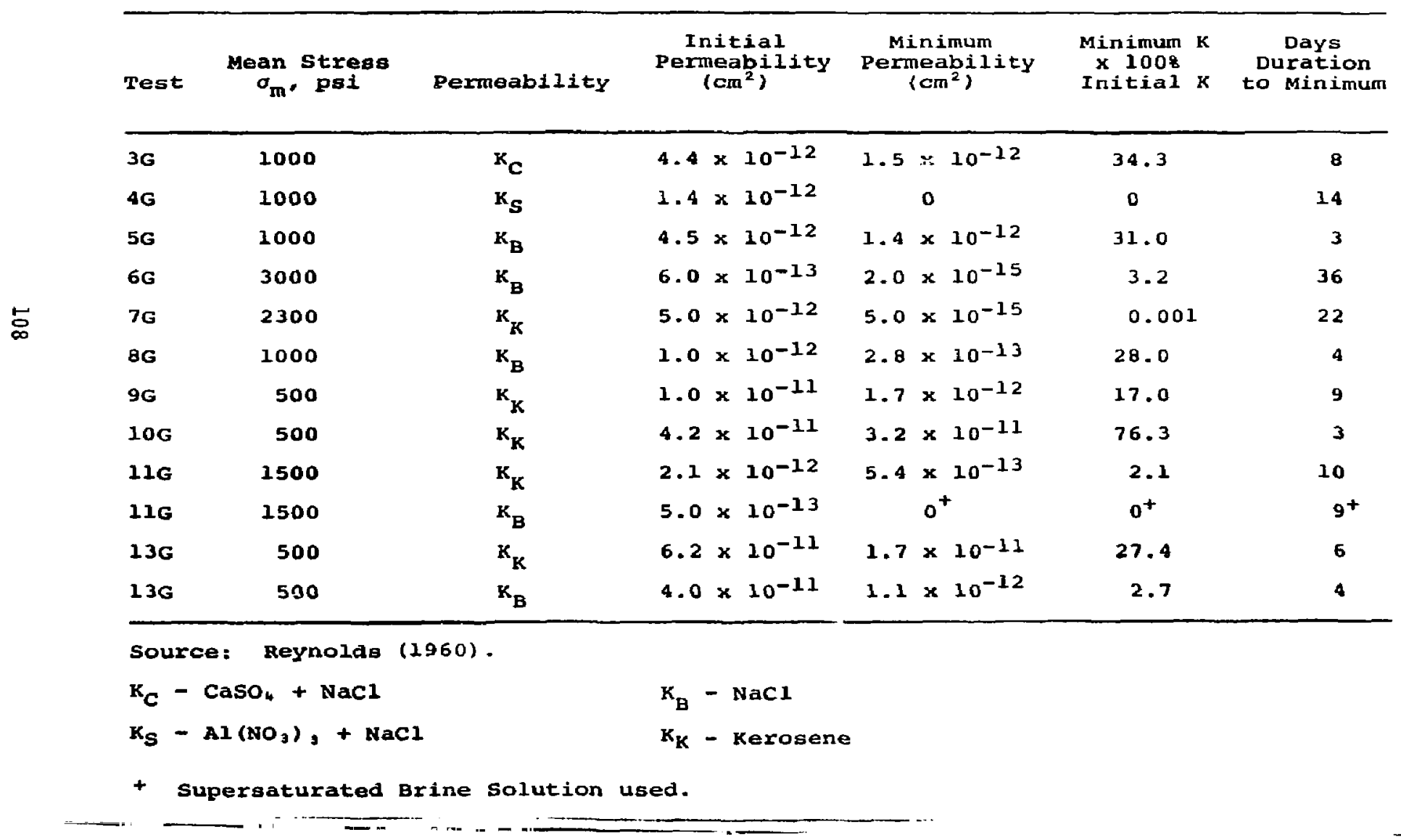


interfacial substrate molecules and the fluid molecules.

3. Plugging Effect--Any air bubbles or impurities carried by the permeating fluid may cause some pores to be plugged up.

Results from Reynolds, Lai, and Sutherland and Cave have shown that the permeability of rock salt decreases as the mean stress increases. The relationships between $K$ and $\sigma_{m}$ for different fluids were plotted in Figure 6-2. In the figure, Curve 1 represents the permeability to mineral oil, and Curve 2 represents the permeability to kerosene. Because of insufficient data, Curve 2 is shown as a dotted line. Curve 3 represents the permeability to helium gas. Because of the relatively nonreactive nature of oil and kerosene, Curves 1 and 2 can be regarded as the permeability of rock salt to nonreactive liquid. To plot curve 3 , the Klinkenberg formula :ras used to convert the gas permeability to the liquid permeability. However, as can be seen, Curve 3 lies far above Curves 1 and 2 (for $\sigma_{\mathrm{m}}>1000 \mathrm{psi}$ ). This suggests that either the data is at fault or else the Klinkerberg formula is not appropriate to relate zas permeabiliky to liquid permeability. Further studies and experiments have to be conducted before any conclusion can ba drawn. Curve 4 is the nonreactive liquid perneability of bedded salt to Argon gas, replotted from Sutherland and Cave's data. 


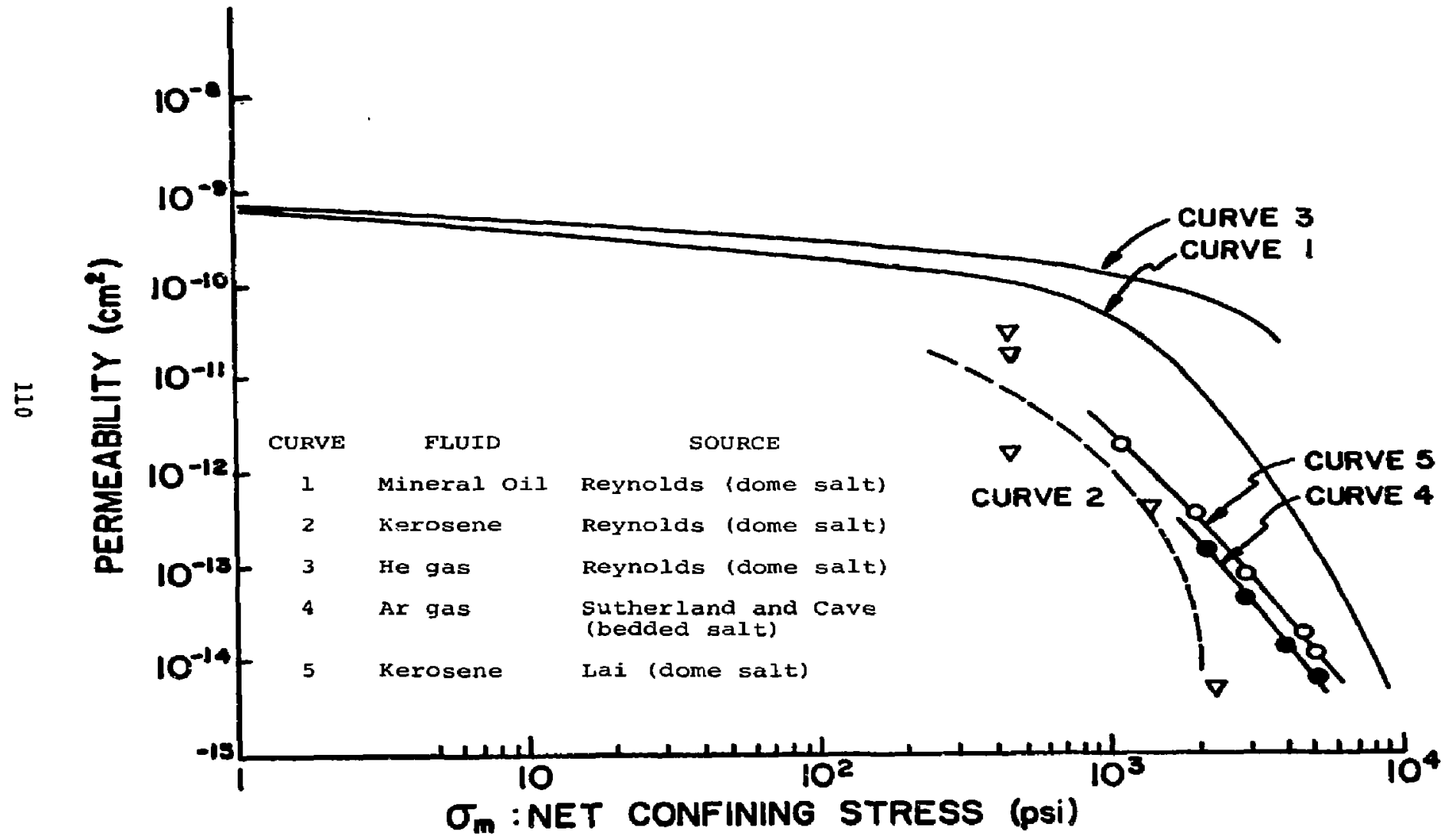

Figure 6-2. Permeability of Rock Salt vs. Confining Pressure Under Ifydrostatic conditions. Adapted from Reynolds (1960). 
The fact that tris bedded salt curve lies in the middle of the various dome salt curves indicates that the geological origin of the salt is not a very significant factor. Curve 5 represents points due to Lai, projected to the hydrostatic condition $\mathrm{t}_{0}=0$, using kerosene and dome salt.

Figure 6-3 shows one run from Sutherland and Cave's data in its original form. It should be noted that Sutherland and Cave have used Argon gas in their experiment, and gas pressure was maintained high enough to assure that the obtained gas result was the actual nonreactive liquid permeability.

An interesting finding evident in Figure 6-3 and also reported by Reynolds (1960) is that the coefficient of permeability, $K$, decreased if cyclic loading or strain hardening was involved. The reason was thought to be that the plastic flow of the salt medium under high stresses would cause the pores to close. In-situ salt is expected to be in a strain-hardened state (see Section 2.1.2).

The reason for the differences of permeability among the various samples is thought to be due to the individual specimen. It is possible that different degrees of microstructural damage occur to the specimens when they are extracted from mines. This damage will tend to increase the pemeability of the specimens. Thus, the most 


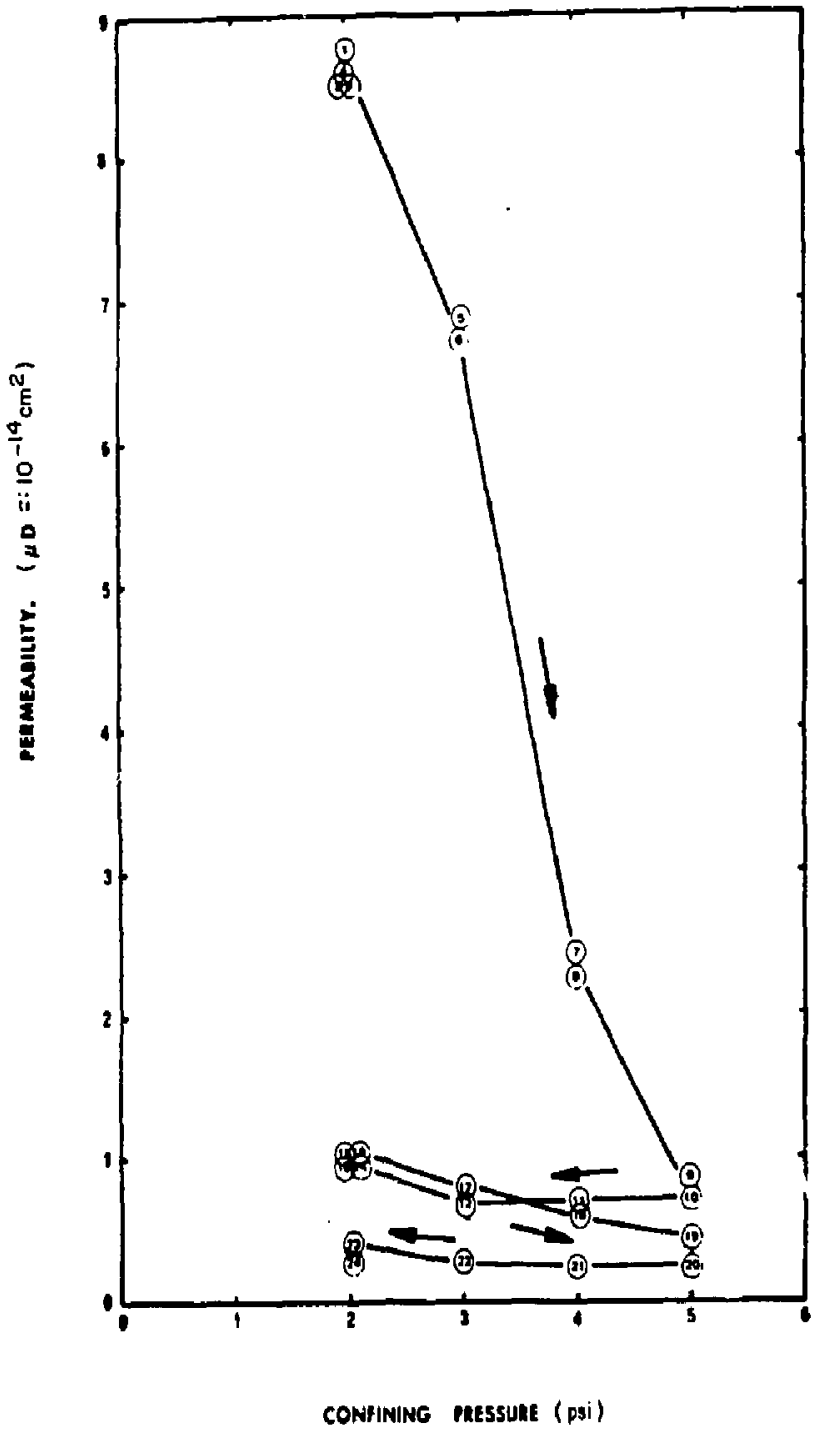

Figure 6-3 Non-reactive Liquid Permeability of Argon Gas-Through Bedded Salt. Cyclic Test Starts at 1 (Top). Source: Sutherland and Cave (1979). 
representative in situ permeability of rock salt is probably the lowest value obtained from a specimen, which indicates the least damage that exists in the somple.

Lai found that the permeability decreased when the mean pressure, $\sigma_{m}$, was increased; and increased when the octahedral shearing stress, $\tau_{0}$, was increased. Equation $6-7$ below was developed by fai to empirically relate both $\sigma_{\mathrm{m}}$ and $\tau_{0}$ with the coefficient of permeability, $K$.

$$
\log K=0.62-.0006 ? \tau_{\mathrm{m}}+.00139 \tau_{0}
$$

The above relationship is presented in terms of $k$ versus $\tau_{0}$ and $k$ versus $\sigma_{m}$ in Figure $6-4$ and Figure $6-5$, respectively. The combined effect of $t_{0}$ and $\sigma_{m}$ is presented in the threedimensional diagram of Figure 6-6. Equation 6-7 provides a simple way to predict the permeability of an underground formation of rock salt under different stress states for nonreactive liguids. The permeability of salt to air as a function of mean stress, $\sigma_{m}$, shearing stress, $\tau_{0}$, and gas pressure, $P_{\text {ma }}$ may be obtained from Equations $6-6$ and 6-7:

$$
\begin{aligned}
\log \dot{K}_{G}= & 0.62-.00067 \sigma_{m}+.00139 \tau_{0} \\
& +\log \left(1+\frac{b}{p_{m}}\right)
\end{aligned}
$$

The data presented so far, except for Lai's results, are for the hydrostatic condition. Lai, however, carried out 


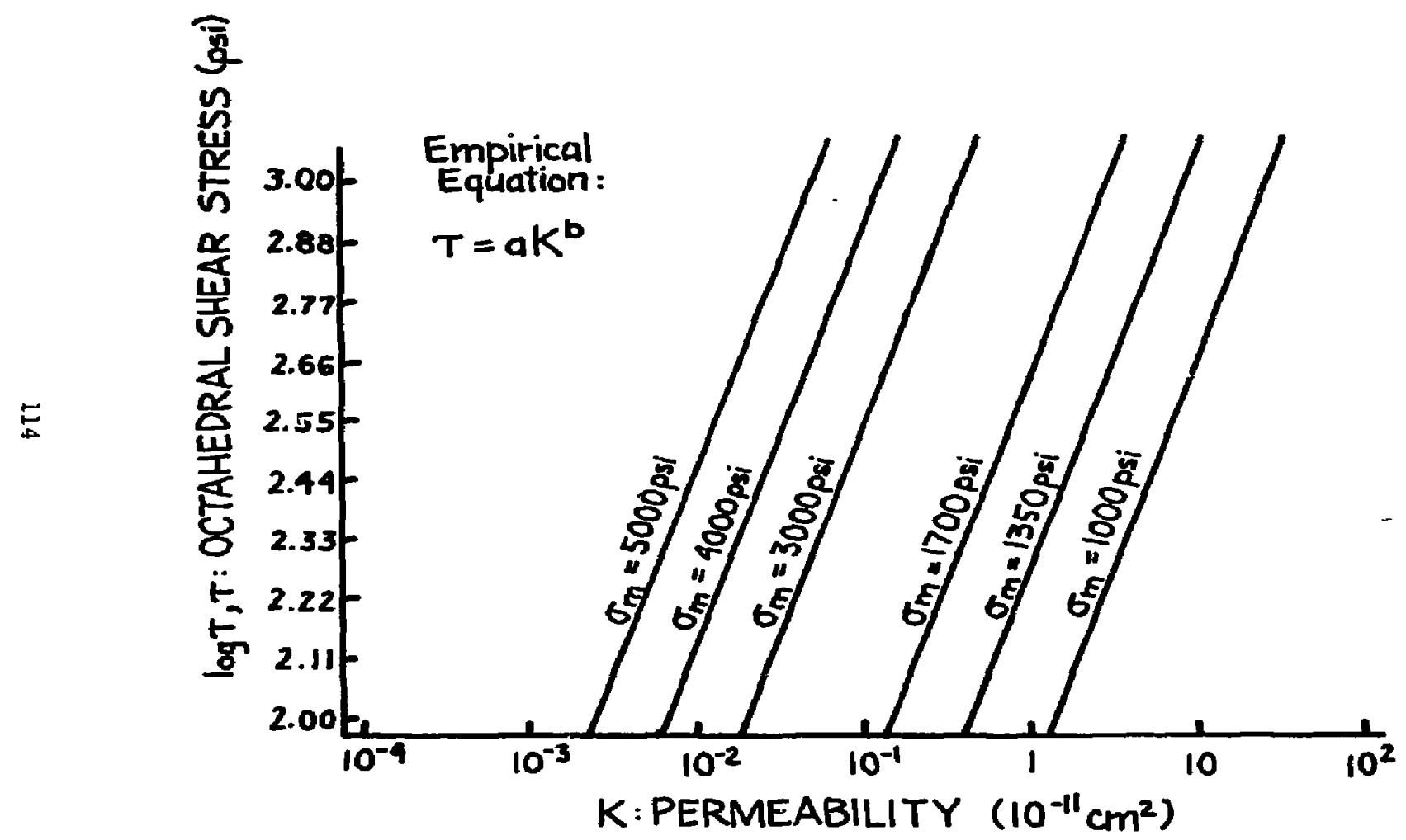

Figure 6-4. The Effect of Octahedral shearing stress Upon permeability for various Mean stresses. Source: Iai (19.71). 


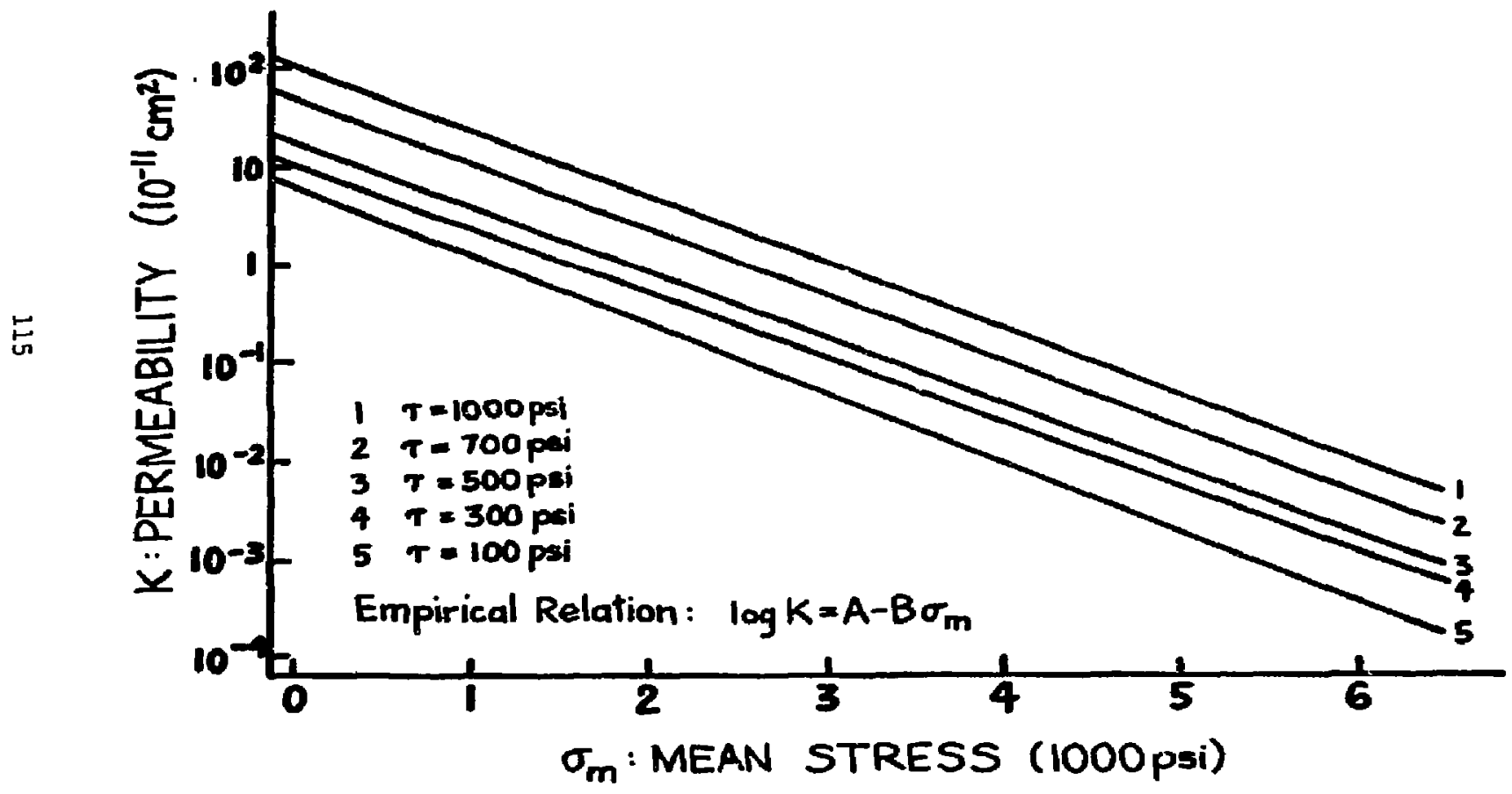

Figure 6-5. The Effect of Mean stress upon Permeability for Various octahedral Shear Stresses. Source: Lai (1971). 


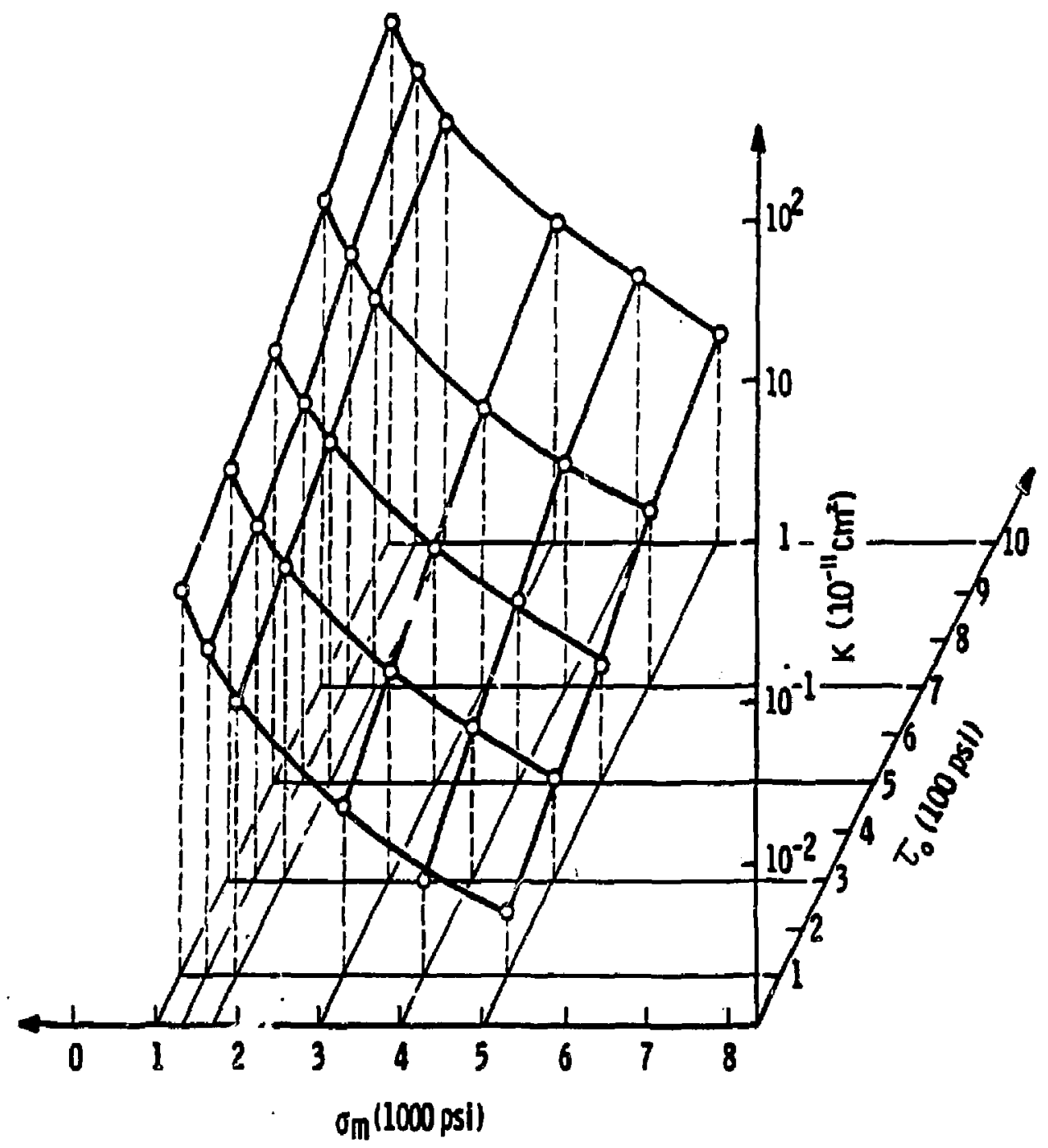

Figure 6-6. Three=Dimensional Plot of $N_{i}$ ?n Stress, Octahedral Shear Stress, and Permeability. Source: Lai (1971). 
the test at different values of $\sigma_{\mathrm{m}}$ and $\tau_{0}$. No pu'e hydrostatic state of stress was tested. Nevertheless, we can still compare Lai's result to the others by noting the tendency of the change of slope of the three-dimensional graph in sigure 6-6. If this is done, as shown in Figure 6-2, it will be found that Lai's results, projected to the hydrostatic state of stress, correlate well with the results of sutherland and cave. The difference between the two sets of permeability values decreases from about one-half of an order of magnitude at $\sigma_{\mathrm{m}}=2000 \mathrm{psi}$ to less than one-third of an ordar of magnitude at $\sigma_{m}=5000 \mathrm{psi}$. Again Lai's results lie between curves 1 and 2 of Figure 6-2. Figure 6-6 provides an excelient global picture of the effect of the stress state on the permeability of rock salt.

\subsection{Conclusions}

The permeability of dome and bedded salt to "nonreactive liquid" ranged from $10^{-9} \mathrm{~cm}^{2}(\simeq 100$ millidarcy) to less than $1.0^{-15} \mathrm{~cm}^{2}$ ( $\simeq 0.1$ microdarcy) for various stress states, The values of germeability decrease with increasing mean stress, $\sigma^{\prime}$ ' and increase with increasing octahedral shear stress, $\tau_{0}$. Bedded salt was not found to differ significantly from dome salt with respect to permeability. Care has to be taken when comparing results from different investigators since the stress state of the sample is important. 
The permoability values given in this chapter are considered to be order of magnitude. For application to in-situ conditions, these permeability values can be used as upperbound values, since undisturbed salt is expected to have a lower permeability (Reynolds, 1960). The in-situ stress state, including both the mean and shearing stresses, must be taken into account when determining the permeability of an underground opening. Figures 6-4 through 6-6 can be used as a guide. The values of permeability decrease with increasing $\sigma_{\mathrm{m}}$ and increase with increasing $T_{0}$.

Care has to be taken in applying the klinkenberg formula to relate tue gas permeability to liquid permeability or the gas permeabilities at different mean gas pressures. In experimental work to measure air permeabilities, it is advisable to design the experiment so that a high mean gas pressure can be applied. A high gas pressure (usually > 500 psi) can assure that the values of permeability obtained are actually the liquid (nonreactive) permeabilities. Even then, tests at different gas pressures should be performed at times to check the consistency of the liquid permeability.

Based on the low permeability values obtained experimentally, it is concluded that leakra of radioactive waste materials from underground salt formations will vary from small to 
possibly negligble, provided that there is no geological discontinuities and undesirable anomalies. Due to the plastic behavior, rock salt acts as a self-sealer for the storage cavity. Furthermora, the mass and density of an underground formation provides shielding against the release of radioactivity. There are studies and computer programs available at the Lawrence Livermore Laboratory which will calculate brine migration in salt under various temperatures. 


\subsection{IN-SITU MEASUREMENT OF SALT OPENING BEHAVIOR}

Underground roms in salt formations exhibit a substantial amount of creep closure immediatly following excavation. If the room is to establish an ultimate structural stability, there is a quick reduction of the deformation creep rate. on the other hand, if the room is to be unstable, the creep closure rate not only remains high but also increases to the point of eventual failure. There are no simple relations to predict the long-term creep behavior of salt openings. The behavior will be governed by three fundamental geomechanics factors-the material properties of the surrounding ground, the in-situ stress state, and the geometry of the opening. However, the behavior can be predicted from knowledge of the nature and magnitude of the initial creep closure characteristics. Many openings which at first appear safe and stable eventually fail either by sudden roof fall or gradual breskdown of the room boundary. Such potentially unstable openings exhibit latent instabilities in their initial creep deformation pattern. This chapter describes methods of detecting these basic creep characteristics for different parts of the salt opening.

\subsection{Room Closure and Roof Failure}

A wide range of room closure patterns is expected for an opening made in a bedded salt formation at any given depth. 
For example, room closures of salt openings observed in various salt formations at depths up to about 3500 feet vary greatly, as shown in Figure $7-1$. Those curves showing quick reduction of the creep rate in the figure represent more stable openings, while the curves showing continuation or increase of the creep rate represent more unstable openings. The stability is not necessarily related to depths of the openings, but is dictated by a number of geological and geometric factors which are discussed in Chapters 8, 9, and 1.0. The unstable openings will suffer long-term ground failure in various degrees, depending upon the quality of the design. Therefore, measurement of room closure and room closure rate is important to predict the degree of long-term stability of the salt openings.

The stability of the openings can be determined immediately following excavation if the creep behavior is measured accurately. Measurements of both the room closure rate distribution pattern across the entire width of the room as well as the internal creep of the roof strata are useful. A scheme for the external and internal creep measurements is illustrated in Figure 7-2, For immediate measurement, Microcreepmeters may be utilized for both internal and external creep measurements. The Microcreepmeter is a portable, highly sensitive deformation measuring device which has electronic means of recording the creep deformation with 


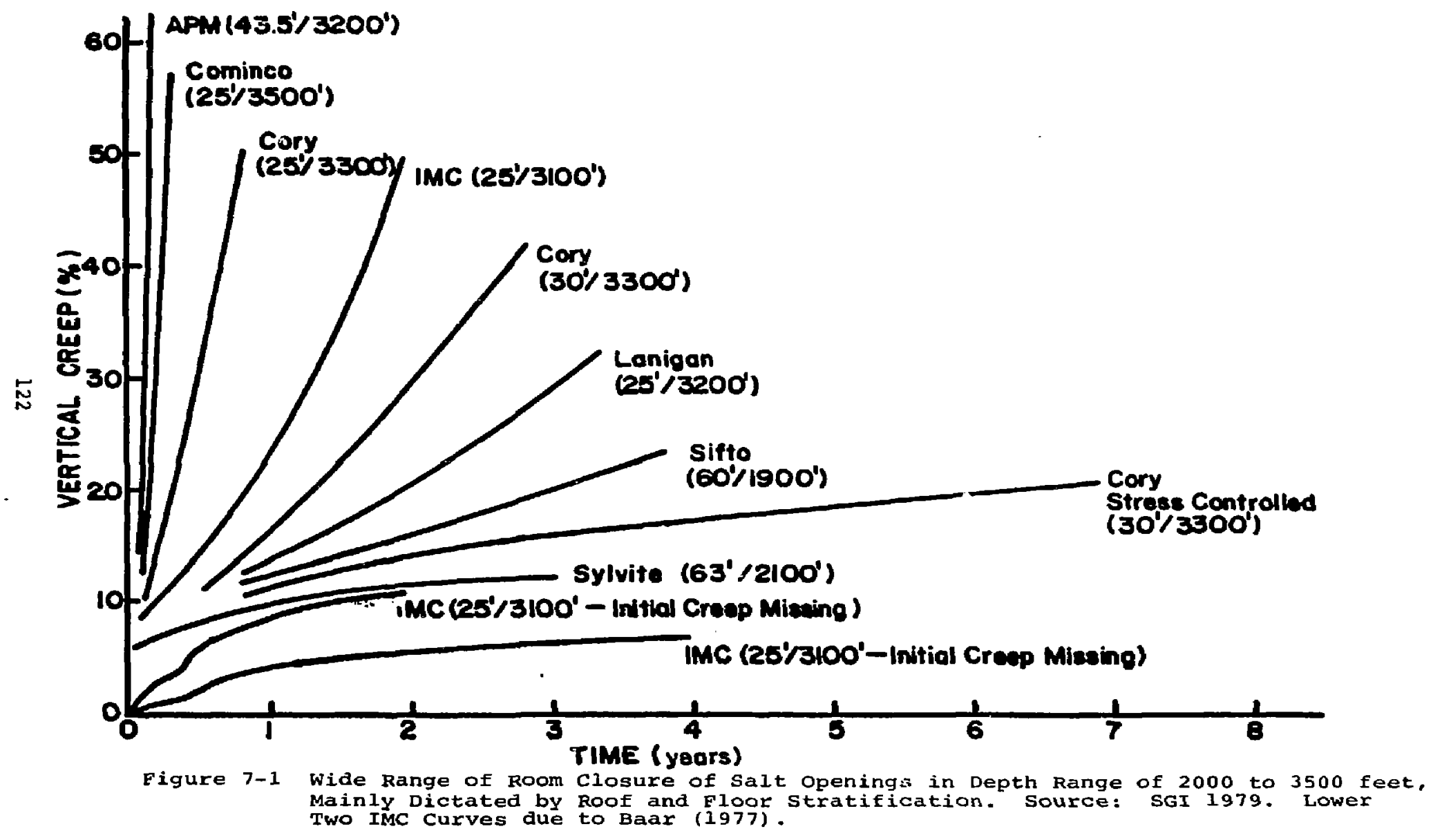




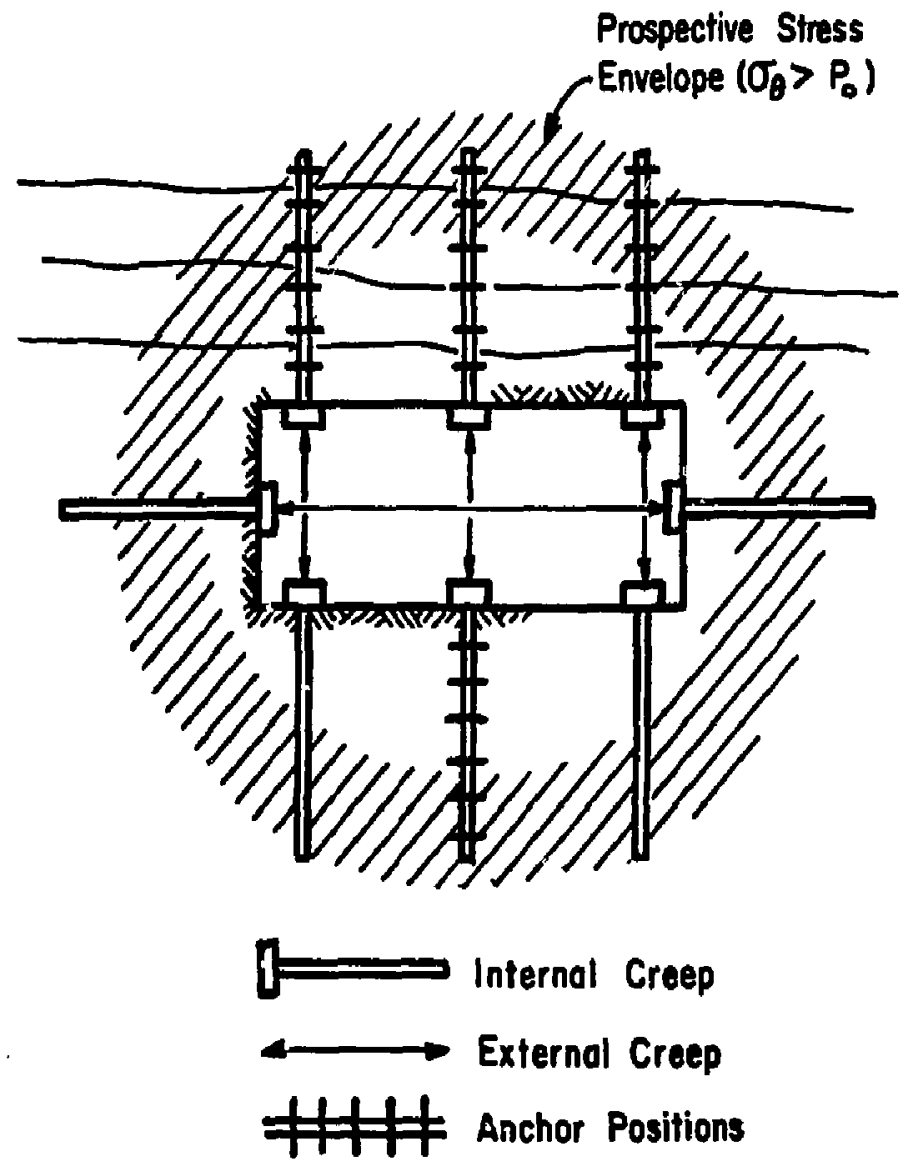

Figure 7-2, Cross-Sectional Design of Measurement Station for Internal and External Creep Deformation. Source: SGI, 1979 . 
an accuracy in the order of $10^{-6}$ inch. A schematic diagram of the Microcreepmeter is shown in Figure 7-3. For longterm observation, the Microcreepmeter should be replaced by more permanent instrumentation. The Microcreepmeter is useful for determining any potential roof or floor failure of an opening, regardless of the age of the opening.

There are several different methods of detecting such potential roof or floor failure. The first is to examine the zistribution of room closure rates across an entire cross section of a room. The degree of room stability is proportional to the uniform nature of the room closure distribution pattern, as illustrated in Figure 7-4. This means that a potentially unstable room exhibits a larger closure rate at the room center compared to the side of the same room. Another way to evaluate the room stability with an early measurment is to examine the creep closure rate in relation to the age of the opening. The stable room reduces its room closure rate uniformly in a generally logarithmic manner, as shown in Figure 7-5. On the other hand, the unstable room with potential failure of the roof media is indicated by an eventual increase of the creep closure rate, as also shown in Figure 7-5. The figure was constructed from data obtained from three potash mines with a depth range of 3200 to 3500 feet in the Saskatoon area, Saskatchewan, Canada. Any instability indicated by the room closure may be analyzed 


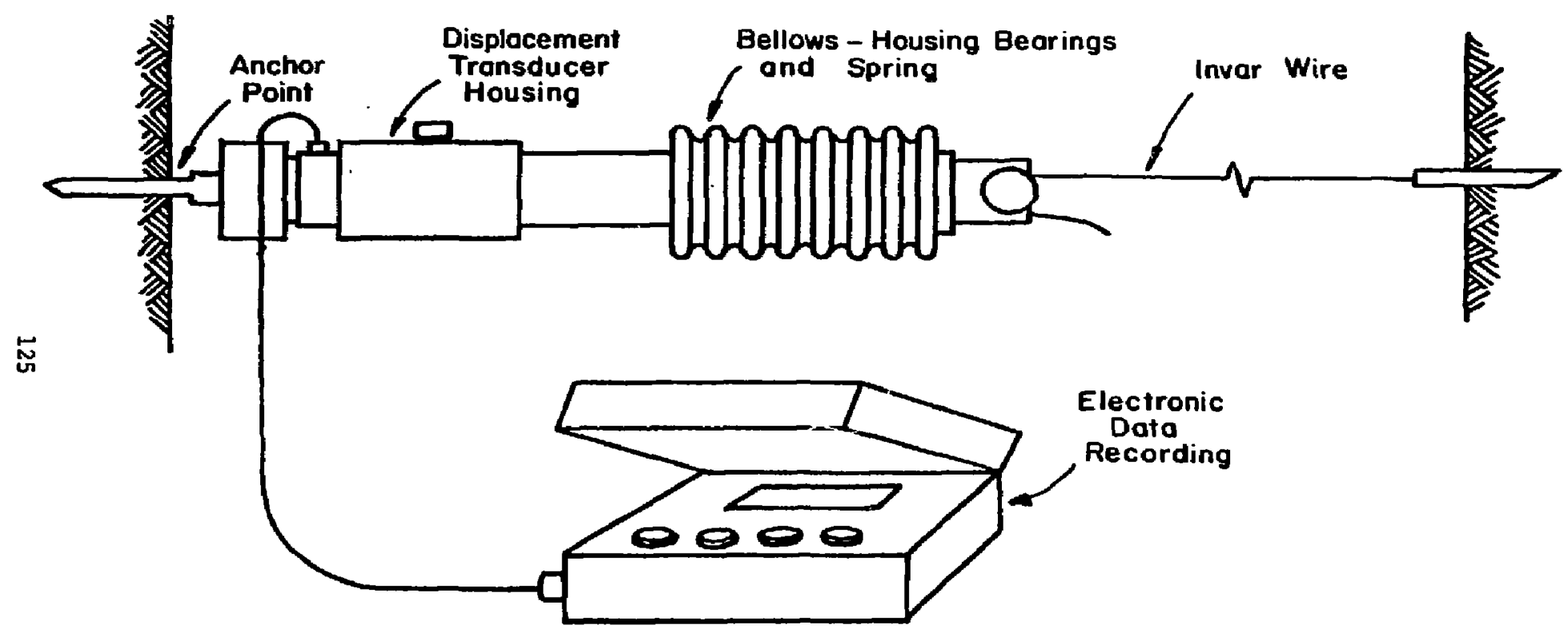

Figure 7-3. Microcreepmeter Diagram.

Source: SGI, 1979. 


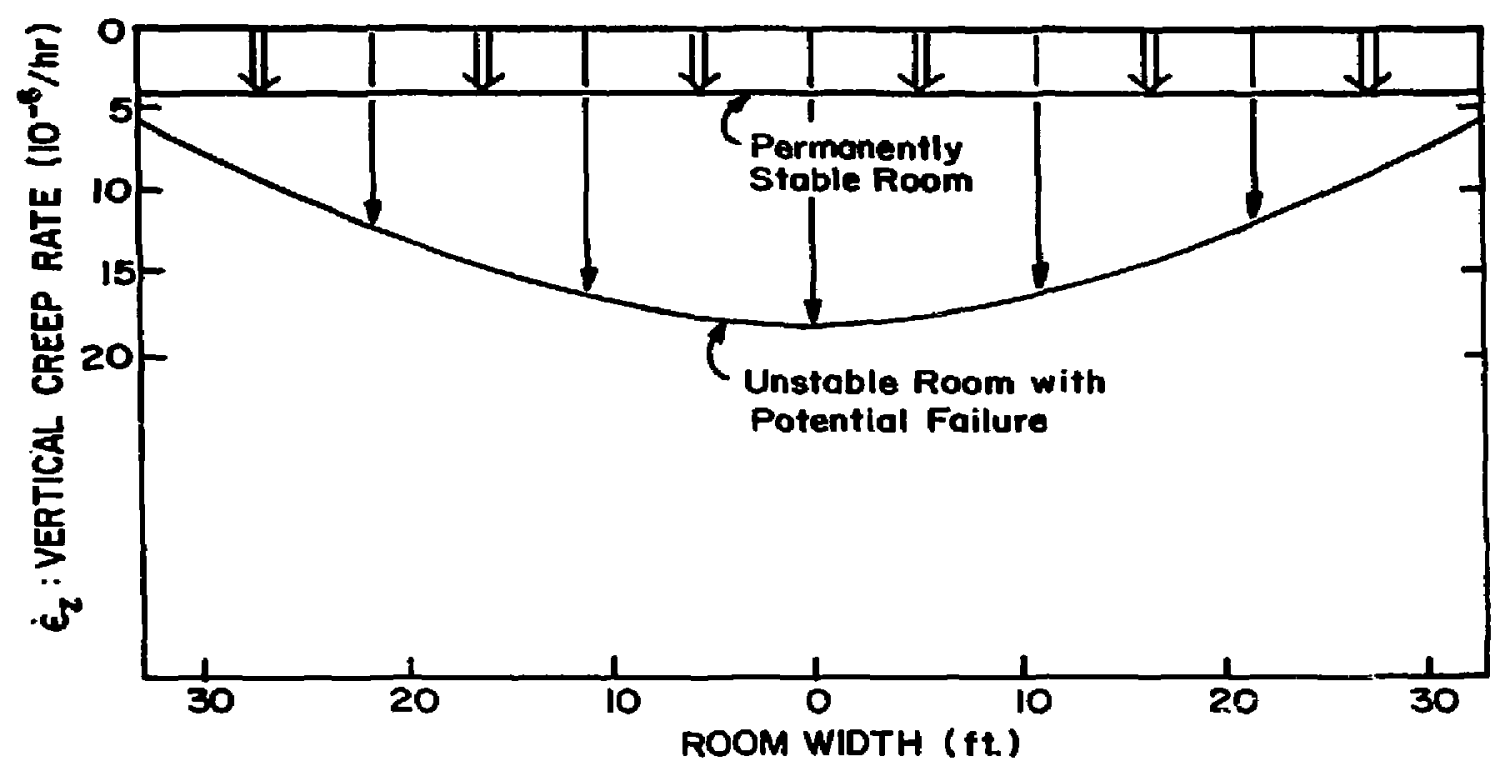

Figure 7-4. Room Closure Creep Rate Distribution Pattern Indicating Potential Roof Failure Problems.

Source: SGI, 1979 . 


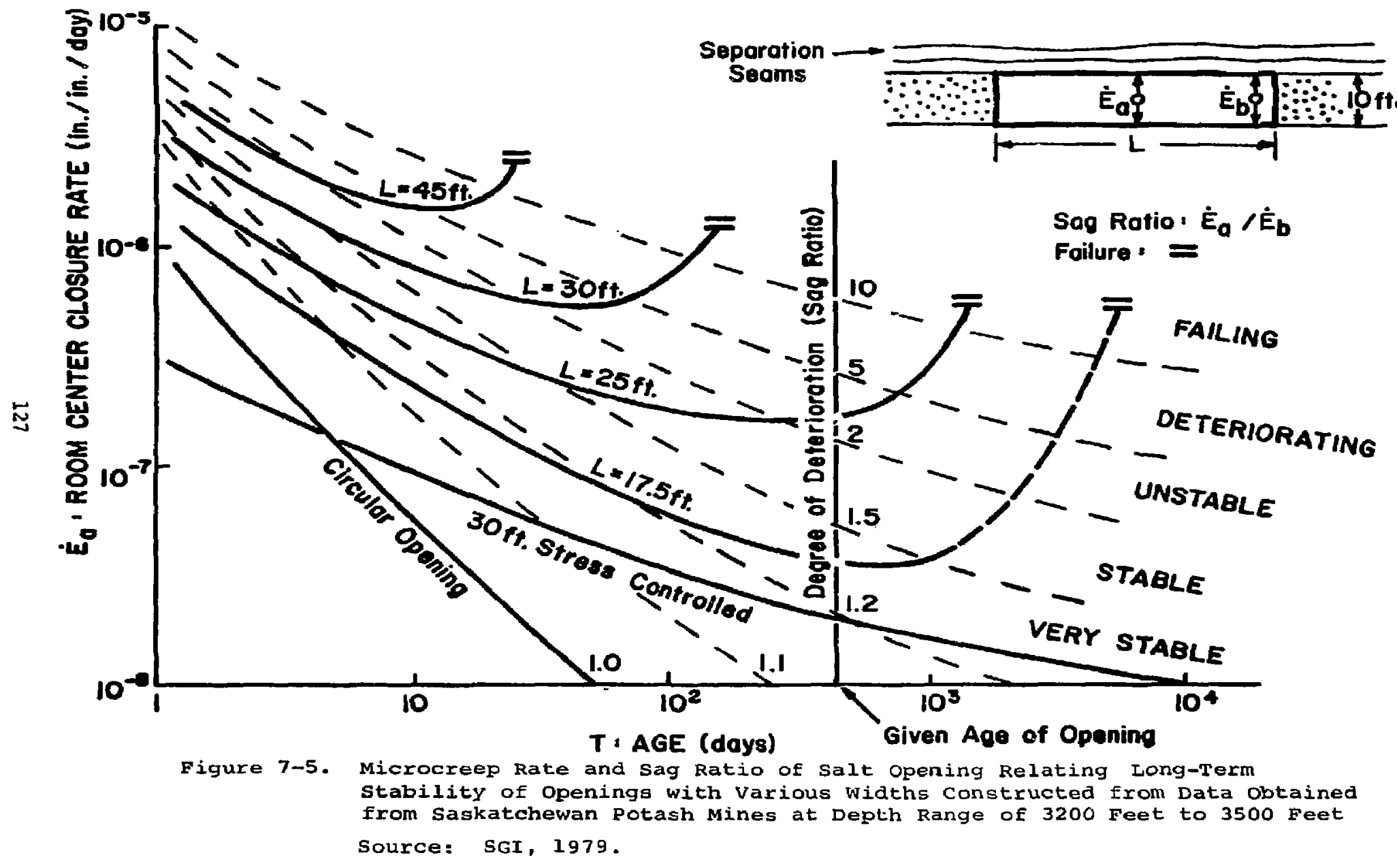


with internal creep measurements. The measurements are made at different depths in boreholes drilled into the roof, floor, or wall in question. The measurements will disclose where and how the separation and expansion of the critical media are taking place. A stable roof, for instance, is indicated by an extrenely small expansion creep rate uniformly distributed throughout the entire roof formation with no indication of any strata separation. For further detailed evaluation, the strain distribution pattern may be analyzed with the rheological finite element computer simulation, utilizing the constitutive equations presented in Chapter 4.

\subsection{Pillar Deformation and Failure}

Most pillars created in underground salt formations appear competent and flawless following initial excavation. However, creep defomation of the opening causes gradual deterioration and eventual failure of the wall of the face of the pillar. Pillar failure ranges from minor surface spalling to large-scale vertical sloughing. Regardless of their sizes, all salt pillars are expected to deteriorate to a certain extent, depending upon their designs. Surface deterioration advances inwarc̈ with variable speed according to the loading conditions of the pillar. This progressive state of surface deterioration can be accurately determined by internal creep measurements using Extensometers. For quick, high-resolution measurement, the Microcreepmeter can 
be used. For long-term observation, a permanent internal creep measuring station should be installed as previously illustrated in Figure 7-2. An example of pillar leterioration measirement is illustrated in Figure 7-6. As shown in the diagram, the magnitude of the creep strain varies widely with the pillar dimensions. Damage to the wall becomes apparent when the cumulative creep strain exceeds several percent, according to field observations.

\subsection{Floor Heave and Failure}

Floor heave is a rather common phenomenon in salt openings. F'loor failure occurs in a manner similar to roof failure. Although floor failure is not a direct threat to safety, it can cause substantial disruption of operations. The potential floor heave can be determined immediately following initial excavation in the same manner that roof failure is determined, by utilizing a Microcreepmeter. If Microcreepmeter measurements indicate the existence of failure potential, long-term observation should be conducted by replacing the Microcreepmeter with a permanent Extensometer station.

\subsection{Surface Subsidence}

The closure of underground salt openings does not necessarily cause surface subsidence. Usually, a significant amount of surface subsidence does not occur until the lateral extent of ground excavation exceeds twice the total thickness of 


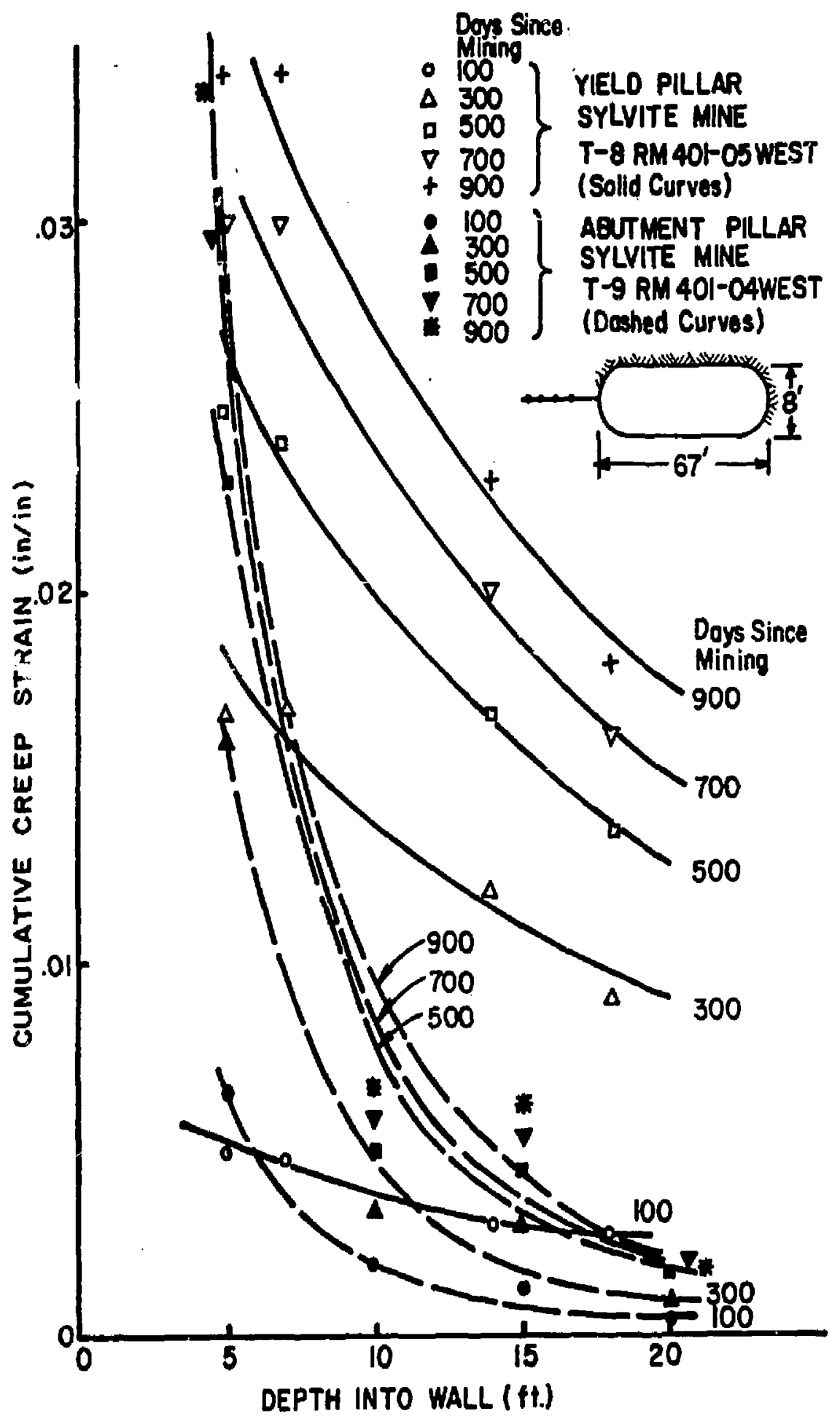

Figure 7-6. Pillar Deterioration with Time: Cumulative Creep Strain versus Depth Into Pillar 
the solid portion of the overburden formation overlying the salt formation. The initial delay of the subsidence is due to the formation of a stress envelope surrounding the entire excavation of the salt opening. The subsidence starts appearing on the surface when the envelope's expansion upward reaches beyond the load-supporting formation. The stress envelope loses its ability to support the overburden weight near the surface, resulting in surface subsidence, $\Delta S$. This condition is illustrated in Figure 7-7. The amount of surface subsidence is related to room closure, floor expansion, roof expansion, and the relaxation of the upper strata in the following manner as also illustrated in Figure 7-7:

$$
\begin{aligned}
\Delta H=\Delta F & +\Delta R+\Delta X+\Delta S \\
\text { Where: } \Delta H & =\text { room closure; } \\
\Delta R & =\text { roof expansion; } \\
\Delta F & =\text { floor heave; and } \\
\Delta X & =\text { deep separation. }
\end{aligned}
$$

The expansions by relaxation of the roof, $\Delta R$, and floor, $\Delta F_{,}$can be measured underground by Extensometers. The surface subsidence, $\Delta s$, can be monitored accurately by installing a long baseline surface-level measuring system. The dynamics of the entire overburden creep behavior of Equation 7-1 may then be analyzed by creep rate measurement from the relation:

$$
\Delta H / \Delta t=\Delta F / \Delta t+\Delta R / \Delta t+\Delta X / \Delta t+\Delta S / \Delta t
$$



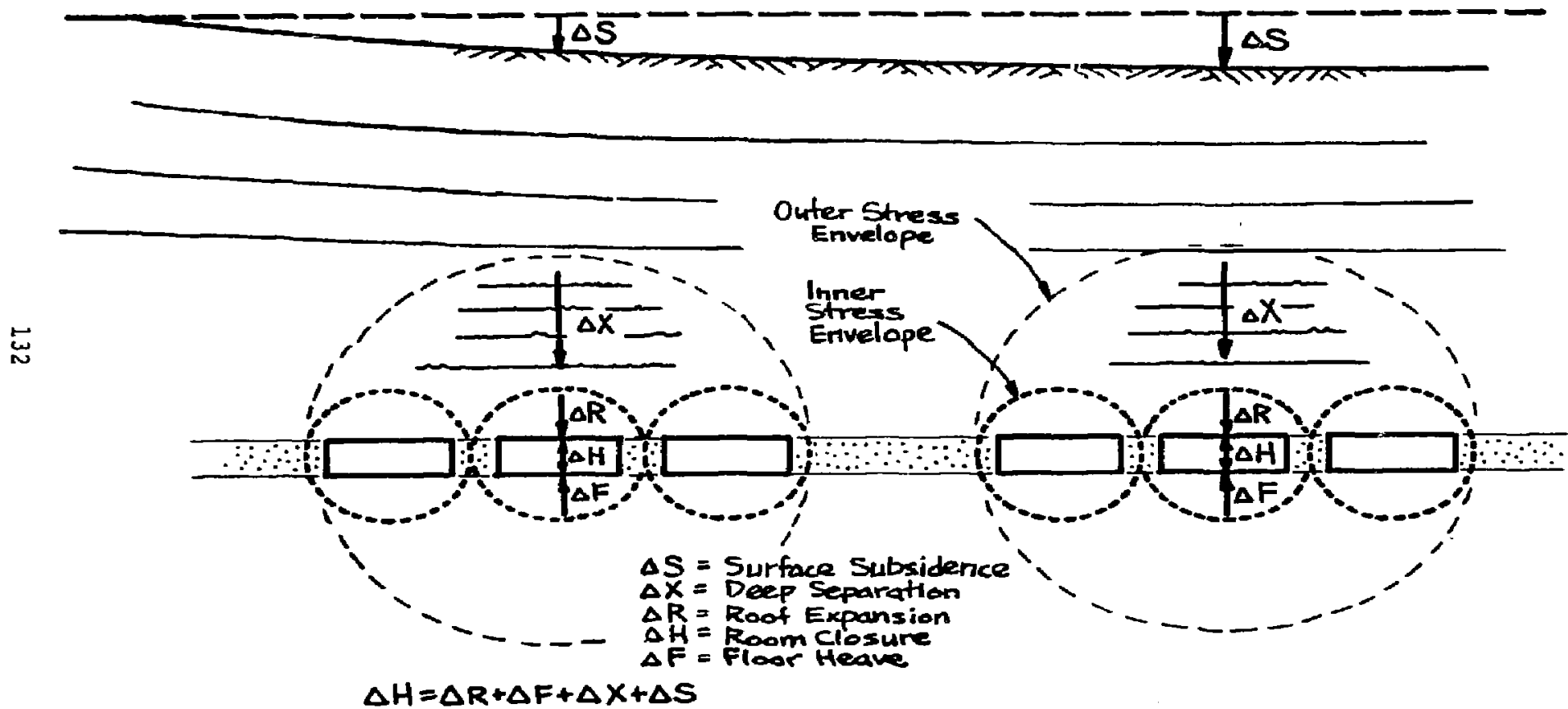

Figure 7-7. Illustration of Surface subsidence, Deep Separation, Roof Expansion, Room Closure, and Floor Heave.

Source: SGI, 1979 . 
This relation is utilized to identify the degree of timedependent deterioration of the overburden strata, $\Delta x / \Delta t$, from the following relation in which all the right-hand side rerms of the equation are measured:

$$
\Delta X / \Delta t=\Delta H / \Delta t-\Delta F / \Delta t-\Delta R / \Delta t-\Delta S / \Delta t .(7-3)
$$

A wide range of $\Delta x / \Delta t$ values has been observed. In the Saskatchewan potash mines, for instance, the range is found to be 0 to 40 inches per year. The magnitude of the value reflects the intensity of strata separation caused by underground excavation. 


\subsection{Tectonic Stress Field and its Measurement}

The initial tectonic stress field in a bedded salt formation should fall in a certain range which is determined by two specific factors. The first is the geological factor of overburden pressure, $\sigma_{V} ;$ and the second is the material factor of octahedral strength, $k_{0}$, of rock salt. The vertical component of the stress field may be considered to be equal to the overburden pressure, $\sigma_{\mathrm{V}}$. The lateral principal stresses, $\sigma_{L}$, are in the horizontal plane in the salt formation and may rot be equal to $\sigma_{\mathrm{V}}$. The following equation derived from elastic theory is used by some investigators to relate the overburden stress to the horizontal stresses:

$$
\sigma_{L}=\frac{v}{l-v}{ }^{\sigma} \mathrm{V}
$$

where $\nu=$ Poisson's ratio.

Salt is not an elastic medium and this equation is not generally valid. There is no specific relationship between $\sigma_{\mathrm{V}}$ and $\sigma_{L}$

The lateral stresses expected in the salt formation should fall within the following range, which is derivet from the basic constitutive equations of chapter 4 . 


$$
\sigma_{L}=\sigma_{V} \pm \frac{3}{\sqrt{2}} K_{O}
$$

where: $k_{0}=$ octahedral shearing strength.

This relationship indicates that lateral stresses can be greater or less that the overburden pressure, $\mathrm{P}_{0^{\prime}}$ by up to the maximum amount of $3 \mathrm{~K}_{0} / \sqrt{2}$. This means the ratio of lateral stress to vertical stress will theoretically range from $-\infty$ to $+\infty$ near the surface; and the range reduces with depth increase, approaching toward 1, as shown in the following relationship illustrating the significance of the viscoplasticity of the material:

$$
\begin{aligned}
& \lim _{P_{O} \rightarrow 0} \frac{\sigma_{L}}{P_{O}}=\lim _{P_{0} \rightarrow 0} \frac{P_{O} \pm 3 K_{O} / \sqrt{2}}{P_{O}}=-\infty \sim+\infty \\
& \lim _{P_{0} \rightarrow \infty} \frac{\sigma_{L}}{P_{O}}=\lim _{P_{0}+\infty} \frac{P_{O} \pm 3 K_{0} / \sqrt{2}}{P_{O}}=1
\end{aligned}
$$

Based on the stress equilibrium relationship of Equation 8-2, the stress field condition expected in a bedded rock salt formation as well as surrounding sedimentary rocks is formulated as illustrated in Figure 8-1. The figure shows that the lateral stress in any strata will be found within the region defined by maximum and minimum lateral stress conditions. The magnitude of deviation of the lateral stress from the hydrostatic state varies greatly depending upon the octahedral shearing strength of the material, $\mathrm{K}_{0}$. The 
$\sigma:$ EARTH STRESSES

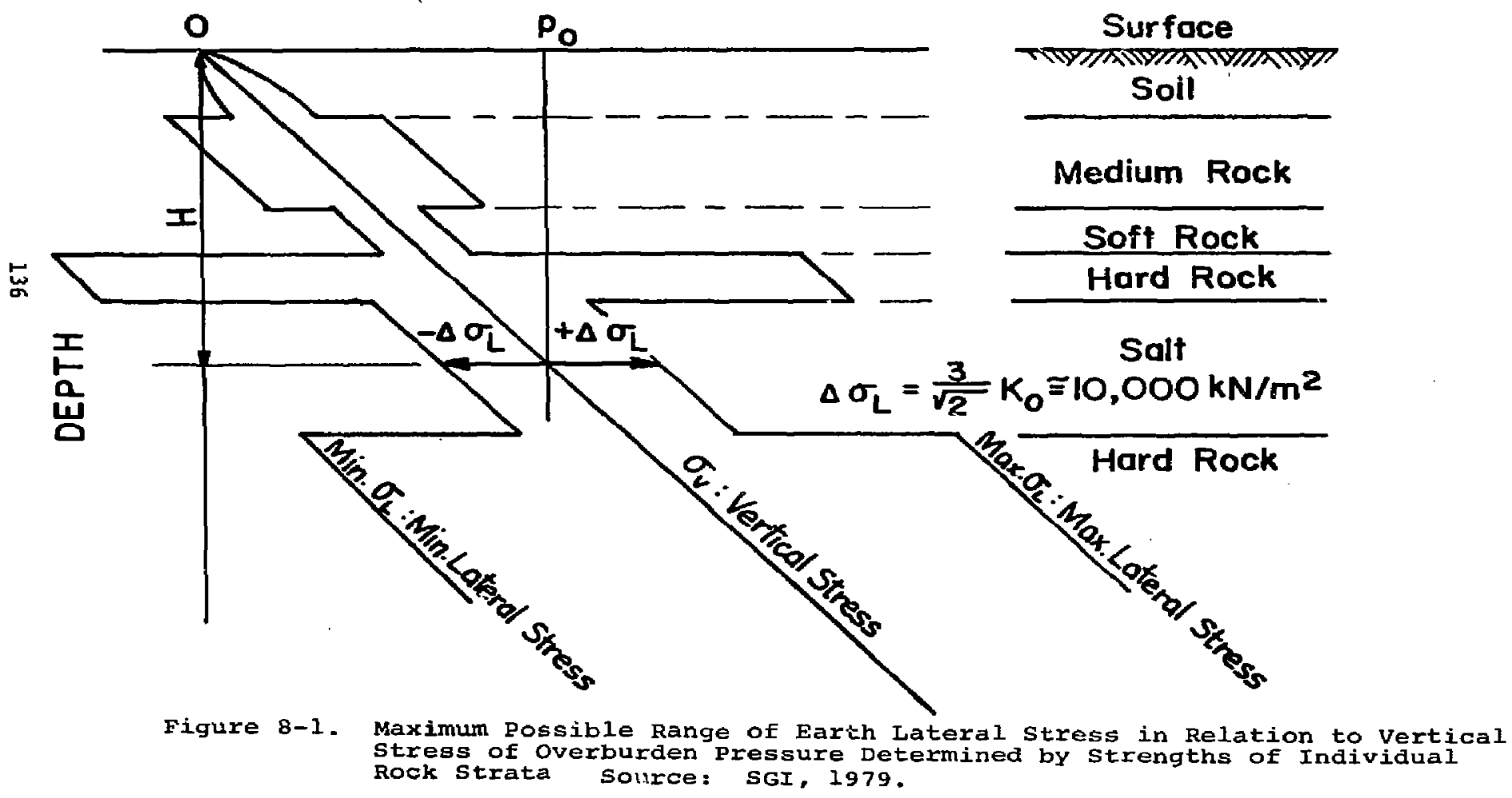


figure illustrates that a discontinuity at the boundary between rock salt and adjacent hard rock could be expected. It also indicates a definite possibility for tension to exist in hard rock immediately overlying rock salt which is subjected to compression. From this analysis, it is apparent that in computer simulations the full range of lateral stress variation should be taken into consideration. Computer analyses show that the magnitude of lateral stress has a significant effect upen long-term stability of the salt opening. In actual development of salt openings, measurement of lateral stress will be very important in relating observed behavior of the salt opening to the computer model. The proper initial lateral stress magnitude is necessary for an accurate long-term computer prediction.

\subsection{Stress Distribution in Roof and Floor}

Roof failure and floor heave are the major problems in securing the long-term safety of salt openings for storage purposes. Roof failure and floor heave are similar in mechanism and are caused by the stress envelopes developed around the openings. Therefore, measurement of the stress distribution pattern in the roof and floor is essential to accurately determine the long-term safety of salt openings. On the other hand, measurement of creep deformation in the roof and floor is more pertinent to determine the current safety of the openings. The stress distribution pattern in the roof and floor of an opening at a given depth is strongly 
affected by lateral stress, geology of the surroundina around, and the geometry of the openings. Any irregularity in the ground, such as clay seams and discontinuity planes, tends to lead toward eventual failure of the roof and floor. Geometry of the opening's cross section has a profound effect upon the stress distribution pattern which could be utilized to eliminate potential failures induced by geological irregularities; this technique of eliminating the failure is presented as the Stress Control Technique in Chapter 10.

A typical stress distribution pattern to be expected in an opening is graphically illustrated in Figure 8-2. Shown in this diagram are the stress envelope and tangential and radial stresses in the roof media at two different times: (1) the condition immediately following the initial creation of the opening; and (2) eventual stability accomplished after substantial creep deformation and subsequent stress relief. At Condition 1 following the excavation, a large tangential stress is found in the roof, as shown by the large value of $\sigma_{\theta}$. It is this tangential stress which gradually causes the roof to deteriorate and forms slab separation. This process de-stresses the immediate roof and displaces the stress envelope outward to Condition 2. The tangential and radial stresses in the immediate roof are not only reduced, but also discontinuities of the tangential stress develop. When slabs are formed and start separating, 


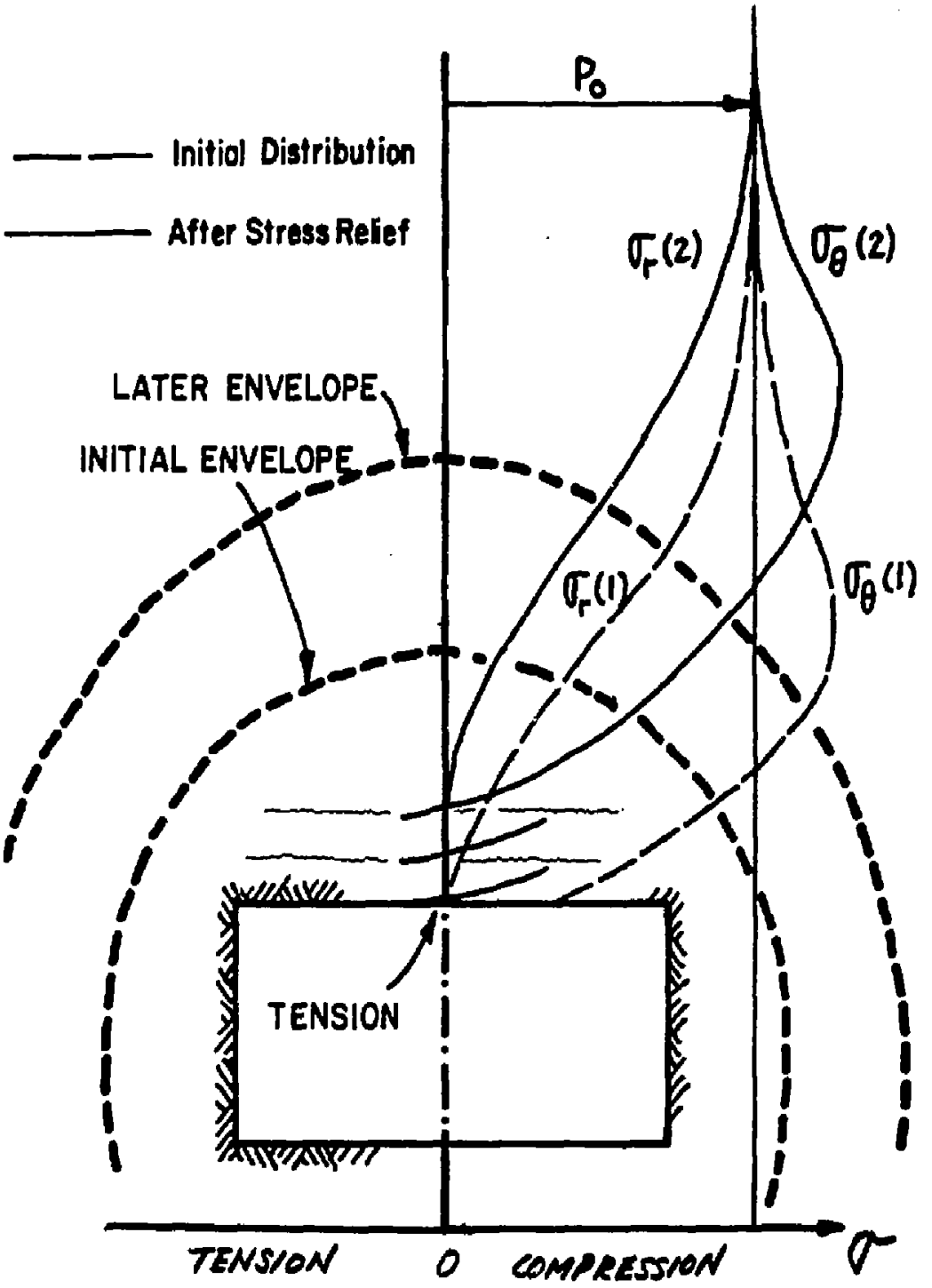

Figure 8-2. Stress Distribution Change over Roof Formations in Relation to Stress Relief

Source: SGI, 1979. 
tensile stress may develop which results in the appearance of cracks in the face of the roof, as illustrated in the figure.

For safe design of a storage opening, slab formation should be eliminated by controlling the stress distribution pattern around the opening. This can be accomplished effectively by properly selecting the cross-sectional form of the opening as well as controlling of the timing of excavation. This technique of stress control is described in detail in Chapter 10. Whatever the actual stress condition may be, it is important to identify the stress condition to accurately assess the degree of stability for the long-term safety of the storage opening.

\subsection{Stress Distribution in Pillars}

Stress conditions in salt pillars are found to vary widely, depending upon the size and arrangement of the pillars. The stress distribution pattern of the pillar has a profound effect upon the long-term stability of the rooms next to the pillars. The results of extensive field measurement of the stress distribution pattern in pillars in salt and potash mines relate the stress distribution pattern to the long-term stability of salt openings. 
Stress distribution in a wide pillar is characterized by the development of two separate stress peaks near the pillar boundaries. These peaks indicate the location of the stress envelopes of the two openings on both sides of the pillar, respectively, as shown in Figure 8-3. The larger the pillar size, the less the interference between these two peaks. In pillars with two clearly isolated stress peaks, further increase of the pillar width has very little effect upon the surrounding room stability.

When the pillar width is reduced, interference between the two peaks starts taking place, and eventually the two peaks overlap to form a single intensified stress peak with its peak position at the cnter of the pillar, as shown in the same figure. The size of the pillar becomes critical when the two stress peaks overlap, resulting in formation of the maximum stress peak. The maximum single stress peak causes maximum destrughtive effects to the roofs of the openings on both sides of the pillar. Further reduction of pillar width from the critical dimension will result in a significant reduction of the stress in the pillar, also shown in Figure 8-3. Under this condition, the pillar yields and the stress is removed from the pillar and redistributed to the ground surrounding the room and pillar system. This pillar is identified as a yield pillar. 


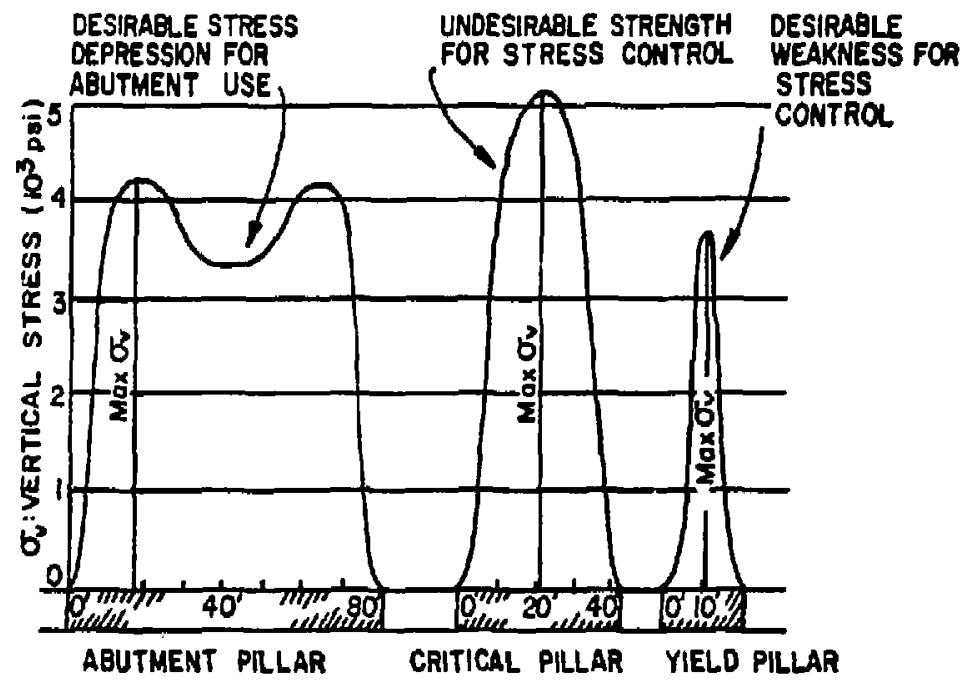

Figure 8-3. Comparison of Three Different Vertical stress Distribution Patterns in Salt Pillars Demonstrating Functional Mechanism of Yield, Critical, and Abutment Pillars. Developed in Saskatchewan Potash Mines, Depths Ranging 3100 - 3500 Feet.

Source: SGI, 1979. 
The critical pillar creates the most damaging effect to long-term stability of salt openings. Therefore, the critical pillar size should be avoided by careful design. Use of the yield pillar is effective in stabilizing salt openings which otherwise cannot be stabilized, and is especially effective in reducing creep deterioration of weak strata found above the roof and below the floor of an opening in bedded salt. The dimensions of a critical pillar are specific to the individual ground condition, and particularly to the strain sensitivity of the roof strata of the openings. The rheological finite element computer method is found most useful in calculating critical pillar size for a given ground condition. The importance of the pillar effect upon strain-sensitive salt openings is illustrated by a comprehensive sumnary of mine studies conducted in a number of salt and potash mines in North America at depths ranging from 1500 to 3000 feet. The stability of rooms was studied in relation to the size of the pillar, with a wide range of relative dimensions of rooms and pillars. The stability of surrounding rooms is related to the size of the abutment pillar, as shown in Figure 8-4. In this diagram, the pillar width, $L$, is related to the stability of rooms next to the pillar; expressed by the period of safety of the room opening in years. Any increase of pillar width beyond 10 times the pillar height $(10 \mathrm{x}$ ) has very little effect upon the room stability, as shown in the figure. 


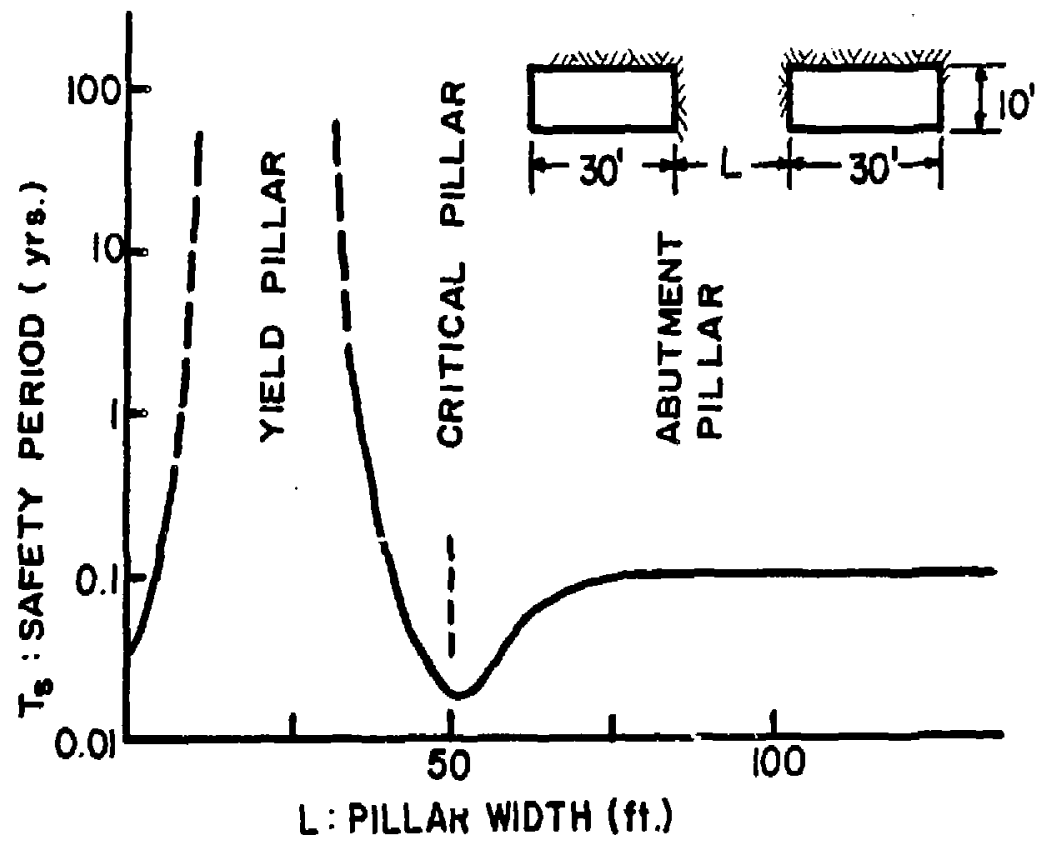

Figure 8-4. Summary of Experimental observation Relating Safety Period of Multiple Salt Openings and Size of Separating Pillars, Identifying Dimension of Yield, Critical, and Abutment Pillars Developed in Saskatchewan Potash Mines at Depths Ranging 3200 - 3500 Feet

Source: SCI, 1979. 
The worst roof condition corresponds to a pillar size of approximately $5 \mathrm{x}$. This is the critical pillar size. Yield pillars are found to be in the range of (I $\left.{ }^{*} 3\right) \times \mathrm{H}$ for this ground. At zero pillar width, the room width will double and the safety period is considerably shorter than the room with large pillar width.

\subsection{Stress Measurement in Rock Salt Formation}

Conventional methods of overcoring or hydrofracturing are not applicable for measurement of stress in rock salt formations. These conventional methods are based on the theory of elasticity, while rock salt behavior is dictated mainly by its nonelastic properties. Because of the importance of stress measurements in situ, a practical method of measuring stress in rock sait formations was developed by Serata over the past 10 years. Usefulnes's of the method has been demonstrated from its field application in various salt and potash mines in the United States and Canada. This measurement method is based on the rheological principle rathe: t'ian elastic or hydrofracturing principles. I schematic diagram of the stressmeter is shown in Figure 8-5. The probe is cylindrical in form and consists of pressurized and non-pressurized sections. The probe is deformed beyond the point of yielding by applying pressure to its pressurized section. The deformation of the borehole in the three-dimensional configuration is then measured by means 
HYORAULIC a

ELECTRICAL ( CONNECTIONS

echuredowe
PRESSURIZED
SECTION

\section{NON-FRESSURIZED} SECTION
DISPLACEMENT

TRANSDUCERS

.

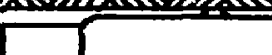

$\stackrel{5}{\sigma}$

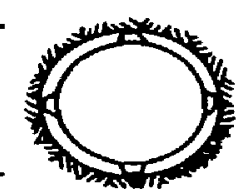

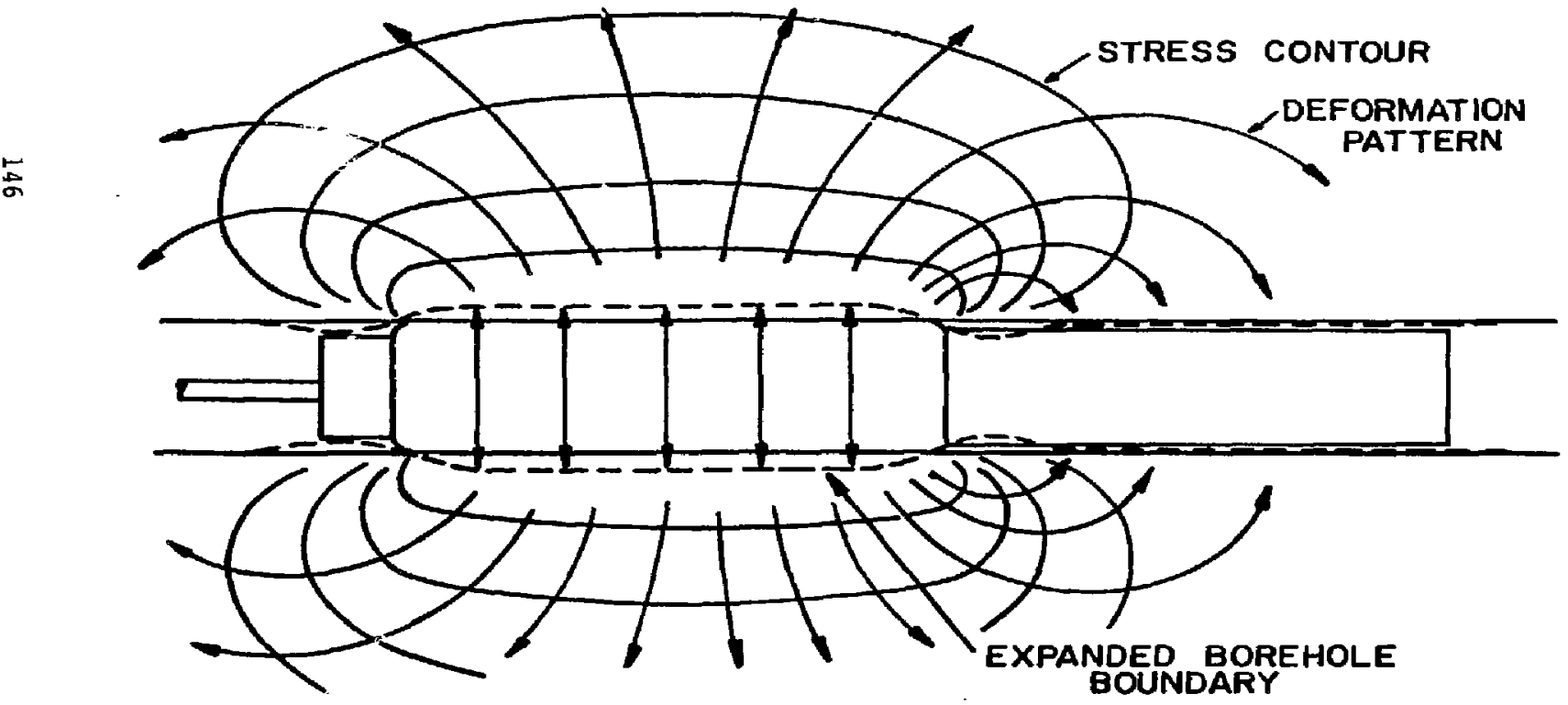

Figure 8-5. Schematic Illustration of stress Measuring system, Consisting of Pressure Regulated and Non-Pressurized Chambers, for Measuring Stress State Through Single Hole in Elastic and Nonelastic Ground Source: SGI, 1979 
of high-resolution transducers which are placed in the pressurized and nonpressurized sections of the probt. By knowing the rheological properties of the surrounding salt formation, the three-dimensional rheological deformation response of the borehole can be related to the in-situ stress field by use of the rheological finite element computer method.

The typical response of nonelastic rock salt to stressmeter loading is illustrated in Figure 8-6. The curves show borehole deformation resulting from different Stressmeter pressures of $500 ; 10,000$; and $20,000 \mathrm{psi}$, respectively. In this example, two different in-situ hydrostatic stresses of 500 and 10,000 psi are compared. At the low in-situ stress of 500 psi, the deformation observed in the nonpressurized section is very small; however, it is very much greater for the higher in-situ stress condition. Conversely, the pressurized section experiences large creep deformation under small in-situ stress and small deformation under large in-situ stresses. This type of sensitivity response allows the Stressmeter to be used for the rapia assessment of in-situ stress distribution in media surrounding a sait openiny. A typical example of the stress conditicis measured around multiple rooms in a multiple room entry system in a potash mine at the depth of 3200 feet is illustrated in Figure 8-7. The load-bearing mechanism of the small yield 


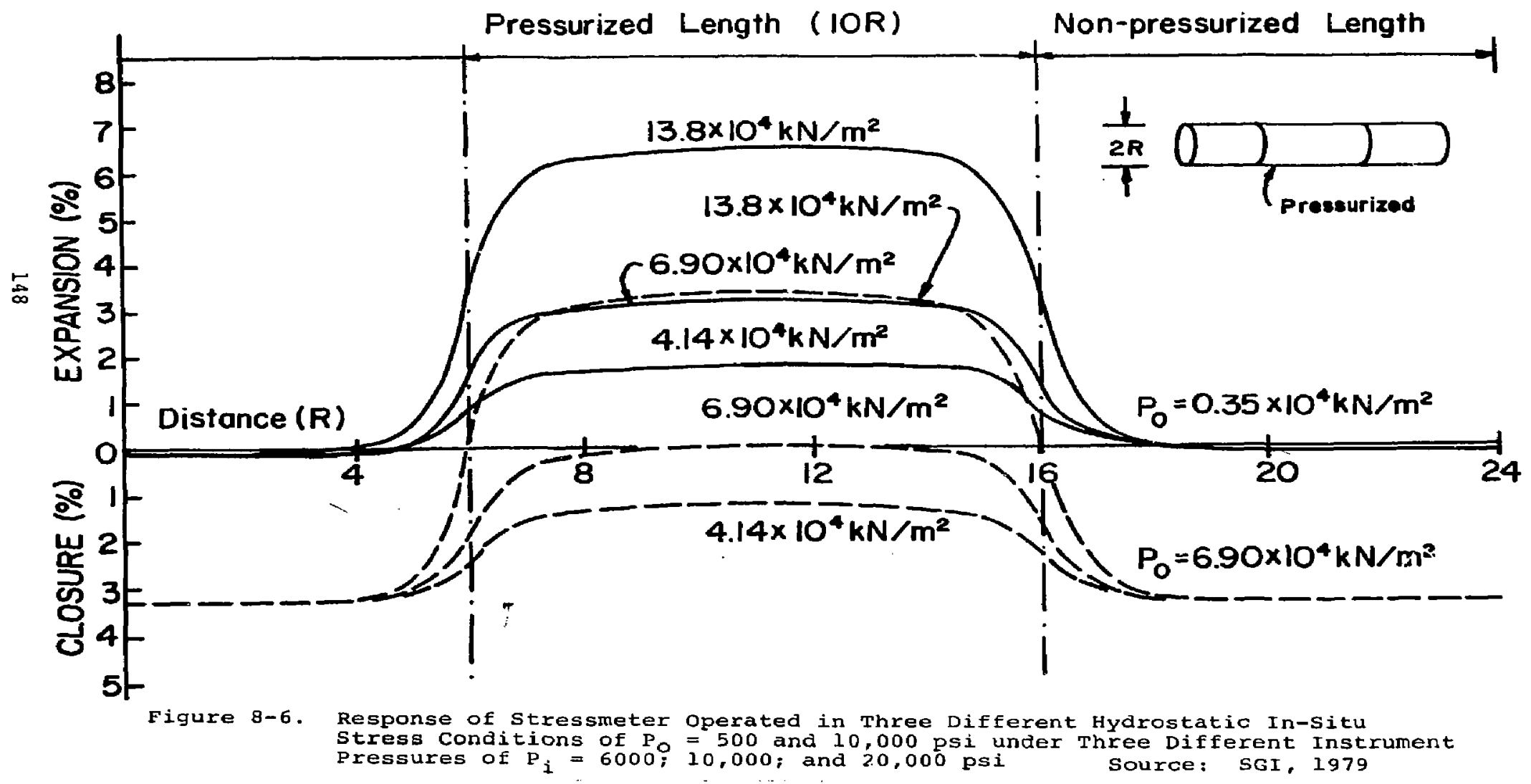




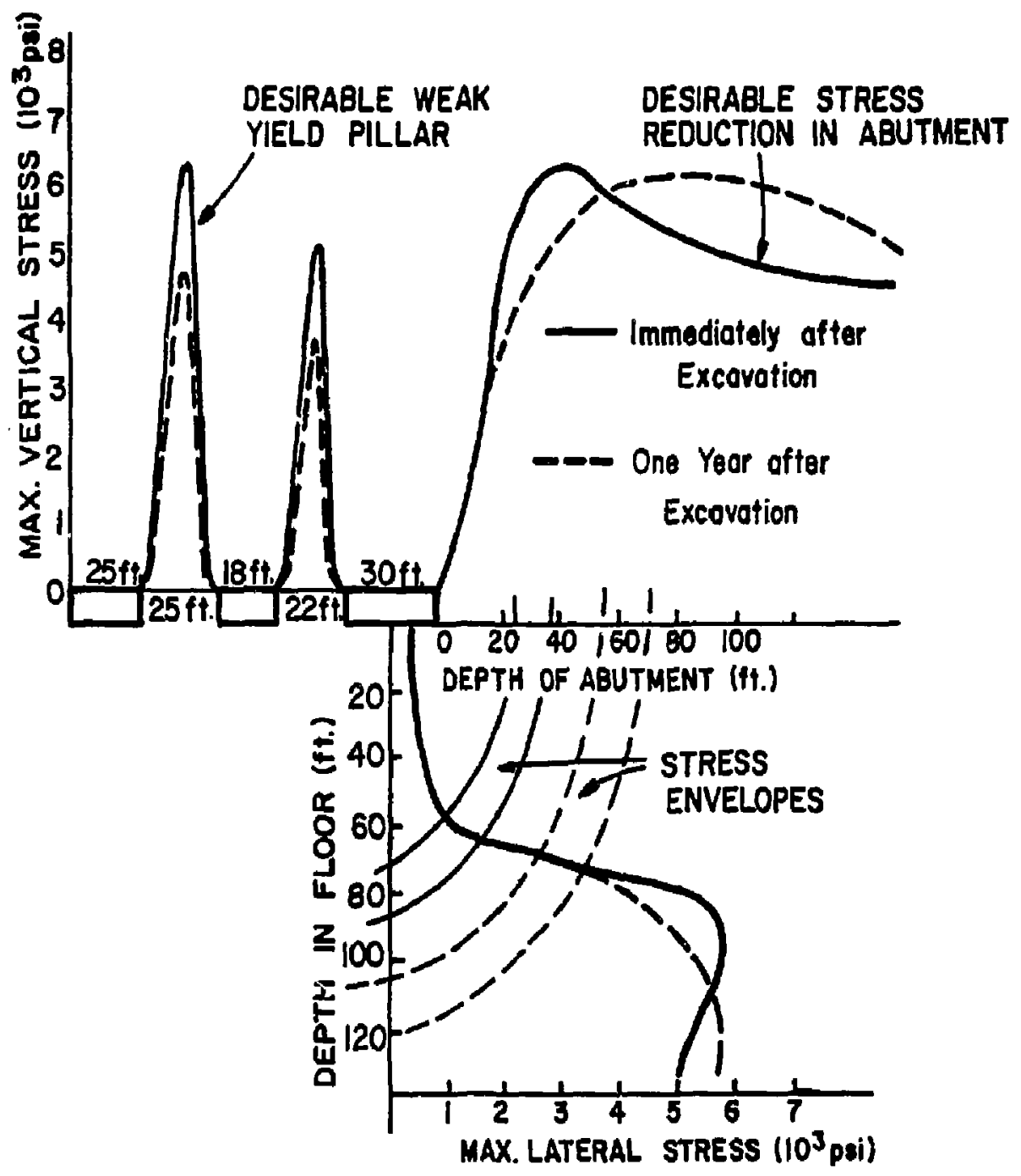

Figure 8-7, Time-Dependent Change in Distribution Patterns in 5-Room Entry in One of Saskatchewan Potash Mines at Depth of 3200 Feet Illustrating Function of Yielding Pillar, Formation of Stress Envelope, and Mechanism of Establishing Long-Term Structural Stability of Multiple-Room Entry System

Source: SGI, 1979. 
pillars and the abutment pillars of the entry system is revealed by this stress distribution pattern. The overall distribution of the stress around the three-entry system and the location of the protective stress envelope are also shown. The reliability of this method has been established by relating three different methods of calibration: (1) overburden pressure of salt formation; (2) laboratory model studies; and (3) computer simulation analysis. The average accuracy of the measurement is in the order of \pm 15 percent, which is adequate for the purpose of rock mechanics studies of salt openings. 


\subsection{EVALUATION OF GEOLOGICAL FACTORS AFFECTING STABILITY OF SALT OPENINGS}

There are three important geological factors affecting the long-term stability of openings made in a bedded salt formation: geological stratification, the in-situ stress condition, and geological anomalies. The anomalies include faults, solution channels, collapse structures, water and gas pockets. The critical stratifications are discontinuity planes which become weakness planes to the prospective openings. A geological examination should determine the geometry of the strata; then the geomechanical characteristics of the strata need to be examined. The vulnerability of the discontinuity planes increases with an increase of the lateral stress, $\sigma_{L^{\prime}}$ in the salt formation. Occasionally, water and gas are encountered in bedded salt formations; these geological factors are evaluated and measures to minimize their deteriorating effects are described.

\subsection{Stratification}

Geological stratification in a bedded salt formation requires close examination to determine its structural effect on prospective openings. This examination should focus on the geomechanical propeities of various strata above and below the openings. The strata above the opaning should be examined for potential roof failure, and the strata below the opening should be examined for potential floor heave. Critical strata are mainly discontinuity planes which are vulnerable to the shear stresses induced 
by excavation of the openings. The discontinuity planes include clay seams, separation planes, impurity layers, anhydrite layers, and other rock strata.

The structural effect of a discontinuity plane is determined frem an assessment of three major geomechanical factors: cohesive bonding strength, resistance to shear, and the friction coefficient in lateral sliding. The structural effect of a weakness plane is detemined from two major geological factors: depth of the plane from roof of the opening and magnitude of the excess lateral stress. The importance of the lateral stress and the measuring method employed has already been discussed in Chapter 8 . The distance to the weakness plane can be controlled by properly selecting the elevation of the prospective openings.

Geological examination of the salt formation is important in identifying the lithological nature of the critical strata and discontinuity planes as well as in establishing the sequence of their occurrence. The examination is also important in establishing marker beds for actual excavation of the prospective opening as well as determining the areal consistency of the stratification. The geological examination has an important supporting role for the geomechanical examination, but the geological examination cannot replace a proper geomechanical examination for design of the openings. 


\subsection{Gas and Water}

Both gas and water are frequently encountered in bedded salt formations. Most of the gas and water found in salt and potash mines are usually contained within a small areal extent, and are not usually connected to sources outside the salt formations. Three forms of water are commonly found in salt formations.

Perched water is trapped between layers of salt and is usually pressurized at the level of the overburden pressure. Therefore, it is a common phenomenon that perched water bursts out at full pressure when suddenly encountered. The water pressure tends to decrease quickly with the flow of the water. The rate of flow also decreases, but at a much slower rate. The flow rate $Q$ generally decreases exponentially:

$$
Q=Q_{0} e^{-f t}
$$

where: $Q_{0}=$ initial flow rate; and

$$
f=\text { decay rate of flow. }
$$

Observation of a number of water flows indicates some general flow characteristics. The magnitude of the initial flow zate, $Q_{0}$, reflects the size and proximity of the water source. The greater the $Q_{0}$ value, the closer and larger the source of the water is. The decay rate of the flow also reflects characteristics of the water source. The larger the $f$ value, 
the smaller the size of the water source and the closer the source is. Therefore, water flows with large $Q_{0}$ values and smaller $f$ values are the most important in terms of potential damaging effects. A wide range in values of $Q_{n}$ and $f$ is found, reflecting the random nature of the size of perched water sources. Frequently, the proximity to perched water can be detected from abnormal creep behavior of openings made near the source of the water. Perched water is not initially moving in the underground. However, the development of a water leak at one location in a salt opening can create a sudden flow through fractured roof strata which are damaged by excavation of the salt opening.

Another form of water often encountered in bedded salt formations is dispersed water which is entrapped in granular interstices between salt crystals, and slowly but consistently squeezes out in forms ranging from slight moisture to continuous dripping.

A third form of water is crystal water completely trapped in cavities within single crystals. These fluid inclusions range in size from microns to millimeters. It has been shown (Rradshaw and Sanchez, 1968, abstracted in Isherwood, 1979) that fluid inclusions will migrate in a thermal gradient. The direction of migration depends upon the vapor content of the inclusion. Inclusions with less that 10 percent 
vapor migrate up the thermal gradient, and those with more than 10 percent move down (Anthony and Cline, 1972, in Holdoway, 1974). Migration up the thermal gradient is due to the difference in solubility of salt between the hot and cold ends of the crystal cavity. Ions from the NaCl crystal go into solution at the hot end and drop out at the cold end.

The only form of water which creates any structural stability problem is the perched water. Other water forms could hamper a fadioactive waste storage operation by causing accelerated canister erosion and possibly by carrying away radioactive material.

Gas is found in salt formations where an abundance of shaly materials exists. Often a layer of shale is found to contain numerous gas pockets which are not connected. Such gas pockets are usually widespread, but occasionally a large isolated gas pocket is found in ground next to a large body of a shale-type deposit.

When considering the long-term structural stability of the salt opening, encountering gas is a less serious matter than encounterirg water. Especially important is the fact that gas does not lubricate neighboring strata as water does. However, gas can be a serious hazard because of the danger of explosion or suffocation. 


\subsection{Stress Conditions}

Stress conditions impose direct geological effects upon the long-term stability of salt openings. Stress conditions are imposed by overburden pressure and the in-situ lateral stress. Overburden pressure can be determined from the depth of the opening but the lateral stress has to be measured, as discussed in Chapter 8 . The presence of an excess in-situ lateral stress above the hydrostatic stress state causes serious deformation to the prospective salt openings, according to the finite element analysis conducted by Serata,

The computer analysis indicates an increase of depth has accelerating effects on the deformation of a salt opening. An example is shown in Figure 9-1, which illustrates the total expected creep after 30 years versus depth in a cylindrical opening. A significant increase in the room closure is noted with a depth greater than 2000 feet, because of marked expansion of the plastic region around the opening when the overburden pressure exceeds about 2000 psi.

The effect of the magnitude of in-situ lateral stress is also analyzed by using the rheological computer simulation for a cylindrical opening. Results of the analysis are shown in Figure 9-2. A sharp increase in the closure of 


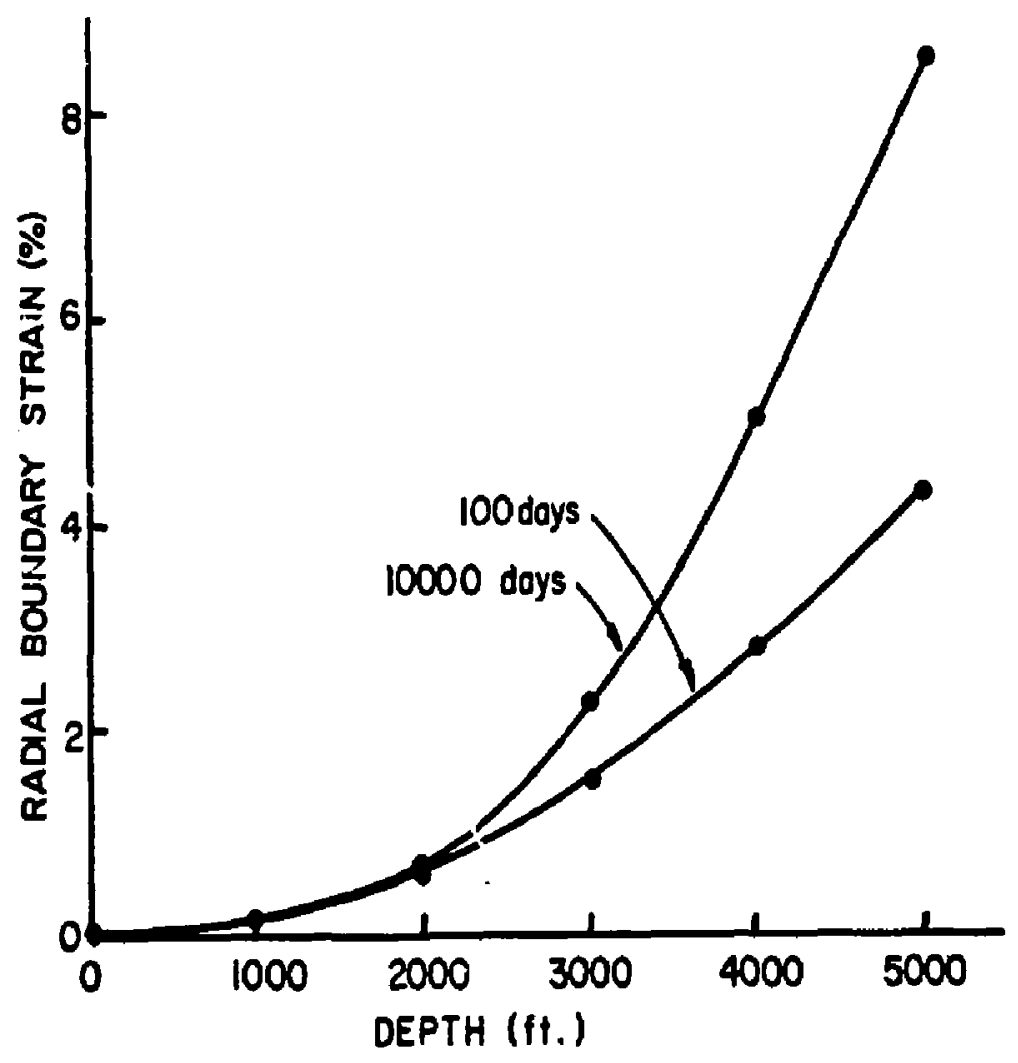

Figure 9-1. Radial closure of Cylindrical salt Opening at Depth of $2000^{\prime}$ at Age of $100 \& 10,000$ Days in Relation to Overburden Depth under Hydrostatic Stress State Computed by Using Rheological Finite Element Simulation.

Source: SGI, 1979.

157 


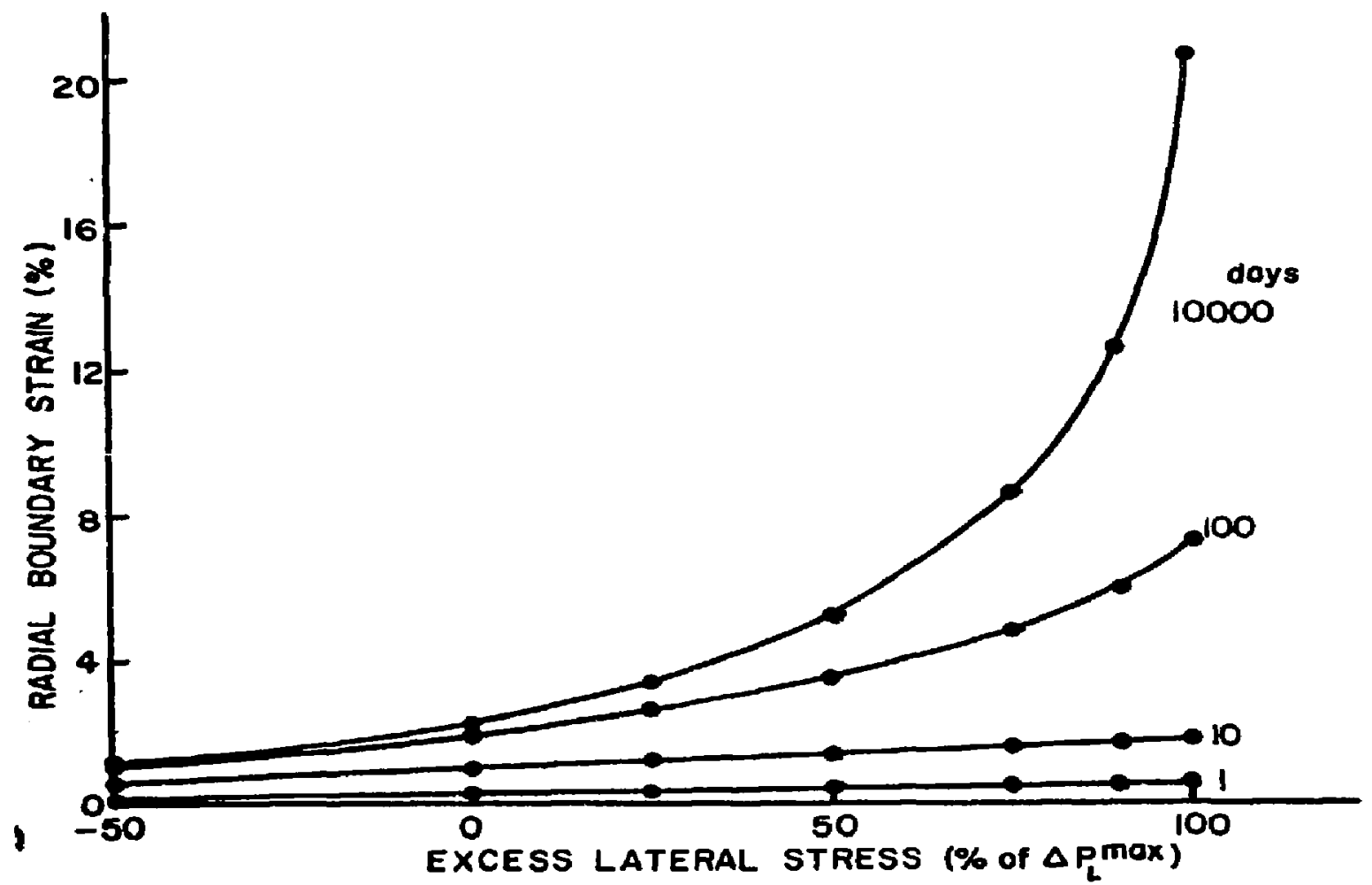

Figure 9-2. Radial closure c. Cylindrical salt Opening at Depih of

$3000^{\circ}$ at Various Ages in Relation to Excess Lateral Stress

Expressed in Terms of Percent of Maximum Excess value of 1200 psi

Source: SGI, 1979 . 
the opening is noted when the excess lateral stress approaches 100 percent of its maximum value, that is $\Delta \sigma_{L}=3 \mathrm{~K}_{0} / \sqrt{2}$ $=i 200$ psi. Results of these computer analyses are found to be in general agreement with underground observations made in bo.h mine openings and solution caverns. It is generally observed in bedded salt formations that openings at depths less than 1000 feet are little affected by the stress conditions, provided that the formations are relatively free from large excess lateral stress. With the depths approaching 2000 feet, openin-s become increasingly sensitive to stratification in both roof and floor. With depths approaching 3000 feet, the room becomes vulnerable even without the presence of weakening strasa. These stability problems caused by the stress conditions may be effectively eliminated by utilizing the Stress Control Technique described in Chapter 10.

\subsection{Design Considerations}

For the design of salt openings, individual discontinuity planes should be studied for thiir potential weakness. Once the discontinuity planes are identified as weakness planes, the structural effect of the weakness planes on the prospective opening should be assessed, first for thei: strength against: potential shear failure and second for their distance from the prospective roof. The closer tha discontinuity plane is, the greater the failure potentia.. 
The failure potential is further assessed by the magnitude of the in-situ lateral stress. The greater the lateral stress, the more vulnerable the planes become, provided that the dicontinuity planes are laterally stratified. The planes are found to te particularly sensitive when the lateral stress exceeds the hydrostatic stress.

The nature and condition of the weakness planes dictate the design of the openings. The width of the openings is affected $i_{\text {, }}$ the distance to the shallowest weakness plane. As a genera] rule for salt formations in the depth range of 2000 ts 3000 feet, the room width should not exceed twice the distance to the shallowest weakness plane. For openings at depths less than 2000 feet, the room width can be increased; and for depths in excess of 3000 feet, the roon width should be decreased. The general rule can be further fefined when specifics o the geomechanical conditions at individual

- sites are $\mathrm{kn} 3 \mathrm{wn}$. For further improvement of the design, the Stress Control Technique may be utilized in conjunction with finite element analysis. 
10.0 STRESS CONTROL TECHNIQUE FOR STABILIZING

SALT OPENINGS

\subsection{Principle of Stress Control Technique}

The Stress Control Technique is based on the principle of redistributing natural stress concentration from the boundary of an opering to the inside of the rock media, farther away from the exposed boundary. The removal of the stress causes stress relief in the media immediately above and below the roof and floor of the opening. once the concentrated stresses are removed from the most vulnerable regions of the roof and floor, those regions become naturally and permanently stable.

T'he redistribution of the boundary stress can be accomplished by controlling the formation of stress envelopes around individual openings. Control is made possible by regulating the designs of both the cross-sectional forms of individual openings and the dimensions of yield pillars separating neighboring rooms. Three different methods of the Stress control Technique have been established to cover all possible situations expected in bedded salt formations. These methods are sumarized as follows:

1. Stress Relief Method--This method is most effective for ground where there are no apparent weak strata above and bilow expected salt openings. 
The required thicknesses of the competent formations above and below are of the order of the width of the opening to be created.

2. Parallel-Room Method--This method can be applied effectively to ground where weakness of the strata is rather limited.

3. Time-Control Method--This is most useful in ground where weakness of strata is extreme and extensive.

With effective use of the above three methods, singly or in combination, the Stress control Technique is expected to be useful for most conditions to be encountered in salt openings used for storage of radioactive materials. Since the development of storage space requires various functional facilities ranging from single-room entries to multiple rooms with a relatively high-extraction area, all three methods can be utilized in one ground condition. The optimum use of the technique could be enhanced by utilizing the rheological finite element method and the constitutive equations described in Chapter 4.

\subsection{Stress Relief Method in Competent Ground} Narrow rooms suffering extensive roof failure and floor heave may be greatly improved and probably permanently stabilized by increasing rather than reducing room width, providing there are no sensitive separation seams lying 
imnediately above or below the openings. The improvement of the roof anc floor stability can be made substantial by widening the room while maintaining the same height, because of the nature of the stress distribution change caused by widening. The greater the room width, the larger the anount of stress relief created in the ground immediately above and below the opening, as long as clay seams or other discontinuity planes do not interfere with the circular expansion of the stress envelope. The mechanism of improvement of room stability is illustrated in Figure 10-1. The increase of room width with the corresponding circular expansion of the stress envelope results in a large mass of rock media which is stress-relieved and consequently stabilized. In the meantime, the area of highest stress concentration is now located in distant ground where the confining pressure is substantially greater than that at the opening boundary. Therefore, the strength of the rock media itself is greatly increased at the maximum stress zone of the expanded stress envelope. This process alone is usually found effective in stabilizing salt openings which used to fail. The mines which have been utilizing this method effectively for their production are: Diamond Crystal Salt Company's Jefferson Island mine in Louisiana; International Minerals and Chemical Company's Esterhazy Mine in Saskatchewan; and Saskatchewan Potash Corporation's Rocanville Mine in Canada. The 


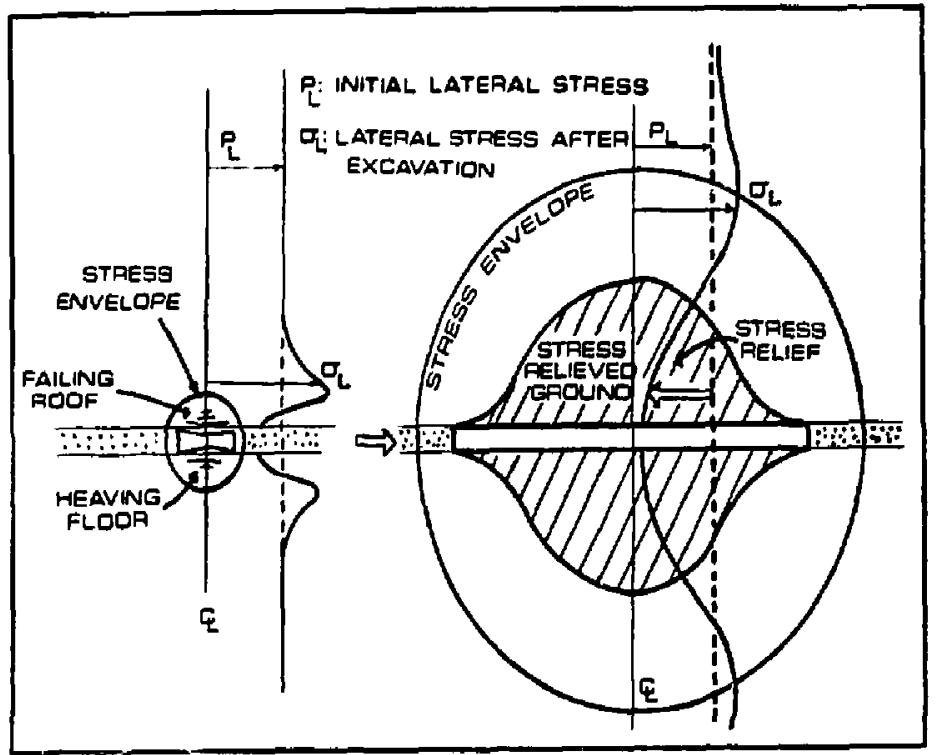

Figure 10-1. Stress-Relief Method of Stabilizing Underground Openings.

Source: SGI, 1979. 
historical development of the expansion of room width with improvement of roof safety in these mines is sumarized in Figure 10-2.

\subsection{Parallel-Room Method in Weak Ground}

In applying the Stress Control Technique to weak ground with separation seams, the Stress-Relief Method is not only useless but also destructive. With the increase of room width, the weak ground will deteriorate more and fail sooner. Therefore, a different approach of the Stress Control Technique is needed in such ground. The Parallel-Room Method was developed for this need. It reguires the excavation of more than one rosin with narrow yielding partition pillars. When roof strata are weak, an assembly of two rooms with a yield pillar between them is found to be more stable than the single room. Excavation of the multiple-room entry in essence results in the same beneficial effect as the Stress-Relief Method, except that weakness of the immediate roof is supported by the presence of one or more of the yield pillars. If all the rooms are intended to be equally stable, they should be extracted simultaneously, mainiaining a line of advancing face of excavation of the parallel rooms.

The Parallel-Room Method is aiso utilized to make selectively safer rooms by excavating the parallel rooms in sequence. 


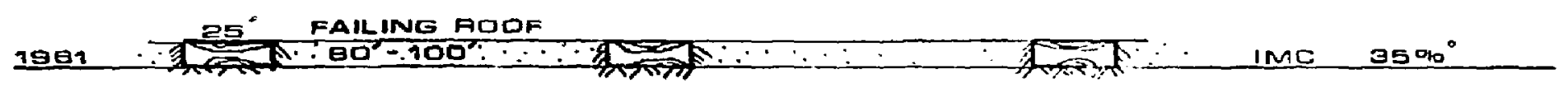
$17.5^{\circ}$ FAILING NOT IMPAOVED

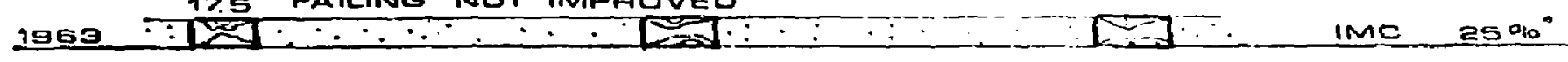
$1989.30^{\circ}$ FAILING GLOWEO DOWN

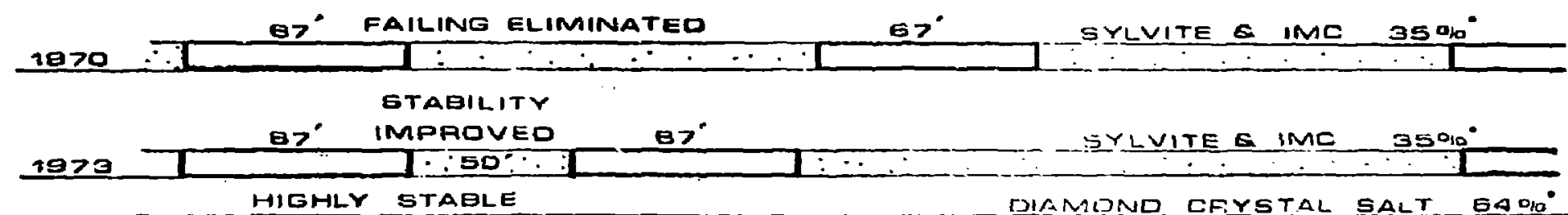
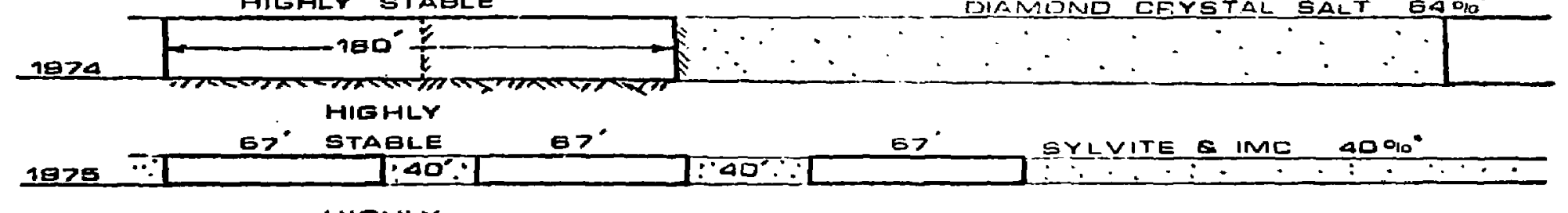

HISHLY

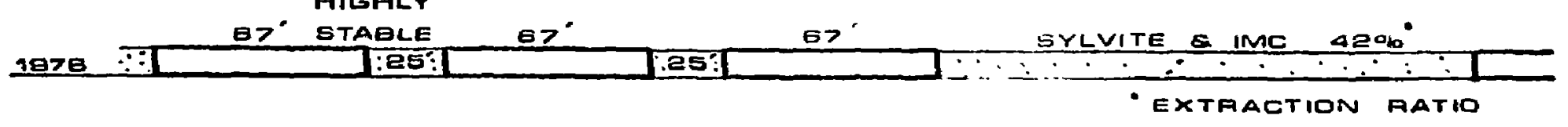

Figure 10-2 Evolution of Mine Entry Design from Failing Room

to Highly stabilized Multiple-Room Entries

Source: SGI, 1979 . 
For example, in a 2-room entry system with a narı sw yield pillar between the rooms, the second room is stabilized at the expense of the first room. Excavation of the second room parallel to the first room causes deterioration of the first room, which results in improvement of the second room by transformation of the two individual stress envelopes into a single secondary stress envelope, as illustrated in Figure 10-3. Inside the stress envelcpe, the stressrelieved ground is formed immediatoly above and below the protected second room, as depicted in the figure. This process can be applied to a multiple-room entry system with more that two rooms. In this case, for example, this process can be applied to a number of openings as illustrated in Figure 10-4. The process of expanding the number of parallel rooms, however, cannot be continued indefinitely. A limit will be imposed by ground deterioration caused by the secondary stress envelope wherever the envelope interferes with weak strata encountered in the upper horizon. The limit of the total width of the assembly should be set by the distance to the interfering strata. Such limitations can be analyzed effectively by utilizing finite element analyses. This approach to ground control has been successfully applied in underground potash extraction in Saskatchewan at the Allan Mine of APM Operator, Inc.: Cominco's Van Scoy Mine; and the Saskatchewan Potash Corporation's Cory Mine. 


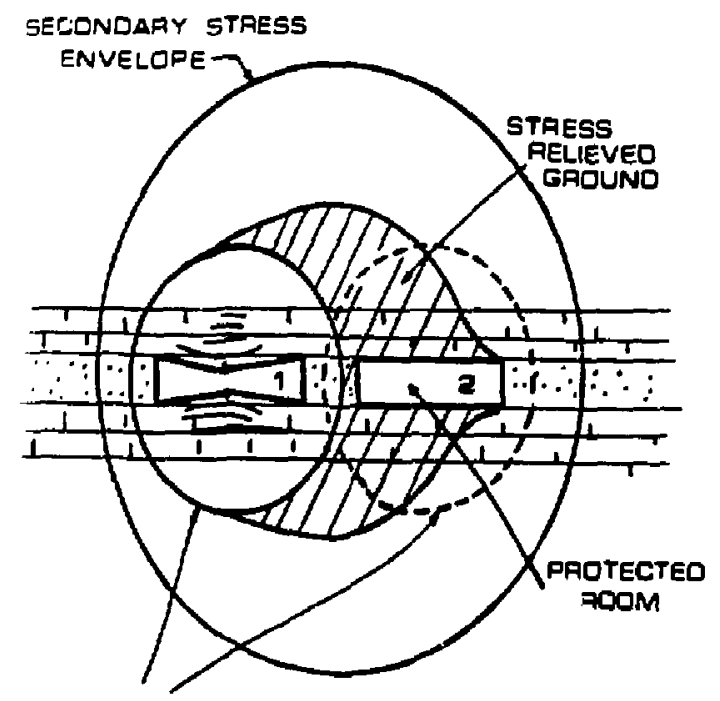

PRIMAGY STRESS ENVELOPE

Figure 10-3, Parallel-Room Method of Stabilizing Underground openings. Note the Formation of a Secondary Stress Envelope.

Source: SGI, 1979. 


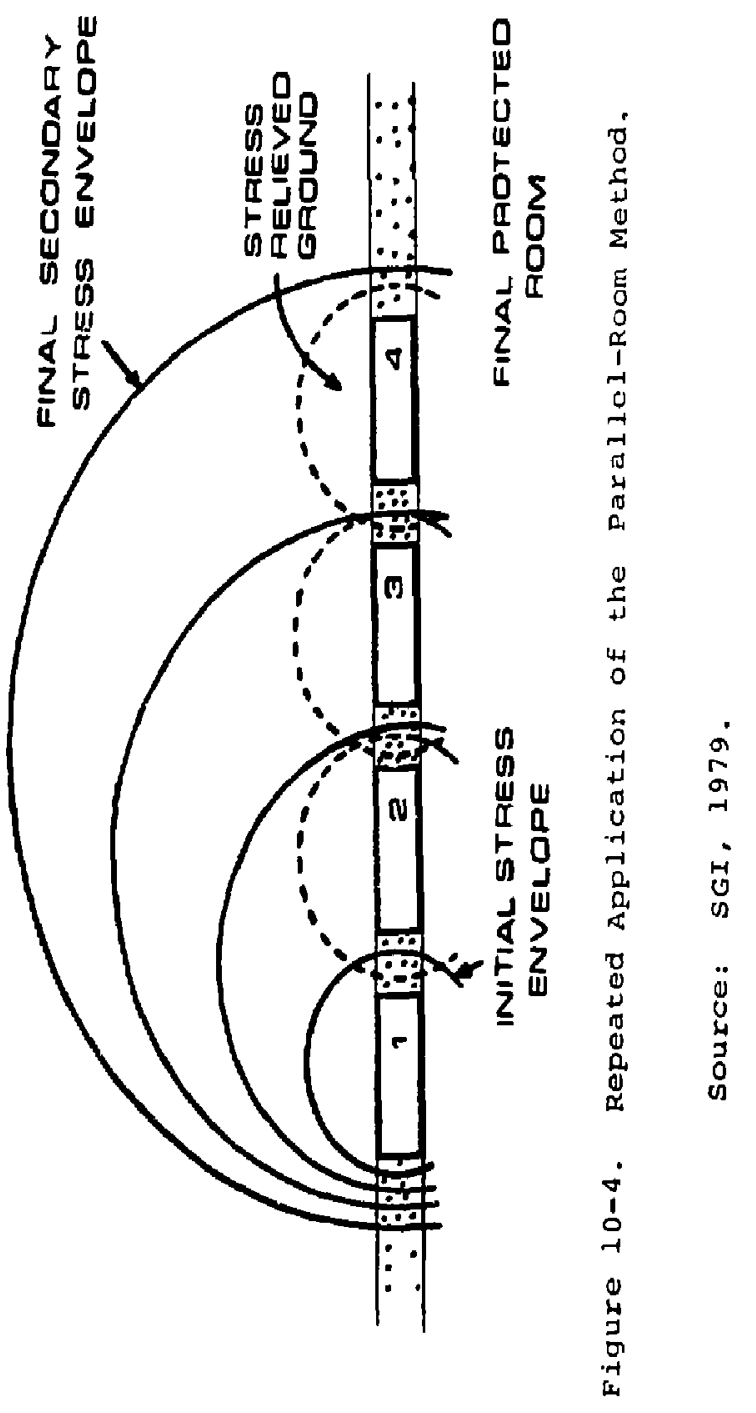




\subsection{Time-Control Gethod in Failing Ground}

The Parallel-Room Method is ineffective for permanently stabilizing ground which contains extremely vulnerable strata above and below the prospective salt openings. In such a case, the Time-Control Method should be utilized to stabilize a failing room which cannot be maintained safely otherwise. This method is based on the same technique of creating stress-relieved ground by the assembly of parallel rooms; however, there is one unique difference, which is the specific time-controlled sequence in excavation of the rooms. Application of the Time-Control Method is illustrated in Figures 10-5 and 10-6. In the first step, shown in Figure 10-5, two rooms are cut sufficiently far apart to allow individual primary stress envelopes to form around individual openings. The spacing Lotween the two openings should be close enough to overload the ground between then and create a strain-hardened ground. A third room, which is to be protected, is excavated between the original two as shown in Figure 10-6. The two pillars thus created start to fail quickly upon excavation of the third room. In the process of failing, however, the three primary stress envelopes surrounding the individual rooms are transformed into a single secondary stress envelope. Formation of the secondary envelope counteracts the failing process of the small pillars and halts the failure as soon as it starts. This results in the creation of a stable 


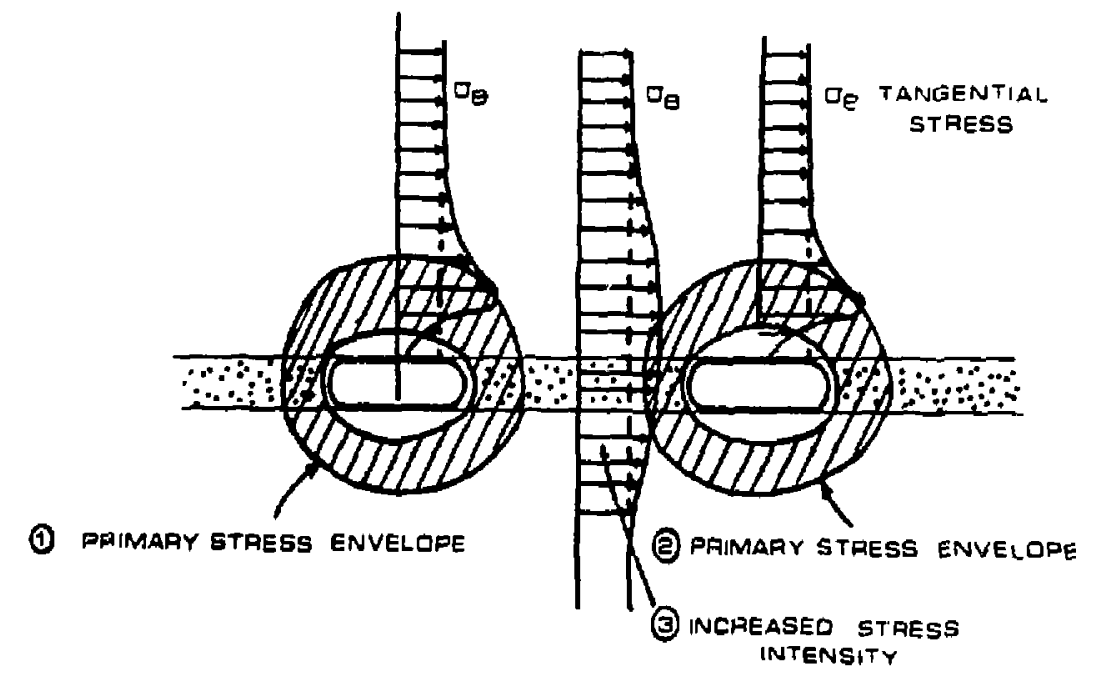

Eigure 10-5. Development of the Two Primary Stress Envelopes during the Initial Stages of Development using the Time-Control Method.

Source: SGI, 1979. 


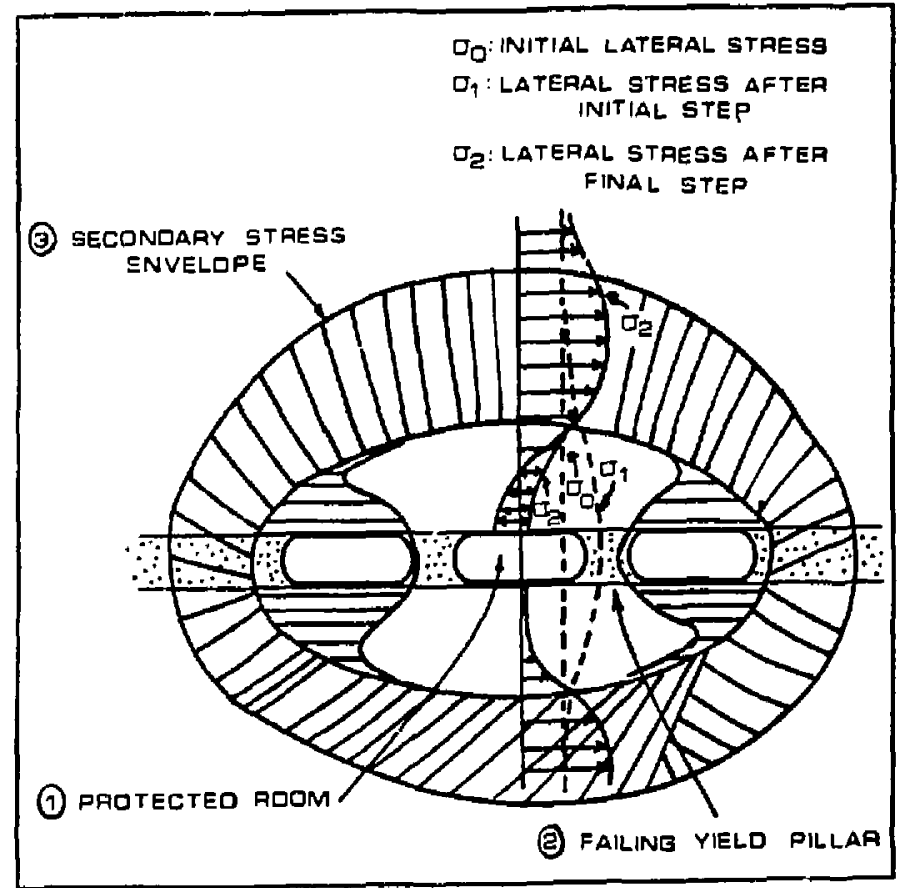

Figure 10-6. The Secondary Stress Envelope Develops when Excavating the Center Room During the Final Stages of the Time-Control Method.

Source: SGI, 1979 . 
equilibrium without pillar failure. The secondary stress envelope surrounding the entire system of 3-room entries stabilizes the center room and concurrently substantially improves the stability of the two outside rooms.

The difference in safety between the center and outside rooms can be controlled by regulating the delay time, $\therefore t$, between excavation of center and outside rooms. The delay time can range from zero to many years. The zero delay time of $i t=0$ means that the three rooms are to be excavated simultaneously, resulting in the uniform stability of all rooms. With an increase of delay time, that is, the center room being cut after the outside rooms with a given time delay, the stability of the inside room increases Ielative to that of the outside roons. It should be noted here that the room stability is a relative matter specific to individual geological conditions and therefore, the uniformly-distributed stability achieved by the zero delay time could provide a sufficiently stable opening in one set. of ground conditions. On the other hand, that stability may not be adequate for other ground conditions. The delay time should be regulated to achieve the required stability of the inside rcom by allowing a controlled deterioration of the outside rooms. The advantage of the Time-control Method is to enable regulation of the stability according to the need and condition of the grourd. The Time-Control 
Method, based on this unique feature of regulating stability, has been patented in the United States and Canada, Patent Nos. $3,673,807$ and 960,048 , respectively.

The three different methods of Stress Control Technicile are compared in the diagram of roof stability versus room width in Figure 10-7. Various ground conditions may be represented by the three solid lines in the figure showing the safety response of a single room in the three categories of ground conditions. The Stress-Relief Method is used only in the uniformly competent ground, as indicated by arrow 1 . The other two ground conditions are weakened by the presence of separation seams and deteriorate with an increase in room width. In weak ground, the Parallel-Room Method can be effectively utilized to improve the stability, as shown by Arrow 2, while the Time-Control Method is required for failing ground which is indicated by Arrow 3. By choosing an appropriate method, most salt openings should be made sufficiently stable for the use of radioactive material storage. One advantage of the Stress-Contol Technique for storage use is that support of the roof is provided by naturally-existing earth material itself, and consequently eliminates the need for roof bolts or any other artificial means of support. When the Stress-Control Technique is successfully implemented, the stability of 


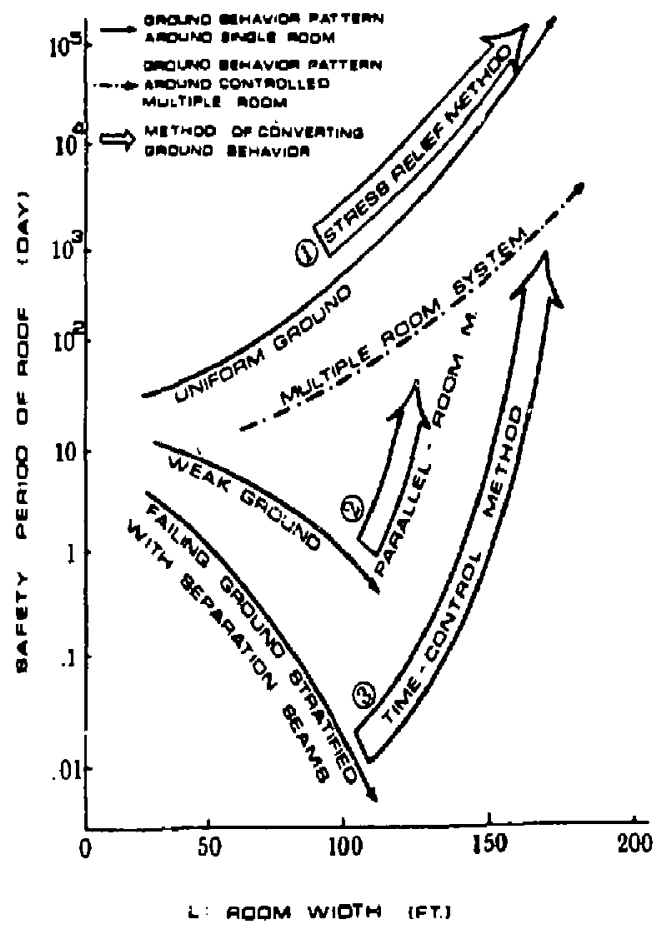

Figure 10-7. Safety Period of Roof vs. Room Width Source: SGI, 1979. 
a roof can be increased to the point at which roof creep strain is only $10^{-4} \mathrm{in} /$ in per year, which requires 100 years to creep 1 percent. A finite element analysis based on the rheological constitutive equations described in Chapter 4 may be used in conjunction with the priciples of the Stress-Control Technique for the maximum stability of salt openings. 


\section{BIBLIOGRAPHY}

Adachi, I. Construction of continum Theories and Their Application to Underground Detection of Stress Conditions. ph. D. Dissertation, University of California, Berkeley, california, 1970.

Agullo-Lopez, F., and Levy, P.W. Effects of Gamma-ray Irradiation on the Mech. Properties of Single $\mathrm{NaCl}$ Crystals , Proc. Brit. Ceramic Soc., No. 1. 1964.

Albrecht, H., and Langer, M. The Rheological Behavior of Rock Salt and Related Stability problems of Storage Caverns, 3rd Congress of Int 1 . Soc. for Rock Mech.. Vol. 28, pp. 967, 1974.

Allen, R.V., et al. Some Instruments and Techniques for Measurements of Tidal Tilt, Phil. Trans. Ro Soc. Lond. A 274 , pp. 219-222, 1973.

Anderson, C.A. An Investigation of the Steady Creep of a Spherical Cavity in a Half-Space, J. Applied Mechanics. ASME Publication, June, 1976.

Anthony, T.R., and Cline, H.E. Thermomigration of Liquid Droplets in Salt, Fourth Symposium on Salt. vol. 1 , pp. 313-321, A.H. Coogan, ed., Cleveland, Ohio, N. Ohio Geological Soc, 1973.

Baar, C.A. Applied Salt-Rock Mech., 1, The In-situ Behavior of Salt Rocks, Elsevier Scientific Pub. Co., 1977.

Brace, W.F., Walsh, J.B., and Frangos, W.T. "Permeability of Granite Tnder High Pressure", J. Geophysical Res.. vol. 73, p. 2225, 1968.

Bradshaw, R.I., Boegly, W.J. Correlation of Convergence Measurements in Salt Mines with Lab Creep Test Data, Proc. 6th Symp. on Rock Mechanics, U. Missouri at Rolla, 1964. 
Bladshaw, R.L., and McClain, W.C. (Eds.) Project salt Vault: A Demonstration of the Disposal of HighActivity Solidified Wastes in Underground Salt Mines. Oak Ridge Nat. Lab. ORNL 4555 uC-70, Oak Ridge, Tennessee, April 1971.

Bradshaw, R.L., and Sanchez, F., Migration of Brine Cavities in Rock Salt. J. Geophysical Research, Vol. 74, pp. 4209$4212,1969$.

Burke, P.M. High Temperature Creep of Polycrystalline SodiumChloride. Ph.D. Dissertation, Stanford U. , Palo Alto, Ca., 1968.

Carter, N.L,, and Heard H.C. Temperature and Rate Dependent Deformation of Halite, Am. J. Sci., Vol, 269, pp. 193249, October 1979.

Coble, R.L. A Model for Boundary Diffusion Controlled Creep in Polycrystalline Materials, J. Applied Phys., Vol. 34, No. 6, June 1963.

Cook, J.C. How to Locate Water Hazards in Salt Mines, Proc. 4 th Symp. on Salt, Vol. 2, N. Ohio Geological Soc., 1973.

Dawson, P.R. Constitutive Models Applied in the Analysis of Creep of Rock Salt. SAND-79-0137, Rough Draft, Sandia Laboratories, Albuquerque, New Mexico, January 15, 1979.

de la Cruz, R.V., Raleigh, C.B. Absolute Stress Measurements at the Rangely Anticline, N.W. Colorado, Int. J. Rock Mech. Min. Sci., Vol. 9, pp. 625-634, 1972.

de la Cruz, R.V., Goodman, R.E. Theoretical Basis of the Borehole Deepening Method of Absolute Stress Measurement, Rock Mech. - Theory and Practice. Proc. 1lth Symp. on Rock Mech., Berkeley, Ca., 1970.

Desai, C.S. and J.F. Abel, Introduction to the Finite Element Method. Van Nostrand Rheinhold, 1972.

Dreyer. $W$. The Science of Rock Mech., Pt. 1 , The Strength properties of Rocks, Trans. Tec, Pub., Bay Village, Ohio, 1972.

Dwyer, M.G. Thoms, R.L. Finite Element Analysis of salt Domes with Stored Hot Wastes, proc. 4th Int. Symp, on Salt, Vol. 2, N. Ohio Geological Soc., 1973. 
Eaton, J. A Portable Water-Tube Tiltmeter, Bull. Seismological Soc. Amer., Vol. 49, No. 4, pp. 301-316, October, 1959.

Fairhurst, C. Methods of Determining In-Situ Rock Stresses at Great Depths, DA-25-056-ENG-14, 765, Missouri River Div., Corps of Engineers, Omaha Nebr., 68102, 1968.

Fossum, A.F. On the Structural Behaviox of Progressively Mined Solution Cavities in Salt (Preprint Copy), RE/SPEC Inc., Rapid City, 5.D., 1976.

Fossum, A.F. Visco-Plastic Behavior During the Excavation Phase of a Salt Cavity, Int. J. for Numerical and Analytical Methods in Geomechanics, Vol. 1, 45-55, 1977.

Haimson, B.C. Determination of Stresses in Deep Holes and Around Tunnels by Hydraulic Fracturing, Proc. AIME, Vol. 2, 1974.

Hall, C.J., and J.R. Hoskins. A Comparative Study of Selected kock Stress and Property Measurement Instruments, Tech. Rept. UI-BMR-2, Advanced Research Projects Agency, ARPA 1579 Amend. 2, June 1972.

Handin, J. An Application of High Pressure in Geophysics, Experimenta1 Rock Deformation. Trans. Am. Soc. Mech. Engrs. 75, Pp. 315-324, 1953.

Hansen, F.D. Case History Rock Mechanics Examination of the Jefferson Island Salt Mine: II, Laboratory Evaluation of Strength and Creep Deformation Characteristics of Dome Salt Under Confining Pressure. For office of Waste Isolation, by RE/SPEC, Technical Report RSI-0057, Rapid City, South Dakota, June, 1977.

Hansen, F.D., and P.F. Gnirk. Design Aspects of the Alpha Repository: III. Uniaxial Quasi Static and Creep Properties of the Site Rock. For Holified National Laboratory, by RE/SPEC, Technical Report RSI-0029, Rapid City, South Dakota, 1975.

Hansen, F.D. Triaxial Quasi-Scatic Compression and Creep Behavior of Bedded Salt from Southeastern New Mexico. For Sandia Laboratories, by RE/SPEC, Technical Report, RSI-0055, Rapid City, S.D., February, 1977. 
Heard, H.C. Steady-State Flow in Polycrystalline Halite at Pressure of 2 kilobars. Geophysical Monograph Series. Vol. 16, AGU, 1972.

Hedley, D.F. An Appraisal of Convergence Measurements in Salt Mines, 4th Rock Mechanics Symp., U. Missouri at Rolla, 1967.

Herring, C. Diffusional viscosity of a Polycrystalline solid, J. Applied Phys., May 2l, 1950.

Höfer, K.H., Knoll, P. Investigations into the Mechanism of Creep Deformation in Carnallite, and practical Applications, Int. J, Rock Mechanics and Min, Sci., Vol. 8, pp. 61-73, 1971.

Holdoway, K.A. Behavior of Fluid Inclusions in salt During Heating and Irradiation, 4th symposium on salt, Vol. I, A.H. Coogan, Ed., Cleveland, Ohio, N. Ohio Geological Soc. Pp. 301-312, 1974.

Hugget, G.R., Slater, L.E. Prenision Leveling with a TwoFluid Tiltmeter, Geophys. Res. Let., Vol. 3, No, 12, December 1976.

Isherwood, Dana J. Fluid Inclusions in salt - An Annotated Bibliography. LLL "Informal Report" UCID - 18102. Available from National Technical Information Service, Springfield, Virginia 22161, January 1979.

Kozeny, J.S., Ber. Wiener Akad., Abt. IIa, pp. 135, 271, 1927.

Lai, C-S. Fluid Flow Through Rock Salt Under various Stress States. Ph.D. Dissertation, Michigan State University, East Lansing, 1971.

Le Comte, P. creep in Rock Salt. J. Geology 73, pp. 469484, May, 1965.

Ledbetter, J.0., Kaiser, W.R., Ripperger, 2.3. "Radioactive Waste Management by Burial in Salt Domes" AEC Contract AT-(40-1)-4639, Eng. Mech. Res. Lab., U. of Texas, Austin. January 1975. 
Lomenick, Thomas F., Accelerated Deformation of Rock Salt at Elevated Temperature and Pressure anä Its Implications for High Level Radioactive Waste, Ph.D. Thesis, U. Tennessee, 1968.

Morrison, D. M., The Transition Test As a Method For Determining the Mechanical Properties of Materials In a Continuous Medium, M.S. Thesis, Michigan State U., East Iansing, 1962.

Mraz, D. Theoretical Predictions Confirmed by In-situ Rock Behavior in Deep Potash Mine, 19th U.S. Rock Mech. Symp., U. Nevada, 1978.

Munson, D.E., Preliminary Deformation--Mechanısm Map for Salt (with Application to WIPP). SAND-79-0076, Rough Draft, Sandia Laboratories, Albuquerque, New Mexico, January, 1979.

Nabarro, F.R.N., Report of a Conference on the Strength of Solids., Physical Soc., London, 75, 2.948.

Nair, K., Chang, C-Y., Singh, R.D., and Abdullah, A.M., Time-Dependent Analysis to Predict closure in Salt Cavities. 4 th Int. Symp. on Salt. N. Ohio Geological Soc., 1973.

Obert, L. Det. of Stress in Rock--A state of the Art Report. Symposioum at 69th Annul Meeting of R. Soc. for Testing and Materials, Atlantic City, N.J., 1966.

Obert, L. Effects oi Stress Relief and other Changes in Stress on the Physical Properties of Rock, USBM RI-6053, 1962.

odé, Helmer, Review of Mechanical Properties of Salt Relating to Salt-Dome Genesis. Geological Soc. Amer., Inc, Special Paper 88, Houston, Texas, 1968.

Panek, L.A. Methods for Determining Rock Pressure, Proc. 4th Symp. on Rock Mechanincs, Penn. State Univ., University Park, pp. 181-184, 1961.

Poirier, J.P. High-temperature Creep of single Crystalline Sodium Cloride, Phil. Mag. 26, pp. 701-725, 1972.

Raj, R. and M.F. Ashby, on Grain Boundary Sliding and Diffusional Croep. Metallurgical Trans., Vol. 2, p. 113, April 1971. 
Reynolds, T.D, Reactor Fuel Waste Disposal Project: Permeability of Rock Salt and Creep of Underground Salt Cavities. AEC Contract At- $(11-1)-490$, Final Report, December 30, 1960.

Rocha, M. Determination of the Deformability of Rock Masses Along Boreholes. 1st Congress Int. Soc. Rock Mech., Lisbon, 1966.

Sakurai, S. Time-Dependent Behavior of Circular Cylindrical Cavity in Continuous Medium of Brittle Aggregate. Ph.D. dissertation, Michigan State University, East Lansing, 1966.

Serata, S. Development of Design Principle for Disposal of Reactor Fuel Waste into Underground Salt Cavities. Ph.D, dissertation, University of Texas, Austin, 1959.

Serata, S. Transition from Elastic to Plastic States of Rocks Under Triaxial Compression. Trans. of the 4 th Symposium of Rock Mechanics, Pennsylvania State University, April, 1961.

Serata, S., and 0. Abu-Gheida, et al. Principles of Stress Fields in Underground Formations. For NSF Progress Report No. 4, Projects G-19791 and GP-2646, by Div. Eng. Research, Michigan State University, East Lansing, Michigan, September, 1964.

Serata, S., S. Sakurai, and T. Adachi. "Theory of Aggregate Rock Behavior Based on Absolute Three-Dimensional Testing (ATT) of Rock Salt." Proceedings of the 10th Symposium on Rock Mechanics, University of Texas, Austin, April, 1968.

Serata, S. Prerequisites for Application of Finite Element Method to Solution Cavities and Conventional Mines. Proc. 3rd Symp. on Salt, Northern Ohio Geological Soc., April, 1969.

Serata, S. Rock Mechanics Problems of Solution Cavities Used for Storage of Gaseous and Solid Matters. Proc. 1973 AIME Annual Meeting, Paper No. 73-AM-79, Chicago, Illinois, March, 1974 .

Serata, S. Stress Control Technique--An Alternarive to Roof Bolting? Mining Engineering, May, 1976. 
Serata, S. Geomechanical Basis for Jesign of Underground Salt Cavities. Energy Technology Conference, ASME, Houston, Texas, November, 1978.

Scheidegger, A.E. The Physics of Elow Through porous Media, U. of Toronto Press, 1957.

Shoua, E.D. and Mase, G.E. Effects of Confining Pressure on Polycrystalline Rock Behavior Analysed by Rheol.ogical Theory, Int. Soc. Rock Mech., Proc., 1966.

Skilton, D. Behavior of Rigid Inclusion Stress-ineters in Viscoelastic Rock, Int. J. Rock Mech. Min. Sci., Vol. 8, pp. 283-289, 1971 .

Sutherland, H.J., and S. Cave. Gas Permeability of SENM Rock Salt. SAND-78-2287, Sandia Laboratories, Albuquerque, New Mexico, 1978.

Thompson, E., and E. Ripperger. An Experimental Technique for the Investigation of the Flow of Halite and Sylvinite. Pyoc. 6th Symp. on Rock Mech., U. Missouri at Rolla, 1964.

Thoms, R.L., and J.D. Martinez. Preliminary Long-Term Stability Criteria for Compressed Air Energy Storage Caverns in Salt Domes. For Battelle PNL, by Institute for Environmental Studies, Jouisiana State University, Baton Rouge, August, 1978.

Thoms, R.L., et al. Site Spcific studies for Possible ongoing Salt Dome Movement, Energy Resources and Excavation Technology, Proc. 18th U.S. Symp. on Rock Mech., Keyscone, Colorado, June 1977.

Unterberger, R. A Laser Radar for Probing salt, proc. 4th Symp on Salt, Vol. 2, N. Ohio Geological Soc., 1973.

Unterberger, R. Electromagnetic Wave propagation in salt. proc. 4th Symp. on Salt, Vol. 2, No Ohio Geological Scc., 
Wawersik, W.R. and D.W. Hannum. Interim Summary of Sandia Creep Experiments of Rock Salt from the WIPP Study Area, Southeastern New Mexico, DOE Contract AT(29-1)-789, Sandia Laboratories, Albuquerque, New Mexico, Rough Draft, 1979.

Wieselman, E.A., Closure Measurements, An Important Tool in Mine Design at Cane Creek Potash Mine, Proc. 19th Rock Mech. Symp. Austin, Texas, 1968.

Winkel, B.V. and Gerstle, K.H., and Ko, W.Y. "Analy'sis of Time-dependert veformation of Openings in Salt Media", Int. J. Rock Mech. Min. Sci. Vol. 9 pp. 249-260, 1972.

Zienkiewicz, O.C. The Finite Element Method in Engineering

Science. McGraw Hill, 1971

\section{NOTICE}

This report was prepared as an account of work sponsored by an agency of the United States Government. Neither the Uriiteu States Govemment nor any agency thereof, ur any of their employees, makes any warranty, expressed or implied, ar assumes any lega? liability or responsibility for any third party's use, or the results of such use, of any information apparatus, product or process disclosed in this report, or represents that its use by such third party would not infringe privately owned rights.

Reference to a cumpany or product naide does not imply approval or recommendation of the product by the University $D^{\circ}$ California or any U.S. Government :gency ti the exciusion of others that may be suitable. 